\title{
Security of Supply in Electricity Markets
}

\author{
Schwenen, Sebastian
}

Document Version

Final published version

Publication date:

2011

License

CC BY-NC-ND

Citation for published version (APA):

Schwenen, S. (2011). Security of Supply in Electricity Markets. Copenhagen Business School [Phd]. PhD series No. 33.2011

Link to publication in CBS Research Portal

\section{General rights}

Copyright and moral rights for the publications made accessible in the public portal are retained by the authors and/or other copyright owners and it is a condition of accessing publications that users recognise and abide by the legal requirements associated with these rights.

\section{Take down policy}

If you believe that this document breaches copyright please contact us (research.lib@cbs.dk) providing details, and we will remove access to the work immediately and investigate your claim. 
COPENHAGEN BUSINESS SCHOOL HANDELSHøJSKOLEN

SOLBJERG PLADS 3

DK-2000 FREDERIKSBERG

DANMARK

www.cbs.dk

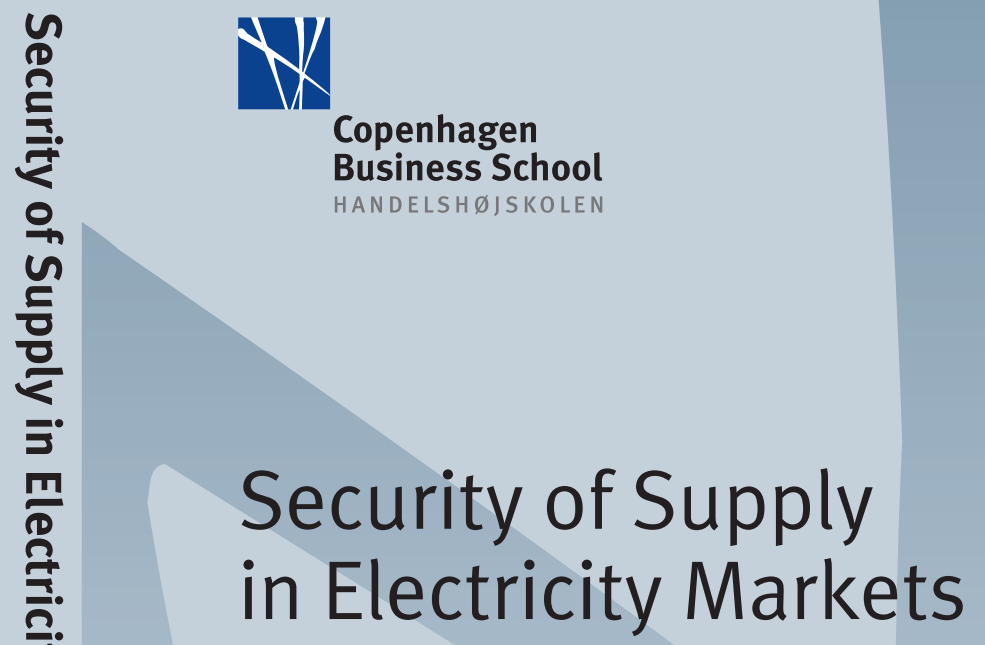

\section{Sebastian Schwenen}




\section{SECURITY OF SUPPLY IN ELECTRICITY MARKETS}

Sebastian Schwenen

September 2011

\section{$\mathrm{PhD}$ Thesis}

Department of Economics

Copenhagen Business School 
Sebastian Schwenen

Security of Supply in Electricity Markets

1st edition 2011

PhD Series 33.2011

(C) The Author

ISSN 0906-6934

Print ISBN: 978-87-92842-26-8

Online ISBN: 978-87-92842-27-5

"The Doctoral School of Economics and Management is an active national and international research environment at CBS for research degree students who deal with economics and management at business, industry and country level in a theoretical and empirical manner".

All rights reserved.

No parts of this book may be reproduced or transmitted in any form or by any means, electronic or mechanical, including photocopying, recording, or by any information storage or retrieval system, without permission in writing from the publisher. 


\section{Acknowledgements}

This dissertation originated as a part of a research project on the choice of technology, security of supply, and market power in electricity markets funded by the Danish Social Science Research Council. I am deeply indebted to my supervisor Anette Boom for innumerous comments and suggestions. I am also indebted to the project leader and my $\mathrm{PhD}$ committee chair Peter Møllgaard. Clinton Levitt provided detailed suggestions on earlier drafts, for which I am very grateful. Furthermore I would like to thank colleagues and $\mathrm{PhD}$ fellows at the Department of Economics at Copenhagen Business School, here especially Petter Berg, Mario Daniele Amore and Henrik Fosse, and at the Department of Economics at London School of Economics \& Political Science for helpful comments. Participants at the 2010 International Industrial Organization Conference in Vancouver, at the 2010 International Association for Energy Economics European Conference in Vilnius and seminar participants at the Department of Economics at Copenhagen Business School and at the Department for Industrial Economics and International Management at ZEW Mannheim provided valuable feedback. All errors remain my own. 


\section{Contents}

English Summary

iii

Dansk Resumé

vi

Introduction

Market Design and Supply Security

in Imperfect Power Markets

Real-time Pricing in Power Markets:

Who Gains?

Strategic Bidding in Multiunit Auctions with Capacity Constrained Bidders:

The New York Capacity Market

Conclusion 


\section{English Summary}

The regulatory approach to supply security in electricity markets has been substantially altered since power markets were partly privatized and reregulated in the mid 1990's, when regulators chose to rely on market based prices and decentralized commercially based decisions on generation capacities. Prior to this market restructuring power systems basically worked as planned economies, however, the decentralization of production decisions introduced stochastic elements to electricity systems.

Additionally, since the early 2000's, power generating companies, often incentivized by the state, started increasing the share of renewable but intermittent energy sources in their generation portfolios. Due to its intermittency the production process of wind, solar and hydro power is difficult to plan and therefore the final amount of power that enters the market at each point in time becomes difficult to predict. As the level of power supply intermittency increases, so also do the number of challenges that market based approaches face in organizing secure power systems.

How markets should be organized in order to effectively signal capacity scarcity and ensure a secure supply of energy is frequently debated, all the more so since the advent of renewable energy sources. This dissertation adds to this discussion of market design and supply security in power markets. It consists of three chapters that aim to understand the economics of supply security in electricity markets.

The first chapter asks to what extent a duopolistic power market can solve efficiency and supply security requirements. I show that in a duopoly market the wholesale auction is characterized by prices above marginal costs and that blackout probabilities can arise through capacity withholding rather than capacity scarcity. In equilibrium, one larger firm prices higher and sells power at the margin, while the smaller firm bids lower energy prices and withholds capacity. Only the larger firm has an incentive to maintain 
balanced grids and supply all stochastic demand. The smaller firm, if not too small and not withholding capacity, risks blackouts when maximizing profits. When the system operator faces high demand that leads to a shortage of supply, and thus has to buy more energy, the smaller firm then becomes a monopolist for out of market purchases.

Then I analyze how markets can be designed to incentivize energy production, support secure supply and minimize blackouts through bid based capacity remuneration mechanisms. When regulators implement capacity remuneration mechanisms, available peak capacity increases, however only if capacity is remunerated above its marginal costs of being available. In that case, capacity mechanisms lower blackout probabilities and energy prices, but increase energy price volatility. I find that energy price caps reduce price volatility without effecting system security in the short run. Hence, energy price caps and capacity mechanisms can mitigate market power in the energy market, but at high costs for available peak capacity. The choice of market design depends on regulatory preferences for supply security. That is, on how much costs regulators are willing to spend for secure supply and on how far regulators are willing to administer capacity mechanisms that distort energy price signals in the long run.

The second chapter analyzes how smart metering, that allows for realtime pricing of final consumers, can soften the market design problem as discussed in the first chapter, and increase market efficiency. The focus of the analysis lies on welfare effects of smart metering when consumers are risk-averse and generating firms have market power. Whether real-time pricing enhances welfare depends on the firms' capacities, the magnitude of the demand shock and on the proportion of consumers on real-time pricing schemes. With large firm capacities that always lead to perfect competition, there is no difference in welfare when all or no consumers are on real-time pricing. When firms' capacities are smaller such that market power arises, firms can price relatively high in times of high demand shocks. When this 
is the case, real-time pricing decreases consumer surplus, because risk-averse consumers dislike high and uncertain prices. At the same time real-time pricing increases producer surplus, because more wholesale customers pay a real-time price above marginal costs. In this case, the social welfare effect of real-time pricing hence depends on the magnitude of these two opposing effects. If however firms' capacities are relatively large and the demand shock does not change the wholesale price, smart metering can increase consumer surplus and welfare. These findings suggest that, before investing in smart meters and smart grids, aggregate market capacities, dominant firm behavior, and the welfare gain of insuring against price fluctuations through fixed retail prices should be taken into consideration.

The last chapter takes the market design discussion to data. I develop a simple multiunit uniform price auction model and apply it to data from capacity auctions in the New York electricity market. The results show that the simple model describes the behavior in the auction to a high degree. As predicted by the model, the largest bidder submits the clearing price in each auction. In this way the firms co-ordinate on an equilibrium that extracts high rents from the auctioneer. Where observed bids violated the model and could have profitably been undercut by the pivotal firm, bidders seem to learn over time. A majority of bids that according to the model could have been profitably underbid were submitted in the first five auctions, and the magnitude of non-optimal bids decreases thereafter. Small firms adjusted their bids according to the largest firm's profits of undercutting, thereby making undercutting not profitable. During the period studied from 2003 to 2008, the capacity market in New York City did not clear as intended by the system operator and was rewarding capacity at too high prices. Capacity remuneration mechanisms, if designed in the form of the capacity auctions studied here, are a costly tool to promote supply security and supply adequacy in electricity markets. 


\section{Dansk Resumé}

Den lovgivningsmæssige tilgang til sikkerhed i enerigforsyningen er blevet væsentligt ændret, siden energimarkedet blev delvist privatiseret og dereguleret i midten af 1990'erne. Myndighederne introducerede markedsbaserede priser og forretningsbeslutninger vedrørende produktionskapacitet blev decentraliseret. Mens energisystemer forud for omstruktureringen af markedet stort set fungerede som en planøkonomi, tilfører decentraliserede produktionsbeslutninger et stokastisk element til el- forsyningssystemer.

Primært motiveret af staten er energiforsyningsvirksomheder siden starten af nullerne ogsåbegyndt at integrere en stigende andel af vedvarende men intermitterende energi i deres portefølje. Produktionen af solenergi, vind- og vandkraft er vanskelig at planlægge, og dermed bliver den mængde energi, der kommer ind påmarkedet påethvert tidspunkt, svær at forudsige. Pågrund af diskontinuiteten i energiforsyningen møder ogsåden markedsbaserede tilgang til at organisere sikker energiforsyning nye udfordringer.

Det er blevet diskuteret gentagne gange, hvordan markeder skal organiseres for at sikre en sikker energiforsyning, men særligt siden indførelsen af vedvarende energikilder. Denne afhandling bidrager til diskussionen af markedsdesign og forsyningssikkerhed påelmarkeder. Den består af tre artikler, der sigter påat forståde økonomiske aspekter af forsyningssikkerheden påelmarkeder.

Den første artikel stiller spørgsmålstegn ved, i hvor stort et omfang et duopolistisk energimarked kan løse effektivitets og forsyningssikkerhedsmæssige behov. Jeg påviser, at en gros marked pået duopolt marked er karakteriseret ved priser over marginalomkostningerne, og at risikoen for strømafbrydelse kan opståpåbaggrund af tilbageholdenhed snarere end pågrund af mangel påkapacitet. I ligevægt prissætter en større virksomhed energi højere og sælger energi påmarginen, mens de mindre firmaer tilbyder lavere energipriser og tilbageholder kapacitet. En større virksomhed har incitament 
til at opretholde et balanceret net og levere til al stokastisk efterspørgsel. En mindre virksomhed, hvis den da ikke er for lille og ikke tilbageholder kapacitet, risikerer strømafbrydelser ved profitmaksimering.

Efterfølgende analyserer jeg, hvordan markederne kan designes for at tilskynde energiproduktion, fremme forsyningssikkerhed og minimere strømafbrydelser gennem et kapacitetsmarked. Hvis myndighederne indfører et kapacitetsmarked, øges den tilgængelig kapacitet ved spidsbelastning, dog kun hvis kapaciteten belønnes udover den marginale omkostninger ved at være til rådighed. I såfald sænker kapacitetsmarkedet risikoen for strømafbrydelse, men øger energiprisernes udsving. Jeg mener, at et loft over energipriser reducerer prisudsving uden at påvirke systemets sikkerhed påkort sigt. Således kan prislofter påenergi og kapacitetsmekanismer afbøde markedskræfterne påenergimarkedet, men med høje omkostninger for den tilgængelige kapacitet ved spidsbelastning. Valget af markedsdesign afhænger af lovgivningsmæssige præferencer for forsyningssikkerheden, dvs. af hvor meget lovgiverne er villige til at ofre påat sikre forsyningen og af, hvorvidt lovgiverne er villige til at administrere kapacitetsmekanismer, der forvrider energipris i det lange løb.

Den anden artikel analyserer, hvordan smart meter, der giver mulighed for real-time prisfastsættelse til forbrugere, kan blødgøre problemet i markedsdesignet som omtalt i den første artikel og øge markedets effektivitet. Fokus i analysen ligger påvirkningerne påvelfærd af intelligent måling, når forbrugerne er risikoaverse og producerende virksomheder har markedsmagten. Hvorvidt real-time prisfastsættelse øger velfærd afhænger af virksomhedernes kapacitet, omfanget af efterspørgslen og påmængden af forbrugere påsmart meters. Med store kapaciteter, der altid fører til fuldkommen konkurrence, er der ingen forskel i velfærd, når alle eller ingen forbrugere er påreal-time priser. Når virksomhedernes kapacitet er mindre, som energimarkedet viser, kan virksomheder sætte prisen relativt højt i tider med høj efterspørgsel. Hvis dette er tilfældet, sænker real-time priserne nytten for forbrugerne, fordi 
risikoaverse forbrugere ikke bryder sig om høje og usikre priser. Samtidigt $\emptyset$ ger real- time priserne producentoverskuddet, fordi flere engroskunder betaler en real-time pris, der ligger over marginalomkostningerne. I dette tilfælde afhænger effekterne af real-time prissætning påvelfærden af omfanget af disse to modsatrettede effekter. Hvis virksomhedernes kapacitet derimod er relativt stor og efterspørgsel ikke ændrer engrosprisen, kan smart meters øge forbrugernes overskud og velfærd. Resultaterne tyder på, at man, før man investerer i at smart meters, skal tage den generelle tilstand af markedet, dvs. samler markedskapaciteten dominerende virksomheders adfærd, og velfærdseffekten af sikrede priser i betragtning.

Den sidste artikel viderefører diskussionen af markedsdesign til data. Jeg udvikler en enkel multiunit uniform prisauktionsmodel og anvender den pådata fra New York ISO kapacitetsauktioner. Resultaterne viser, at denne simple model i høj grad beskriver opførslen påauktionen. Som forudsagt af modellen, vil udbyderen af den største mængde af kapacitet fastsætter markedsprisen i enhver auktion. Pådenne måde koordinerer virksomheder ud fra en ligevægt, som trækker høj profit fra auktionarius. Byderne synes at lære med tiden, når det drejer sig om observerede bud, der overtrådte modellen og med profit kunne være blevet underbudt af en stor virksomhed. Et flertal af bud, der ifølge modellen med profit kunne være blevet underbudt, blev fremlagt i de første fem auktion runder, og omfanget af ikke-optimale bud falder derefter. Mindre virksomheder reagerede påde største virksomhedens profit og deres fortjeneste ved underbud ved at justere sine egne bud. I løbet af den undersøgte periode fra 2003 til 2008 blev kapacitet belønnet med alt for høje priser. Kapacitetsmarkedet er ikke velegnet til at fremme forsyningssikkerheden og sikre tilstrækkeligt udbud påelmarkeder, hvis den er designet som de kapacitetsauktioner, der er undersøgt i denne afhandling. 


\section{Introduction}

The regulatory approach to supply security in electricity markets has been substantially altered since power markets were partly privatized and reregulated in the mid 1990's, when regulators chose to rely on market based prices and decentralized commercially based decisions on generation capacities. Prior to this market restructuring power systems basically worked as planned economies, however, the decentralization of production decisions introduced stochastic elements to electricity systems.

Additionally, since the early 2000's, power generating companies, often incentivized by the state, started increasing the share of renewable but intermittent energy sources in their generation portfolios. Due to its intermittency the production process of wind, solar and hydro power is difficult to plan and therefore the final amount of power that enters the market at each point in time becomes difficult to predict. As the level of power supply intermittency increases, so also do the number of challenges that market based approaches face in organizing secure power systems.

How markets should be organized in order to effectively signal capacity scarcity and ensure a secure supply of energy is frequently debated, all the more so since the advent of renewable energy sources. This dissertation adds to this discussion of market design and supply security in power markets. It consists of three chapters that aim to understand the economics of supply security in electricity markets.

The International Energy Agency finds energy supply to be secure if it is adequate, affordable and reliable. ${ }^{1}$ Adequacy, affordability and reliability imply a relatively large production at low costs, a relatively low market price, and a low price variance, respectively. Reliability in electricity markets however imposes an additional requirement that is foreign to the standard

\footnotetext{
${ }^{1}$ See The International Energy Agency (2007).
} 
economic idea of relative scarcities. Blackouts, a binary state of the world, have to be avoided - but at what price? Blackouts occur and cause significant economic damage. ${ }^{2}$

The following three chapters analyze supply security in electricity markets in terms of prices and output, but also in terms of reserve margins and blackout probabilities, and costs and benefits of different means to alter them. The overarching goal of this thesis is to ask to what degree markets can ensure a secure supply of energy, how markets can be designed to enhance secure supply, and how technological improvements such as smart metering and smart grids can shift the frontier to a more efficient and reliable use of power generating resources.

Beyond the scope of this thesis are economic and political developments that shape the primary energy markets. The technology mix of energy sources will be taken as given. ${ }^{3}$ Currently, the technology mix is changing in favor of an increased use of intermittent renewable energy sources. The resulting relation between stochastic supply and demand constitutes a starting point for this thesis. As for instance plans to rely on a market share of around 50\% wind energy in the Danish market by 2025 show, the integration of intermittent renewable power indeed comes with significant challenges for power systems. ${ }^{4}$ Throughout this thesis the term energy market, or sometimes power market, will always refer to the commodity electricity. I mostly focus on the generation level, but also include downstream levels and consider retailers and final customers. Transmission constraints in the power grid are neglected.

Energy markets are characterized by only a few players on the supply side. Production decisions and market prices are determined by the game

\footnotetext{
${ }^{2}$ See The International Energy Agency (2005).

${ }^{3}$ For an overview and measurement of external supply risks see Le Coq and Paltseva (2009).

${ }^{4}$ See Xu et al. (2009).
} 
of dominant firms who face stochastic demand and hence uncertain profits. To account for the strategic interaction among producers all three chapters rely on industrial organization models and apply them to electricity markets. Why are standard industry models not sufficient to describe electricity markets? Electricity is not storable on a large scale and in an economically viable way. The non-storability results in various constraints that all players in the market - firms, consumers and regulators alike - have to take into account.

Non-storability requires efficient market clearing and a balance between supply and demand at each point in time. Neither excess demand nor excess production should occur to not waste surplus or profits. ${ }^{5}$ Non-storability also implies that consumers cannot smooth consumption over time and their demand becomes highly inelastic. Inelastic and stochastic demand leads to high price fluctuations. Electricity prices are high and transmission constraints possibly binding, when consumers need electricity the most, say for cooking dinner. The problem of instantaneous market clearing gets further aggravated by the fact that in current electricity markets most consumers cannot observe and react to price signals. The absence of a robust demand side is a central flaw in electricity markets. This market flaw also requires that, after forward markets close, the system operator has to act as an agent for all market players and buy or sell electricity to clear the market and balance the grid in real-time.

Hence while decentralized decisions to produce power with intermittent technologies result in uncertain supply, non-storability is the major source of randomness on the demand side. Therefore all three following chapters

\footnotetext{
${ }^{5}$ Supply has to equal demand also due to engineering constraints. In most parts of the world including Europe the grid frequency has to be close to 50 Hertz. In US power systems $60 \mathrm{Hertz}$ are required for grid stability. When demand is larger than supply and more power leaves than enters the grid, the frequency drops, while if supply is larger than demand the frequency rises. By common standards, system operators have to keep deviations between \pm 0.8 Hertz. Hence for economic efficiency but also due to engineering constraints supply has to equal demand at all time. Note that storability would solve both the economic and the engineering constraint.
} 
share a common modeling framework that incorporates stochastic demand and supply. 6

The first chapter derives to what extent market mechanisms alone can ensure a secure supply of energy. Starting from this benchmark I then show how and at what costs different market designs can promote supply security. The second chapter analyzes how smart metering can ease the market design problem and increase market efficiency. The focus of the analysis lies on welfare effects of smart metering when consumers are risk-averse and generating firms have market power. While these first two chapters are of theoretical nature, the third chapter eventually takes the market design discussion to data and investigates the efficiency of market designs for reliability using data from the New York electricity market. Besides contributing with empirical insights, the last chapter also confirms the modeling framework that is used throughout this thesis to describe strategic firm behavior.

\section{References}

Le Coq, Chloé and Elena Paltseva (2009) "Measuring the Security of external Energy Supply in the European Union," Energy Policy, Vol. 37, p. 44744481.

The International Energy Agency (2005) "Learning From the Blackouts - Transmission System Security in Competitive Electricity Markets," OECD/IEA. - (2007) "Contribution of Renewables to Supply Security," IAE Information paper.

Xu, Zhao, M. Gordon, M. Lind, and J. Ostergaard (2009) "Towards a Danish power system with $50 \%$ wind: Smart grids activities in Denmark," Power \& Energy Society General Meeting, 2009.

\footnotetext{
${ }^{6}$ Note that stochastic supply can also be described as stochastic residual demand for operating units.
} 


\title{
Market Design and Supply Security in Imperfect Power Markets
}

\author{
Sebastian Schwenen ${ }^{\mathrm{a}}$ \\ Copenhagen Business School
}

\begin{abstract}
This paper studies supply security in imperfect electricity markets. In a multiunit uniform price auction for electricity with two firms, strategic firm behavior allows for endogenous blackout probabilities, that arise through capacity withholding rather than capacity scarcity. When regulators impose market designs for reliability and introduce capacity obligations or reserve capacity procurement, blackout probabilities and energy prices decrease only if the capacity price is above marginal costs. Capacity mechanisms can mitigate market power in the energy market, but at the cost of non-competitive capacity prices and increased energy price volatility.
\end{abstract}

Keywords: Auctions, Electricity, Market Design. JEL-Classification: D43, D44, L11, L13

${ }^{\mathrm{a} C}$ Copenhagen Business School, Department of Economics, Porcelanshaven 16 A, DK2000 Frederiksberg, e-mail: ses.eco@cbs.dk 


\section{Introduction}

During the 1990's most industrialized countries deregulated their electricity sector and introduced a more decentralized approach to supply security. Energy regulators and academics have ever since been debating the extent to which liberalized power markets can ensure a secure supply of energy. Large-scale blackouts during the last decade, as for example the substantial supply breakdowns in Europe and North America in 2003, stress this debate's relevance. ${ }^{1}$ In recent years, the advent of renewable but intermittent power sources like wind has increased the uncertainty in production planning and highlighted the need for a functioning power market design even further. Well functioning power markets ensure market efficiency but also meet desired supply security standards. ${ }^{2}$

The regulatory debate over supply security resulted in a variety of different market designs across power systems. Although market designs differ, virtually all electricity markets face problems arising through market power. The relation between market power and supply security, and how market design affects this relation, is largely unexplored. Surprisingly, while a huge strand of literature deals with market power in power markets, most contributions on supply security focus on competitive markets.

This paper contributes by exploring the effects of market design on supply security in imperfect power markets. It analyses the two main competing power market design tracks: the energy-only market and the capacity market design. While in England and Wales or in Scandinavia energy-only markets exist, in a majority of U.S. markets regulators rely on various forms of capacity mechanisms. ${ }^{3}$ Energy-only markets rely on high peak-time prices to induce sufficient investment. The capacity market design introduces price

\footnotetext{
${ }^{1}$ See The International Energy Agency (2005).

${ }^{2}$ See The International Energy Agency (2007).

${ }^{3}$ For brief overviews of international market designs see Stoft (2002) and Sioshansi and Pfaffenberger (2006).
} 
caps to lower the energy price spikes for consumers. In addition, regulators implement capacity mechanisms, that reward available generation capacity regardless of whether they actually produce energy or not. In an ideal world, capacity mechanisms generate rents that level out the missing revenues that result from the price cap in the energy market, while at the same time reducing market power and price volatility. In the US the discussion on market design centers around market power and price risks. In the EU the increasing use of intermittent power sources like wind energy has drawn attention on optimal market design considerations. ${ }^{4}$

Previous contributions to the relation of market design and supply security led to ambiguous conclusions. Hogan (2005) argues in favor of energyonly markets. He states that arguments in favor of capacity mechanisms merely assume that pure energy-only markets are politically not feasible as they allow for high price spikes. Also Oren (2000) finds that capacity mechanisms are the least desirable tool to enhance power market reliability. He concludes that risk management and price hedging tools, including demand side participation, yield efficient investment. On the contrary, Cramton and Stoft (2005) argue that capacity markets, if well designed, hedge energy market risk, suppress market power and avoid regulatory risk. In this regard also Besser et al. (2002) find that capacity markets lower peak-time prices and decrease price and reliability risks for consumers. ${ }^{5}$ Joskow and Tirole (2007) first derive optimal prices, output and investment in competitive power markets and then show how this optimum can be reached under oligopoly competition with price caps and capacity payments. Creti and Fabra (2007)

\footnotetext{
${ }^{4}$ As more intermittent wind energy enters the power system, the demand for peaking units and hence the profitability of investment in peak capacities becomes more difficult to predict. Capacity markets could restore incentives for peak production, see Eurelectric (2011).

${ }^{5}$ Note that such arguments for capacity markets differ from those for standard forward markets derived by Allaz and Villa (1993), whose setting also is not directly applicable to the capacity market context. While in their standard setting the same commodity is traded in the forward and in the spot market, on capacity markets the commodity is capacity itself instead of energy that eventually is traded in real-time.
} 
explicitly model capacity markets and focus on the monopoly and the competitive case, deriving the opportunity costs of committing capacity to the home market instead of selling it to foreign markets.

Motivated by the fact that most electricity markets are oligopoly or duopoly markets, this paper introduces dominant firm behavior on both the energy and the capacity market and to this end relies on a duopoly auction framework. As in Creti and Fabra (2007) production capacities are given, and the focus lies on firms' optimal behavior and equilibrium outcomes that decide on short run supply security, rather than on optimal investment in capacities and system adequacy. ${ }^{6}$ The main goal of this paper is to ask to what extent markets can ensure a secure supply of energy and how market designs for reliability effect equilibrium outcomes in generation capacities, market prices and blackout probabilities when generating firms have market power.

Main findings are that for a range of asymmetric firm sizes, energy-only markets can cover the full support of stochastic energy demand. However if firms are sufficiently similar in size, capacity withholding becomes attractive and may lead to blackouts. In both cases equilibrium energy prices exceed marginal costs. Capacity mechanisms can decrease energy prices and blackout probabilities, but require that capacity is paid above marginal costs. Hence, when firms behave strategically, consumers can only 'buy supply security' from dominant firms. This contradicts the perception shared in Besser et al. (2002) that capacity mechanisms are a costless tool to decrease market power during peak times. Furthermore, capacity markets only decrease energy price volatility if they coincide with the implementation of energy price caps. $^{7}$ If no energy price cap is introduced, capacity markets increase the

\footnotetext{
${ }^{6}$ For definitions on supply security and supply adequacy see Stoft (2002). Market designs with short run capacity mechanisms, that directly affect energy market competition, are currently run in the New York control area, and until recently have also been used in the PJM market, as described in Creti and Fabra (2007).

${ }^{7}$ Tishler et al. (2008) present a similar argument and find that capacity expansion due
} 
volatility of energy prices because more capacity commitment may result in lower prices but at the same time does not prevent high energy prices. Another surprising result is that system security, that is the relation of demand to total market capacity, is independent of the price cap for energy, because capacity withholding only depends on each competitor's offered quantity but not on the level of the price cap. Hence, energy price caps together with capacity mechanisms can mitigate market power in the energy market, but imply that generating firms therefore earn high rents on the capacity market.

The model is based on the electricity auction framework of Fabra et al. (2006) and introduces the possibility of a blackout. Fabra et al. (2006) allow for consumer rationing, which results in capacity reaction functions that do not yield closed form solutions. Including the possibility of blackouts allows for closed-form solutions and hence for deriving statements on blackout probabilities and the impact of capacity markets on firm individual energy supply, system security and welfare.

The outline is as follows. Section 2 briefly stylizes the energy-only market and the capacity market approach and compares the two opposing market designs. Section 3 presents a simple duopoly model for energy-only markets and derives energy prices, equilibrium capacities and blackout-probabilities. Section 4 analyses the capacity market approach by deriving the capacity market equilibrium and examining its impact on the energy market outcome. Section 5 draws relevant policy implications and concludes.

\section{The market design problem}

In energy-only markets, energy is traded. High demand induces high and volatile price spikes that signal profitability of new power plants. In addition, to a higher number of firms in the market will not decrease price spikes. 
high prices encourage the demand side to consume less power during peaktimes. $^{8}$

In the capacity market approach, energy-only markets are price-capped and backed up by reliability mechanisms. Energy and capacity are rewarded. ${ }^{9}$ The price cap lowers the energy price (volatility). However, to maintain sufficient energy supply despite the price cap, the regulator or the system operator $(\mathrm{SO})$ sets a critical required capacity level that has to be available in real-time. There are at least two ways of implementing such regulatory driven capacity decisions. One option for the $\mathrm{SO}$ is to procure reserve capacity so that the desired amount of real-time capacity is reached, like in the reserve procurement auctions in the Californian system. Alternatively, the SO can introduce capacity obligations on retailers, like in the PJM or the New York ISO capacity market. If generation capacity is scarce, such reliability mechanisms generate extra rents that in the ideal case level out all forgone peak-unit profits when market prices are capped and in an energyonly market would be above the price cap. Capacity that is contracted in the capacity market is rewarded regardless of whether these units actually produce energy or not. However, rewarded capacity commits to be available in real-time and thus becomes a relevant strategic variable for the real-time market. Hence, the regulatory rationale of capacity mechanisms lies in abolishing market power and high energy price spikes via energy price caps, and securing sufficient generation capacity at the same time via rewarding idle peak capacities on secondary markets. ${ }^{10}$

\footnotetext{
${ }^{8}$ High prices can flatten demand fluctuations if consumers are able to react to real-time prices. Therefore an argument in favor of energy-only markets, that is not studied here, is that they induce demand side learning.

${ }^{9}$ For an overview of reliability mechanisms see Batlle et al. (2007). For a general overview of electricity market structure see Wilson (2002).

${ }^{10}$ Power demand is highly volatile and sufficient reserve capacity has to be ready for dispatch at any point in time to cover all real-time demand. When supply cannot meet demand, consumers have to be rationed and, in the worst case, the system breaks down. Therefore markets for capacity serve a dual purpose. They reward generation capacity and ensure instantaneously balanced grids at the same time, see also Stoft (2002).
} 
Although capacity markets in practice are more elaborate than described above, their existence always distorts the real-time energy price and influences all forward contracting and day ahead markets. The market outcome becomes influenced by the SO's decision on the available capacity requirement. Reserve capacity, whether procured by the SO or set in obligations, usually lies in the range of $10-20 \%$ of peak load. ${ }^{11}$

\section{The energy-only benchmark}

The model for the energy-only benchmark employs an auction approach and relies on Harbord and Von der Fehr (1993), Fabra et al. (2006) and Fabra et al. (2011). Related works in this tradition include LeCoq (2002) and Crampes and Creti (2005) on capacity withholding, and Boom (2009) on vertical integration.

\subsection{Basic setup}

Supply security is relevant in real-time. In real-time, supply has to meet demand in order to maintain a balanced power system. This is the SO's responsibility, who acts as a single buyer and auctioneer in the real-time market. All firms can submit supply bids for real-time energy to the SO. Naturally all bids have to be submitted before real-time. In most power systems real-time markets open after the wholesale market clears and a few hours before actual delivery. Before the realization of actual real-time demand is known, each

\footnotetext{
${ }^{11}$ See Stoft (2002) and Borenstein (2005). Note that the term reserve markets often refers to systems in which the SO buys reserves of $10-20 \%$ on top of what is contracted in the day-ahead market, while in the standard capacity market concept the SO obliges retailers to procure reserves. Hence retailers, depending on the system, have to purchase between $110-120 \%$ of their individual forecasted peak-load. The model abstracts from whether reserve capacities are procured by the $\mathrm{SO}$ or by retailers and analyzes the general impact of market based capacity remunarations.
} 
generating firm submits a quantity-price pair for electricity to the SO that specifies how much power a firm is willing to sell at or above a certain price.

Real-time energy demand is stochastic and completely inelastic. Let $\theta$ denote real-time energy demand and be uniformly distributed on the unit interval, $\theta \in[\underline{\theta}, \bar{\theta}]=[0,1] .{ }^{12}$ Whenever realized real-time demand $\theta^{*}$ exceeds real-time supply, the grid breaks down. ${ }^{13}$ The supply side consists of two generating companies, $i, j=1,2$ and $i \neq j$. Both firms submit one energy bid $b_{i}$ for all capacity they offer, $k_{i}$. They simultaneously submit their bid $\left(b_{i}, k_{i}\right)$ to the SO. ${ }^{14}$ The model focuses on a high demand regime. In this setting, both firms' capacities are needed to cover the full support of demand uncertainty. More precise, capacity endowments (i.e. residual capacities from the wholesale and forward market commitment) are such that $\bar{k}_{i}+\bar{k}_{j}=T \leq$ $\bar{\theta}$ holds, where $\bar{k}_{i}$ is each firms' maximum available capacity and $T$ total available market capacity. ${ }^{15}$ Marginal costs are assumed to be constant and normalized to zero.

The SO clears all bids and organizes the dispatch. Thereby the realization of real-time demand, $\theta^{*}$, determines the real-time market price according to a uniform price auction. Relatively low demand will lead to a price equal to the low price bid. If demand is higher than the low bidder's offered capacity, the high price bid becomes price setting. If demand is higher than total available capacity the system breaks down and profits become zero. ${ }^{16}$ In the stylized example in figure 1 , firm $i$ 's bid is setting the price for low demand

\footnotetext{
${ }^{12}$ In Appendix A.3 I relax the assumption on the uniformly distributed demand and show that the energy market outcome also holds in a more general setting.

${ }^{13}$ At first some consumers would be rationed and a complete blackout avoided. However, when supply is far too low to meet demand, grids break down. I focus on this latter case.

${ }^{14}$ Fabra et al. (2006) show that the equilibrium outcome is independent of the number of steps in the bid function.

${ }^{15}$ This high demand respectively low capacity setting neglects global subgame perfectness in capacity decisions in that firms might also invest so that $\bar{k}_{i}+\bar{k}_{j} \geq \bar{\theta}$ holds, but is convenient for analyzing supply security in peak times when generation capacity is scarce.

${ }^{16}$ Fabra et al. (2011) find that in the case where firms can cover the maximum demand realization and blackouts never occur, no closed form solutions in capacity decisions exist.
} 


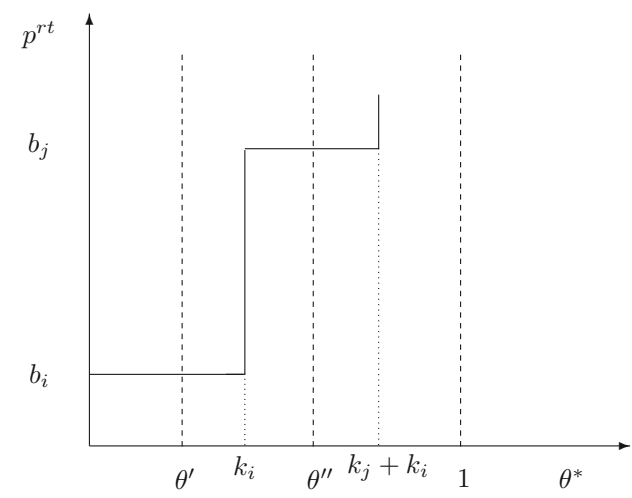

Figure 1: Stylized Real-time Market.

realizations, $\theta^{\prime}$. If demand is higher than firm $i$ 's offered capacity, at $\theta^{\prime \prime}$, the bid of firm $j$ clears the auction. For demand realizations larger than total offered capacity the market does not clear and the system breaks down. The real-time market price $p^{r t}$ can be written as

$$
p^{r t}= \begin{cases}b_{i}=\min \left\{b_{1}, b_{2}\right\} & \text { if } \theta^{*} \leq k_{i} \\ \max \left\{b_{1}, b_{2}\right\} & \text { if } \theta^{*} \geq k_{i} \\ 0 & \text { if } \theta^{*} \geq k_{i}+k_{j}\end{cases}
$$

where the price of electricity is zero during blackouts. ${ }^{17}$ There exists a realtime market price cap $P^{r t}$, at which the SO stops procuring energy. ${ }^{18}$

\footnotetext{
${ }^{17} \mathrm{~A}$ price of zero reflects the price producers obtain during a blackout. For consumers, the price is infinite.

${ }^{18}$ It is important to note that in practice the SO acts as an agent for all buyers and decides on a price cap, equal to the value of lost load. At this price, the loss of a blackout is lower than the price of procuring real-time energy. When this price is set at the value of lost load, it rather imitates a reservation price than it is a regulatory price cap. This artificial reservation price is an important feature of energy-only markets, not readily measurable and difficult to implement in practice.
} 


\subsection{Energy pricing}

The low bidding firm is the first to sell. For all demand realizations lower than its offered capacity, it supplies energy according to its own price-bid. The high price bidder is called and clears the auction only in case real-time energy demand is higher than what the low bidder offers. In this event the auction clearing price equals the bid of the high bidder, who supplies the residual demand that the low bidder leaves unsatisfied. The demand uncertainty causes conflicting incentives for each bidder. For high demand states in which no firm can satisfy all demand, each bidder wants to bid sufficiently low to induce the opponent not to underbid but to supply all residual demand at the price cap. However, if a firm bids low and the demand realization is lower than its offered capacity, its own bid becomes the clearing price and each firm would like to price high in that event. These two conflicting forces destroy pure strategy equilibria, see Fabra et al. (2011). Appendix A.1 presents a proof for the non-existence of pure strategy equilibria when firms collect zero profits during blackouts.

Mixed strategies follow firm $i$ 's maximization of its expected energy market profits

$$
\begin{aligned}
E\left[\pi_{i}^{e}\right]= & \int_{\underline{b}}^{b_{i}} b_{i}\left(\int_{k_{j}}^{k_{i}+k_{j}}\left(\theta-k_{j}\right) d \theta+\int_{k_{i}+k_{j}}^{1} 0 d \theta\right) f_{j}\left(b_{j}\right) d b_{j}+ \\
& +\int_{b_{i}}^{P^{r t}}\left(b_{i} \int_{0}^{k_{i}} \theta d \theta+b_{j} \int_{k_{i}}^{k_{i}+k_{j}} k_{i} d \theta+\int_{k_{i}+k_{j}}^{1} 0 d \theta\right) f_{j}\left(b_{j}\right) d b_{j},
\end{aligned}
$$

where $\underline{b}$ is the lowest price in the support of each firms' mixed strategy. The first term represents all cases where firm $i$ is undercut by firm $j$. In that event firm $i$ can satisfy the expected residual demand at its own bid in case the demand is sufficiently high. The second term shows the case where firm $i$ is the low bidder and either sells at its own bid or at its competitor's bid, if the latter becomes price setting for high demand realizations. Both respective 
last terms in the two brackets state the probability of a system breakdown. If demand is higher than total capacity, profits become zero. Rearranging the first order condition yields firms' cumulative density functions of their mixed strategy price bids:

$$
\begin{aligned}
F_{i}\left(b_{i}, k_{i}, k_{j}\right) & =\frac{k_{j}}{2 k_{i}} \log \left(\frac{b_{i}}{\underline{b}}\right) \\
F_{j}\left(b_{j}, k_{i}, k_{j}\right) & =\frac{k_{i}}{2 k_{j}} \log \left(\frac{b_{j}}{\underline{b}}\right)
\end{aligned}
$$

where without any loss of generality $k_{i} \leq k_{j}$, firm $i$ offers less or equal capacity than firm $j$, and in equilibrium the lowest bid in the support of the firms' bid strategies is

$$
\underline{b}=e^{-\frac{2 k_{i}}{k_{j}}} P^{r t} .
$$

For a complete derivation see Appendix A.2. Note that both firms' price strategies coincide for symmetric capacity offers. For asymmetric capacities, $k_{i} \leq k_{j}$, firm $j$ that offers a larger amount of capacity prices stochastically higher. The large firm has a masspoint at the price cap and therefore submits a bid equal to the price cap with positive probability. This result, which is in line with previous findings of Fabra et al. (2011), is summarized in proposition 1.

Proposition 1 In the real-time energy market, the firm with the greater capacity offer plays the price cap with a positive probability and submits higher prices with greater probability than the firm with a lower offer of generating capacity. The lowest price bid in the support of each firm's price strategy is positive and above marginal costs.

Proof. See the argument above in equation (3) and Appendix A.2.

The source of this market power are firms' capacity constraints. If both firms could cover the whole market demand on their own, the equilibrium 
would be the Bertrand outcome and prices would equal marginal costs. Just as under Edgeworth competition the capacity constraints allow prices to be above marginal costs. Expected energy market profits, again for $k_{i} \leq k_{j}$, become

$$
E\left[\pi_{i}^{e}\left(k_{i}, k_{j}\right)\right]=\left(k_{i}+2 k_{j}-\frac{2 k_{i}^{2}}{k_{j}}\right) \frac{k_{i}}{2} P^{r t}
$$

and

$$
E\left[\pi_{j}^{e}\left(k_{j}\right)\right]=\frac{k_{j}^{2}}{2} P^{r t}
$$

Profits of firm $j$ with the larger offer of capacity are strictly increasing in its offered real-time energy. Firm $i$ that offers less capacity however, has concave profits. Its profits are first increasing in its capacity until it becomes too big and the firm with the larger offer relaxes its high price policy and starts pricing more aggressively. When this price effect is outweighing the effects of additional capacity, the profits of the firm with the smaller offer decrease again. Note that generators cumulative rents become bigger the more asymmetric their offered capacities are.

\subsection{Equilibrium market supply}

Given the above derived mixed price strategies, firms maximize their profits and choose their optimal supply offers. The first order conditions of each firm's profit function, given that $k_{i} \leq k_{j}, k_{i} \leq \bar{k}_{i}$ and $k_{j} \leq \bar{k}_{j}$, imply

$$
\begin{gathered}
\frac{\partial \pi_{j}^{e}\left(k_{j}\right)}{\partial k_{j}}=k_{j} P^{r t}>0 \\
\frac{\partial \pi_{i}^{e}\left(k_{i}, k_{j}\right)}{\partial k_{i}}=\left(k_{i}+k_{j}-\frac{3 k_{i}^{2}}{k_{j}}\right) P^{r t} .
\end{gathered}
$$


Firm $j$ always supplies up to its maximum available capacity, since the first order condition is strictly positive. Thus the optimal supply of firm $j$ is

$$
k_{j}^{*}=\bar{k}_{j}
$$

and independent of player $i$ 's capacity. On the contrary, firm $i$ 's best response function depends on player $j$ 's offered supply. At the same time firm $i$ is possibly binded by its capacity constraint, $\bar{k}_{i}$. Hence firm $i$ offers

$$
k_{i}^{*}=\min \left\{\bar{k}_{i}, k_{i}\left(\bar{k}_{j}\right)=\frac{1}{6}\left(\sqrt{13} \bar{k}_{j}+\bar{k}_{j}\right)\right\} .
$$

Proposition 2 In the energy market equilibrium, two firms offer asymmetric capacities. The firm that offers more capacity submits all its available capacity. The firm that offers less capacity withholds capacity to be optimal against the larger bidder's available capacity, if not binded by its capacity constraint before reaching the optimal offer.

Proof. See equations (9) and (10) above.

Equilibrium market shares are asymmetric. The small bidder has an optimal supply, that trades-off gains by rising capacity and losses of becoming bigger and facing more aggressive price bids of its competitor. If the capacity constraint becomes binding before the small bidder reaches its profit maximum, it offers to supply up to its capacity constraint. The firm with the larger capacity offer does not gain profits by capacity withholding and supplies its maximum capacity. For equilibrium profits see Appendix A.4. The expected equilibrium real-time energy market price is

$$
E\left[p^{e}\right]=\left(k_{i}+k_{j}\right)\left(\left(\frac{3}{2}-\frac{k_{i}}{k_{j}}\right) P^{r t}-\frac{1}{2} \underline{b}\right) .
$$

It is important to discuss that the small firm's capacity withholding results from the fact that the demand realization is not known prior to real- 
time energy trading. The result that capacity withholding can take place shows that the market alone cannot ensure balanced grids at all demand realizations. What is not modeled here is that the SO when observing excess demand can refer to out of market operations and call energy from the withholding firm. Out of market operations then, however, would leave the small firm in a monopoly situation and weaken the signaling effect of the real-time price even further.

So far the model does not specify which firm is the withholding firm in equilibrium. The potential existence of two equilibria in supply offers - each firm can be the small bidder given that its rival submits the larger supply offer - does not allow for stating unique blackout probabilities.

\subsection{Equilibrium selection and blackout probabilities}

This section abstracts from technical network blackouts and considers blackouts that arise through the inability of power supply to meet real-time demand, as derived above. Total market supply and hence the ability to satisfy real-time load is the sum of both firms equilibrium capacities. For convenience, let us in the following distinguish between the small (large) firm, which is the firm with the small (large) capacity endowment, $\bar{k}_{i}$, and the small (large) bidder, which is the firm that in equilibrium bids the smaller (larger) amount of capacity, $k_{i}$. Without loss of generality we continue for the case in which firm $j$ is the large firm, thus for $\bar{k}_{i}<\bar{k}_{j}$. For analytical purposes we can separate two cases. Both lead to the same result: The small firm bids the smaller amount of capacity, see equation (9), and the larger firm becomes the large bidder, and thus, according to equation (10), offers all its available capacity.

The first of the two cases comprises all combinations of capacity endowments, such that the large firm does not find it profitable to withhold capacities and become the small bidder. Intuitively, the large firm is too big to 
become the small bidder. An extreme illustration for this intuition is that a monopolist would still price close to the monopoly price if an infinitesimal small firm would enter the market and bid a low price. As long as

$$
\bar{k}_{j}>\sqrt{\frac{19+13 \sqrt{13}}{54}} \bar{k}_{i} \approx 1.1 \bar{k}_{i},
$$

the larger firm $j$ 's profits are strictly higher when being the large bidder. Hence, for all capacity endowments that fulfill equation (12) only one equilibrium exists, in which the larger firm submits the larger amount of capacity and the small firm becomes the small bidder. For a derivation of equation (12) see Appendix A.5.

In the second case, whenever equation (12) does not hold and firms are of sufficiently similar size, two equilibria exist. Both firms find it profitable to be the small bidder, given that their rival submits the large capacity offer. However, the equilibrium in which the large firm becomes the large bidder and the small firm is the small bidder risk dominates the equilibrium in which the larger firm is the small bidder, see Appendix A.5.

Eventually, in both cases, whether capacity stocks fulfill equation (12), or they do not and risk-dominance is applied, the larger firm will offer more capacity on the real-time market than its rival. This is summarized in the following proposition.

Proposition 3 The firm with the smaller capacity endowment, $\bar{k}_{i}$, offers the smaller amount of equilibrium capacity $k_{i}$. The firm that enters the realtime market with a greater capacity endowment, $\bar{k}_{j}$, submits all its capacity $k_{j}=\bar{k}_{j}$.

Proof. See Appendix A.5.

This result is consistent with the empirical findings that Wolfram (1998) presents on the spot market competition in the England and Wales pool. 


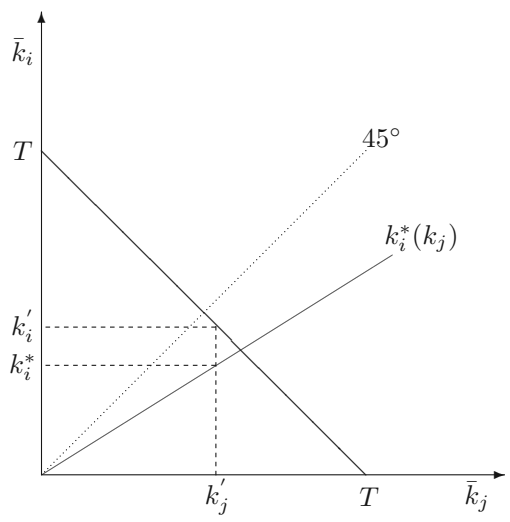

Figure 2: Capacity reaction functions for $\bar{k}_{i}<\bar{k}_{j}$.

Furthermore, this result can explain why it is the larger firm that also submits the larger amount of capacity and prices higher than the smaller firm.

Figure 2 plots equilibrium supply, depending on capacity endowments and given that both firms select the risk dominant equilibrium if two equilibria exist. For sufficiently asymmetric capacity endowments both firms supply their maximum capacity. For capacity endowments that are sufficiently similar, the small firm reduces its capacity and the large firm cannot fill this gap, e.g. for initial endowments of $\left[k_{i}^{\prime}, k_{j}^{\prime}\right]$ firm $i$ 's optimal offer in this illustration is $k_{i}^{\prime *}$. Demand can exceed all supply offers in the energy market and, with the uniform demand distribution and $\bar{\theta}=1$, there is a probability of an endogenous blackout of $k_{i}^{\prime}-k_{i}^{\prime *}$. The small firm finds it optimal to reduce its capacity, even though this leads to positive blackout probabilities, as described in equation (13). Blackout probabilities, denoted by $\beta$, become

$$
\beta= \begin{cases}1-\bar{k}_{j}-\bar{k}_{i} & \text { if } \bar{k}_{i} \leq \frac{1}{6}\left(\sqrt{13} \bar{k}_{j}+\bar{k}_{j}\right) \\ 1-\frac{1}{6}(7+\sqrt{13}) \bar{k}_{j} & \text { else. }\end{cases}
$$


Blackout probabilities are exogenous for $\bar{k}_{i} \leq \frac{1}{6}\left(\sqrt{13} \bar{k}_{j}+\bar{k}_{j}\right)$ : Both firms are capacity constrained, cannot cover the full support of demand realizations, and blackouts can occur. For $\bar{k}_{i}>\frac{1}{6}\left(\sqrt{13} \bar{k}_{j}+\bar{k}_{j}\right)$, blackouts are at least partly endogenous and arise through capacity withholding: Even if total available capacity could cover the complete support of demand uncertainty, the small firm will withhold capacity. It is striking that the price cap for energy does not play a role in determining system security. ${ }^{19}$ The price cap only determines firms profits, thus long run investment and system adequacy, but not system security. Short run withholding is independent of the price cap, because the small firm's supply offer reacts to the larger firm's capacity, but not to the price cap. Blackout probabilities depend on the relative capacity constraints, with which the firms enter the real-time market.

Last, the derived pricing strategies and capacity choices also shed light on the nature of supply security, which often is referred to as being a public good, see for instance Abbott (2001). Starting from the simple observation that a monopolist ensures supply for all possible demand realizations and prices energy at the price cap, it becomes clear that, for a very small firm entering the market, the incumbent's incentive to supply all demand will not change. However, when firms become similar in size, both firms could freeride on its competitor to secure supply. Incentives to balance the grid therefore will differ with respect to each firm's position in the merit order. In line with propositions 2 and 3 small firms that bid inframarginal units may withhold capacity, although this can cause rationing and blackouts. Larger firms that supply marginal units care about serving all residual demand and about maintaining network balance. Hence, small firms may freeride, withhold capacity, and force larger firms to secure stable grids at the margin. This observation also explains the slope of the small firm's capacity reaction function, illustrating the strategic complementarity in supply offers. If large firms have large stakes in the market, small firms also increase their

\footnotetext{
${ }^{19}$ This results also holds when introducing positive constant marginal costs.
} 
capacities without fearing aggressive pricing by their larger competitors. If the larger firm has a lower capacity endowment the smaller firm does not increase its offer to satisfy more demand, but reduces its capacity offer to avoid aggressive pricing.

\section{Capacity mechanisms}

In the capacity market regime the $\mathrm{SO}$ enforces regulatory driven capacity decisions to increase system security. The $\mathrm{SO}$ can procure reserve capacity on its own or set capacity obligations on retailers. ${ }^{20}$ Both mechanisms introduce rewards for holding peak capacity available in real-time. Before capacity is traded, the $\mathrm{SO}$ sets a capacity requirement, denoted as $R$. $R$ is assumed to be completely inelastic. In equilibrium, the capacity price $p^{c}$ reflects the relation of all firms' offered available capacity to the SO's required level of available capacity. If energy from these reserved units is called, they are rewarded at the prevailing energy market price. Denote the capacity they offer on the capacity market as $k_{i}^{c}$ and the amount of capacity that is procured from each firm as $r_{i}$. Firms then earn profits of

$$
E\left[\pi_{i}^{c}\right]=E\left[\pi_{i}^{e}\left(k_{i}, r_{i}\right)\right]+r_{i} p^{c} .
$$

Profits at the capacity stage $\pi_{i}^{c}$ are the expected profits each firm obtains from their respective energy market capacities and from the part of these capacities that are rewarded a second time on the capacity market. Marginal costs of holding capacity available are assumed to be zero. Each firm commits to have its procured available capacity ready for dispatch and hence in real-time must offer capacity equal to or above its obligation, $k_{i} \geq r_{i}$. In real-time, all operating units, whether reserved or not, are rewarded at the

\footnotetext{
${ }^{20}$ In the latter case when retailers can buy capacity rights, in most power systems the SO still acts on behalf of all retailers in the spot market for capacity and re-sells all capacity to the retailers.
} 
prevailing real-time energy market price. Capacity mechanisms clear before generating firms compete in the energy market, see the timeline in figure 3.

\begin{tabular}{cc} 
Capacity market & Energy market \\
\hline $\begin{array}{c}\text { rewards available capacity } \\
\text { at the capacity price, }\end{array}$ & determines energy price \\
firms bid $\left(b_{i}^{c}, k_{i}^{c}\right)$ & and real-time capacity,
\end{tabular}

Figure 3: Stylized timeline.

Firms choose a price for capacity $b_{i}^{c}$ as well as the amount of available capacity they want to offer on the market $k_{i}^{c}$. These bids determine the capacity market price $p^{c}$ and each firms capacity obligation $r_{i}$. Each firm's bid constitutes the capacity market price according to the uniform pricing rule

$$
p^{c}= \begin{cases}b_{i}^{c}=\min \left\{b_{1}, b_{2}\right\} & \text { if } R \leq k_{i}^{c} \\ \max \left\{b_{1}, b_{2}\right\} & \text { if } R \geq k_{i}^{c} .\end{cases}
$$

Furthermore, due to the price-inelastic requirement, $R$, regulators set a capacity market price cap $P^{c}$.

\subsection{Capacity pricing}

Equilibrium capacity price bids depend on each firm's capacity offer $k_{i}^{c}$, as characterized by the following proposition.

Proposition 4 Firms' equilibrium bids for capacity, $b_{i}^{c}$, can be summarized in four cases.

(i) If $k_{i}^{c}>R$ and $k_{j}^{c}>R$ firms bid the unique equilibrium $b_{i}^{c *}=b_{j}^{c *}=0$. 
(ii) If $k_{i}^{c}<R$ and $k_{j}^{c}>R$ firm $i$ chooses a bid in

$$
\left[0, b_{i}^{c *} \leq P^{c} \frac{\max \left\{R-k_{i}^{c}, 0\right\}}{\min \left\{k_{j}^{c}, R\right\}}\right],
$$

while firm $j$ bids the price cap $b_{j}^{c *}=P^{c}$.

(iii) If $k_{i}^{c}<R, k_{j}^{c}<R$ and $k_{i}^{c}+k_{j}^{c}>R$, each firm can bid according to equation (16) while the other firm bids the price cap.

(iv) If $k_{i}^{c}+k_{j}^{c}<R$, then both firms bid the price cap for capacity, $b_{i}^{c *}=$ $b_{j}^{c *}=P^{c}$.

Proof. See LeCoq (2002) and Boom (2009) or A.6.

This pricing strategy includes the Bertrand outcome: If both firms offer more capacity than $R$, both will price equal to zero. However, if firm $i$ offers less capacity than $R$, it can bid according to equation (16). At this price its competitor $j$ is indifferent between undercutting or taking the residual capacity demand $R-k_{i}^{c}$ and bidding the price cap. Firm $j$ earns $\max \{R-$ $\left.k_{i}^{c}, k_{j}^{c}\right\} P^{c}$ while firm $i$ 's profits become $k_{i}^{c} P^{c}$. The same holds mutually for firm $j$ submitting the low price bid for $k_{j}^{c}<R$. For $k_{i}^{c}<R$ and $k_{j}^{c}<R$, two kinds of equilibria exist in which both firms can submit a price according to equation (16) while its rival submits the price cap.

Proposition 5 If the SO wants to increase aggregate energy market capacity through capacity mechanisms, the equilibrium price for capacity has to equal the price cap for capacity.

Proof. First note that if the SO wants to prevent capacity withholding and influence energy market prices, the SO has to set $R$ bigger than $k_{i}^{*}$, thus bigger than the small firm's optimal energy market supply without the capacity mechanism. Hence, if $R>k_{i}^{*}$, according to equation (15) and proposition 4 
the capacity market price must equal the price cap. If $k_{j}^{c}>R$, it cannot be an equilibrium strategy for firm $i$ to offer any $k_{i}^{c}>R$, because the capacity price would fall to zero and in that case firm $i$ would prefer to not commit capacity at all and remain at its energy market optimum. If $k_{j}^{c}<R$ the capacity price also equals the price cap, irrespective of $k_{i}^{c}$.

Due to the concavity of firm $i$ 's profits, firm $i$ only deviates from its energy market optimum at positive capacity prices, which in equilibrium have to equal the price cap. ${ }^{21}$ This result is not surprising and supported by the observation that capacity prices are either close to zero or near to the capacity price cap, see Stoft (2002).

\subsection{Energy market distortions}

Rewarding capacity changes final energy market capacities, prices and blackout probabilities. First note that for the large firm, the capacity market does not cause any strategic effects on its capacity offer. The large capacity firm still has no incentives to withdraw capacities on the energy market. To see this, suppose that the larger bidder on the real-time market could have all its energy market capacity rewarded as available capacity on the capacity market, $k_{j}^{*}=r_{j}$. Its profits are still monotonously increasing in $r_{j}$, and the large firm always maximizes its profits in equation (14) for selling an as high reserve capacity part of its real-time capacity as possible:

$$
r_{j}^{*}=k_{j}^{*}=\bar{k}_{j}
$$

Now suppose the smaller energy market bidder, firm $i$, could choose its capacity, given any price for capacity. For any positive $p^{c}$, the small firm supplies

\footnotetext{
${ }^{21}$ Assuming price elastic demand functions for capacity would not change the overall result. The equilibrium price of capacity then would not be the price cap, but the residual monopoly price that the high bidding firm would charge.
} 
more capacity than without the capacity reward. The small firm will find it optimal to offer capacity so that it maximizes equation (14) such that

$$
r_{i}^{*}=\max _{r_{i}} E\left[\pi_{i}^{r t}\left(r_{i}\right)\right]: \frac{\partial \pi_{i}\left(r_{i}\right)}{\partial r_{i}}=-p^{c} .
$$

The marginal loss from leaving its optimum in the real-time market - the optimum when capacity is not rewarded - have to equal the marginal revenue of selling one more unit of reserve capacity, or simply the capacity price. If the equilibrium capacity price is zero, there is no incentive for the small firm to deviate from its real-time market optimum. If the equilibrium capacity price is positive, the small firm starts to offer more capacity, if not bound by its capacity constraint. The optimality condition in equation (18) also exhibits a strategic relation between the SO's choice of the price cap and the capacity requirement. Capacity requirements, $R$, that are too low can constrain capacity from being offered on the energy market, although the capacity price (which in equilibrium is the price cap $P^{c}$ ) actually is high enough to attract more available capacity from the withholding firm. In turn, capacity price caps can be too high for a given capacity requirement and increase the costs of procurement.

As derived, efficient Bertrand competition in capacity markets does not change system security and energy market outcomes. Dominant firms do not deviate from their strategic optimum when capacity markets yield zero profits. Given that $R$ is set high enough so that equation (18) holds, aggregate energy market capacity with capacity payments is the sum of both firms capacity offers in equations (17) and (18). Blackout probabilities then become

$$
\beta= \begin{cases}1-\bar{k}_{j}-\bar{k}_{i} & \text { if } \overline{k_{i}} \leq \frac{1}{6}\left(\sqrt{13} \bar{k}_{j}+\bar{k}_{j}\right) \\ 1-\frac{1}{6}\left(7 \bar{k}_{j}+\sqrt{\bar{k}_{j}\left(13 \bar{k}_{j}+12 \frac{P^{c}}{P^{r t}}\right)}\right) & \text { else. }\end{cases}
$$

Proposition 6 At a competitive price for capacity system security is un- 
changed. The SO can only change energy market capacities and system security at noncompetitive and positive capacity prices. Blackout probabilities increase in energy market price caps and decrease in capacity prices.

Proof. See equation (19).

Equation (19) also shows that blackout probabilities increase for higher energy market price caps. Higher energy market profits require higher capacity market prices to set sufficient incentives for the firms to deviate from the energy market optimum.

In times when capacity markets yield profits, aggregate real-time market capacity increases. As intended by the SO, this effect decreases the expected price for energy. To see this, note that in the short run the $\mathrm{SO}$ can only raise capacities from the withholding small bidder, firm $i$. Therefore the price effect, derived from equation (11), is

$$
\frac{\partial E\left[p^{r t}\right]}{\partial k_{i}}=\frac{\left(k_{j}-4 k_{i}\right)}{2 k_{j}} P^{r t}+\frac{2 k_{i}+k_{j}}{2 k_{j}} \underline{b}
$$

which is negative for all $k_{i}^{*}\left(\bar{k}_{j} \mid p^{c}=0\right) \leq k_{i} \leq k_{j}$, that is, for all additional capacity of firm $i$ greater than its real-time offer at a capacity price of zero. Capacity markets lower the expected price for energy. However, since $\underline{b}=$ $e^{-\left(\left(2 k_{i}\right) / k_{j}\right)} P^{r t}$ and

$$
\frac{\partial \underline{b}}{\partial k_{i}}=-\frac{2 e^{-\frac{2 k_{i}}{k_{j}}} P^{r t}}{k_{j}}
$$

is negative for all $k_{i}^{*}\left(\bar{k}_{j} \mid p^{c}=0\right) \leq k_{i} \leq k_{j}$, the strategy space of both firms' pricing strategies increases. Price volatility rises, since firms' capacities become more similar. Thus, the quantity effect of contracting available capacity decreases the energy price but increases price volatility. The only possible channel leading to a decrease in the energy price volatility are lower 
energy price caps, which as shown above decrease energy market profits but do not influence production decisions.

The result that capacity mechanisms and energy price caps can mitigate market power and capacity withholding are in line with the findings of Joskow and Tirole (2007) who show that capacity obligations and associated capacity payments have the potential to compensate generators for the shortfall in profits incurred by the price cap on the energy market. Endogenizing the capacity price as above, however, shows that capacity markets are only effective when they reward capacity above the marginal costs of being available and firms inflate their capacity market bids according to the losses they incur from deviating from the energy market optimum.

\section{Conclusion}

This paper analyzes the effects of different market designs on supply security in imperfect power markets. The analysis focuses on peak time situations and finds that energy-only markets can ensure enough available peak capacity only for sufficiently asymmetric firm sizes. When firms are similar in size, each firm likes to withhold capacity and freeride on its competitor to satisfy residual demand and to secure continuous trade on balanced power networks. As a consequence, endogenous blackout probabilities arise that are caused by capacity withholding rather than scarcity. In the duopoly market equilibrium, this result translates into a larger firm that bids higher prices and sells power at the margin, while the smaller firm bids lower energy prices and withholds inframarginal capacity. Only the larger firm has an incentive to maintain balanced grids and supply all stochastic demand. The smaller firm risks blackouts when maximizing profits. When the system operator faces high demand that leads to a shortage of supply, and has to buy more energy, the smaller firm then becomes a monopolist for out of market purchases. 
When regulators implement capacity mechanisms such as SO reserve procurement or capacity obligations, available peak capacity increases as long as capacity prices are above marginal costs. In that case, capacity mechanisms lower blackout probabilities, but increase energy price volatility. However, energy price caps can reduce price volatility without effecting system security. Hence, energy price caps and capacity mechanisms can mitigate market power in the energy market, but at high costs for available capacity.

The choice of market design depends on the firm size relation of dominant firms in the market, but also on regulatory preferences for supply security. Regulators have to balance the costs of capacity remuneration and the willingness to administer capacity mechanisms and distort energy price signals in the long run with short run benefits of lower market prices and less capacity withholding.

The future development of real-time pricing in the retail segment will add an interesting new element to the discussion on market design and will, on the first glance, back up benefits of energy-only markets. Consumers will be able to react to price spikes and the need for price caps diminishes. In turn, flattening price spikes with capacity mechanisms and at the same time incentivizing consumers to react to price spikes via smart meters might counteract potential benefits from smart grid and smart meter technology. In what ways real-time pricing will effect future electricity market designs constitutes an interesting and open question for further research.

\section{A Appendix}

\section{A.1 Non-existence of pure strategy equilibria in real- time pricing}

Suppose a pure strategy for firm $i$ exists. Firm $i$ submits a bid that is low enough to attract firm $j$ not to underbid but to bid the price cap and take the expected residual 
demand. If firm $j$ then would underbid firm $i$, it would bid $b_{j}=b_{i}-\epsilon$, where $\epsilon$ is close to zero. The critical low price, $b_{i}^{*}$, for firm $i$ thus has to satisfy

$$
\left[b_{i}-\epsilon\right] \int_{0}^{k_{j}} \theta d \theta+b_{i} \int_{k_{j}}^{k_{i}+k_{j}}\left(\theta-k_{j}\right) d \theta \leq P^{r t} \int_{k_{i}}^{k_{i}+k_{j}}\left(\theta-k_{i}\right) d \theta
$$

or, rearranging and ignoring $\epsilon$

$$
b_{i} \leq \frac{k_{j}^{2}}{k_{i}^{2}+k_{j}^{2}} P^{r t}=b_{i}^{*} .
$$

Since for all $0 \leq k_{i}, k_{j} \leq 1, \frac{k_{j}^{2}}{k_{i}^{2}+k_{j}^{2}}$ is between 0 and 1 , such a price exists. Firm $i$ 's profits for that strategy become $b_{i} \frac{k_{i}^{2}}{2}+P^{r t} k_{i} k_{j}$. The first order condition with respect to $b_{i}$ is strictly positive. Given that firm $j$ bids at the price cap, firm $i$ should bid the highest possible price in order to maximise its profits, which is bidding equal to the price cap minus an infinitely small $\epsilon$. In turn, firm $j$ would underbid the price cap by two $\epsilon$, because now $b_{i}>b_{i}^{*}$. Both firms would race to the bottom, until firm $i$ bids $b_{i}^{*}$ again. This contradicts the only reasonable pure strategy candidate $b_{i}^{*}$.

\section{A.2 Mixed strategy pricing in the real-time market}

Expected profits in (2) can be rewritten to

$$
E\left[\pi_{i}\right]=b_{i} \frac{1}{2} k_{i}^{2} \int_{\underline{b}}^{b_{i}} f_{j}\left(b_{j}\right) d b_{j}+\int_{b_{i}}^{P^{r t}}\left(b_{i} \frac{1}{2} k_{i}^{2}+b_{j} k_{i} k_{j}\right) f_{j}\left(b_{j}\right) d b_{j}
$$

and further to

$$
E\left[\pi_{i}\right]=b_{i} \frac{1}{2} k_{i}^{2}+k_{i} k_{j}\left[P^{r t}-b_{i} F_{j}\left(b_{i}\right)-\bar{F}_{j}\left(P^{r t}\right)+\bar{F}_{j}\left(b_{i}\right)\right]
$$

where $\bar{F}_{j}(\cdot)$ is the antiderivative of $F_{j}(\cdot)$. Taking the first order condition, rearranging and assuming a symmetric support of $F_{i}\left(b_{i}\right)$ and $F_{j}\left(b_{j}\right)$ :

$$
f_{j}\left(b_{j}\right)=\frac{k_{i}}{2 k_{j} b_{j}}
$$


Integrating yields:

$$
F_{j}\left(b_{j}\right)=\frac{k_{i}}{2 k_{j}} \log \left(b_{j}\right)+C,
$$

where $\mathrm{C}$ is the constant of integration. Exploiting $F_{j}(\underline{b})=0$ :

$$
F_{j}\left(b_{j}\right)=\frac{k_{i}}{2 k_{j}} \log \left(\frac{b_{j}}{\underline{b}}\right)
$$

Now, for $k_{i} \leq k_{j}$, at any given $\underline{b}, \lim _{b_{j} \rightarrow P^{r t}} F_{j}\left(b_{j}\right) \leq \lim _{b_{i} \rightarrow P^{r t}} F_{i}\left(b_{i}\right)$, what implies that $\lim _{b_{i} \rightarrow P^{r t}} F_{i}\left(b_{i}\right)=1$ must hold. Using $F_{i}\left(P^{r t}\right)=1$ yields $\underline{b}=e^{-\frac{2 k_{i}}{k_{j}} P^{r t}}$.

\section{A.3 Generic real-time demand distribution}

Profits in equations (5) and (6) can be rewritten as

$$
\begin{aligned}
E\left[\pi_{i}^{e}\left(k_{i}, k_{j}\right)\right]= & \left(\lim _{b_{j} \rightarrow P^{r t}} F_{j}\left(b_{j}\right) \int_{k_{j}}^{k_{j}+k_{i}}\left(\theta-k_{j}\right) d \theta\right. \\
& \left.+\left(1-\lim _{b_{j} \rightarrow P^{r t}} F_{j}\left(b_{j}\right)\right)\left(\int_{0}^{k_{i}} \theta d \theta+\int_{k_{i}}^{k_{i}+k_{j}} k_{i} d \theta\right)\right) P
\end{aligned}
$$

and

$$
E\left[\pi_{j}^{e}\left(k_{i}, k_{j}\right)\right]=\int_{k_{i}}^{k_{i}+k_{j}}\left(\theta-k_{i}\right) d \theta P .
$$

Adding a general distribution of demand, $g(\theta)$, to the maximization problem in equation (2), deriving the mixed strategies and calculating profits then similarly to above yields

$$
\begin{aligned}
E\left[\pi_{i}^{e}\left(k_{i}, k_{j}\right)\right]= & \left(\lim _{b_{j} \rightarrow P^{r t}} F_{j}\left(b_{j}\right) \int_{k_{j}}^{k_{j}+k_{i}}\left(\theta-k_{j}\right) g(\theta) d \theta\right. \\
& \left.+\left(1-\lim _{b_{j} \rightarrow P^{r t}} F_{j}\left(b_{j}\right)\right)\left(\int_{0}^{k_{i}} \theta g(\theta) d \theta+\int_{k_{i}}^{k_{i}+k_{j}} k_{i} g(\theta) d \theta\right)\right) P
\end{aligned}
$$

and

$$
E\left[\pi_{j}^{e}\left(k_{i}, k_{j}\right)\right]=\int_{k_{i}}^{k_{i}+k_{j}}\left(\theta-k_{i}\right) g(\theta) d \theta P .
$$


It is easy to show that profits of the larger firm $j$ are increasing in $k_{j}$ and that as in equation (6) the F.O.C. with respect to $k_{j}$ is greater than zero. Next note that $\lim _{b_{j} \rightarrow P^{r t}} F_{j}\left(b_{j}\right)$ increases in $k_{i}$ in the small firm's profit function. In our setting of $k_{i} \leq k_{j}$, we have $E\left[\pi_{i}^{e}\right]=E\left[\pi_{j}^{e}\right]$ whenever $k_{i}=k_{j}$, because $\lim _{b_{j} \rightarrow P^{r t}} F_{j}\left(b_{j}\right)$ equals one and the second term in firm $i$ 's profit function becomes zero. Then, firm $i$ could always gain by withholding an infinitesimal amount of capacity and therefore being the first to sell in expectation. Hence in line with proposition 10, depending on $\bar{k}_{i}$ firm $i$ either offers all available capacity or withholds capacity.

\section{A.4 Equilibrium profits in the energy market}

For expected real-time profits for firm $i$ and $j$, for $k_{i} \leq k_{j}$, the withholding and the nonwithholding case have to be separated. In the non-withholding case profits are equal to equations (5) and (6) with $k_{i}=k_{i}^{*}=\bar{k}_{i}=T-\bar{k}_{j}$ and $k_{j}=\bar{k}_{j}$. For the withholding case, $k_{i}\left(k_{j}\right)=\frac{1}{6}\left(\sqrt{13} \bar{k}_{j}+\bar{k}_{j}\right)$, profits of the small firm change to

$$
\pi_{i}\left(\overline{k_{j}}\right)=\frac{1}{108}(19+13 \sqrt{13}) \bar{k}_{j}^{2} P^{r t}
$$

\section{A.5 Equilibrium selection}

Equilibrium selection is relevant when capacity endowments are sufficiently similar and allow for two equilibria. Otherwise, when firm size is sufficiently asymmetric, the large firm always finds it profitable to become the large bidder. In this case, the equilibrium in which the large firm is the small bidder vanishes. The critical capacity relation that decides about the number of equilibria can be derived as follows. Profits of the larger firm $j$ when being the small bidder are

$$
\pi_{j}\left(\overline{k_{j}}\right)=\frac{1}{108}(19+13 \sqrt{13}){\overline{k_{i}}}^{2} P^{r t} .
$$

The latter term are profits of the small firm and corrected for the fact that if the larger firm $j$ submitted the smaller capacity it had to react optimally to $\bar{k}_{i}$. This equilibrium in which the large firm is the small bidder disappears when deviation profits are higher than the profits of being the small bidder. When firm $j$ deviates, and instead of $k_{j}^{*}\left(\bar{k}_{i}\right)$ plays $\bar{k}_{j}$ and offers all capacity, profits are

$$
\pi_{j}\left(\overline{k_{j}}\right)=\frac{{\overline{k_{j}}}^{2}}{2} P^{r t} .
$$


Setting both terms equal one obtains the critical level of the small firm $i$ 's capacity so that the large firm $j$ will always find it optimal to be the large bidder,

$$
\bar{k}_{j}{ }^{*}\left(\bar{k}_{i}\right)=\sqrt{\frac{19+13 \sqrt{13}}{54}} \bar{k}_{i} .
$$

Whenever firm $j$ holds less capacity and capacity endowments therefore are sufficiently similar, both firms will find it profitable to be the small bidder, given that its rival is the large bidder. In that case two equilibria in capacity offers remain.

Below I show that risk dominance applies and the equilibrium in which the firm with larger capacity endowment submits the larger capacity risk dominates the equilibrium in which the larger firm is the small bidder. Again, for $\overline{k_{j}}>\bar{k}_{i}$, all possible profits can be summarized by the matrix

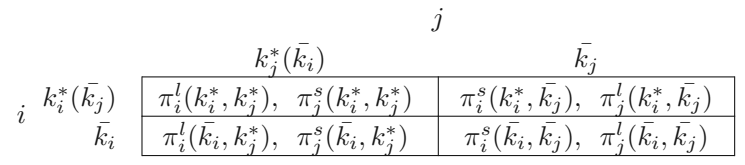

where the indices $s$ and $l$ indicate which player offers the smaller respectively larger capacity in each outcome. For the equilibrium $\left[k_{i}^{*}, \bar{k}_{j}\right]$ to risk dominate $\left[\bar{k}_{i}, k_{j}^{*}\right]$ and therefore the large firm to submit the large quantity in the auction

$$
\begin{array}{r}
{\left[\pi_{i}^{s}\left(\bar{k}_{i}, \bar{k}_{j}\right)-\pi_{i}^{s}\left(k_{i}^{*}, \bar{k}_{j}\right)\right]\left[\pi_{j}^{s}\left(k_{i}^{*}, k_{j}^{*}\right)-\pi_{j}^{l}\left(k_{i}^{*}, \bar{k}_{j}\right)\right] \geq} \\
{\left[\pi_{i}^{l}\left(k_{i}^{*}, k_{j}^{*}\right)-\pi_{i}^{l}\left(\bar{k}_{i}, k_{j}^{*}\right)\right]\left[\pi_{j}^{l}\left(\overline{k_{i}}, \overline{k_{j}}\right)-\pi_{j}^{s}\left(\overline{k_{i}}, k_{j}^{*}\right)\right]}
\end{array}
$$

needs to hold. Inserting the respective profit functions we get the inequality 


$$
\begin{aligned}
& {\left[\left(\bar{k}_{i}+2 \bar{k}_{j}-\frac{2 \bar{k}_{i}^{2}}{\bar{k}_{j}}\right) \frac{\bar{k}_{i}}{2} P^{r t}-\frac{19+13 \sqrt{13}}{108} \bar{k}_{j}^{2} P^{r t}\right]} \\
& {\left[\frac{7+\sqrt{13}}{-36 \bar{k}_{j}} \overline{k_{i}}\left(2{\overline{k_{i}}}^{2}-{\overline{k_{i}}}_{\bar{k}_{j}}+2{\overline{k_{j}}}^{2}\right) P^{r t}-\frac{{\overline{k_{j}}}^{2}}{2} P^{r t}\right] \geq} \\
& {\left[\frac{\left(\overline{k_{j}}+\sqrt{13} \bar{k}_{j}\right)^{2}}{72} P^{r t}-\frac{{\overline{k_{i}}}^{2}}{2} P^{r t}\right]\left[\frac{{\overline{k_{j}}}_{2}^{2}}{2} P^{r t}-\frac{19+13 \sqrt{13}}{108} \bar{k}_{i}^{2} P^{r t}\right]}
\end{aligned}
$$

which holds for all $\overline{k_{i}}<\overline{k_{j}}<{\overline{k_{j}}}^{*}\left(\bar{k}_{i}\right)=\sqrt{\frac{19+13 \sqrt{13}}{54}} \overline{k_{i}}$ and $\overline{k_{i}}+\overline{k_{j}}=T \leq \bar{\theta}=1$.

\section{A.6 Capacity pricing}

Case (i) is the Bertrand outcome. In case (iv) capacity offers are so small such that both firms cannot serve their residual demand and charge the monopoly price. Cases (ii) and (iii) are derived as follows. For any capacity requirement $R$ a firm $i$ can submit a bid

$$
b_{i}^{c *} \min \left\{k_{j}^{c}, R\right\} \leq P^{c} \max \left\{R-k_{i}^{c}, 0\right\}
$$

that makes firm $j$ indifferent between undercutting and earning $\left(b_{i}^{c *}-\epsilon\right) \min \left\{k_{j}^{c}, R\right\}$ and supplying the residual demand $\max \left\{R-k_{i}^{c}, 0\right\}$ and bidding the price cap. Rearranging yields equation (16). The high bidding firm never wants to deviate by construction. The firm that submits the low bid as derived above never wants to overbid, because the equilibrium price would still be the price cap and the overbidding firm would only sell less capacity and loose profits.

\section{References}

Abbott, Malcolm (2001) "Is the Security of Electricity Supply a Public Good?" The Electricity Journal, Vol. 14, No. 7, pp. 31-33.

Allaz, Blaise and Jean-Luc Villa (1993) "Cournot Competition, Forward Markets and Efficiency," Journal of Economic Theory, Vol. 59, pp. 1-16.

Batlle, Carlos, Carlos Vazquez, Michel Rivier, and Ignacio J. Perez-Arriaga (2007) "En- 
hancing power supply adequacy in Spain: Migrating from capacity payments to reliability options," Energy Policy, Vol. 35, pp. 4545-4554.

Besser, Janet G., John G. Farr, and Susan F. Tierney (2002) "The Political Economy of Long-Term Generation Adequacy: Why an ICAP Mechanism is Needed as Part of Standard Market Design," The Electricity Journal, Vol. 15, No. 7, pp. 53-62.

Boom, Anette (2009) "Vertically Integrated Firms' Investments in Electricity Generating Capacities," International Journal of Industrial Organization, Vol. 27, pp. 544-551.

Borenstein, Severin (2005) "Time-varying Electricity Retail Prices: Theory and Practice," Electricity Deregulation: Choices and Challenges, University of Chicago Press, pp. 317358.

Crampes, Claude and Anna Creti (2005) "Capacity Competition in Electricity Markets," Economia delle Fonti di Energia e dell'Ambiente.

Cramton, Peter and Steven Stoft (2005) "A Capacity Market that Makes Sense," The Electricity Journal, Vol. 18, No. 7, pp. 43-54.

Creti, Anna and Natalia Fabra (2007) "Supply Security and Short-run Capacity Markets for Electricity," Energy Economics, Vol. 29, pp. 259-276.

Eurelectric (2011) "RES Integration and Market Design: Are Capacity Remuneration Mechanisms Needed to Ensure Generation Adequacy?" Discussion paper.

Fabra, Natalia, Nils-Henrik Von der Fehr, and Maria-Angeles de Frutos (2011) "Market Design and Investment Incentives," The Economic Journal, forthcoming.

Fabra, Natalia, Nils-Henrik Von der Fehr, and David Harbord (2006) "Designing Electricity Auctions," RAND Journal of Economics, Vol. 37, No. 1, pp. 23-46.

Harbord, David and Nils-Henrik Von der Fehr (1993) "Spot Market Competition in the UK Electricity Industry," The Economic Journal, Vol. 103, No. 418, pp. 531-546.

Hogan, William (2005) "On an Energy Only Electricity Market Design for Resource Adequacy," Harvard University, Mimeo.

Joskow, Paul and Jean Tirole (2007) "Reliability and Competitive Electricity Markets," RAND Journal of Economics, Vol. 38, No. 1, pp. 60-84. 
LeCoq, Chloé (2002) "Strategic Use of Available Capacity in the Electricity Spot Market," SSE/EFI Working Paper, Series in Economics and Finance, No. 496.

Oren, Shmuel S. (2000) "Capacity Payments and Supply Adequacy in Competitive Electricity Markets," Conference paper, VII Symposiom Of Specialists In Electric Operational And Expansion Planning.

Sioshansi, Fereidoon and Wolfgang Pfaffenberger (2006) "Electricity Market Reform: An International Perspective," Elsevier Global Energy Policy and Economics Series.

Stoft, Steven (2002) "Power System Economics," IEEE Press and Wiley-Interscience.

The International Energy Agency (2005) "Learning From the Blackouts - Transmission System Security in Competitive Electricity Markets," OECD/IEA.

— (2007) "Contribution of Renewables to Supply Security," IAE Information paper.

Tishler, Asher, Irena Milstein, and Chi-Keung Woo (2008) "Capacity Commitment and Price Volatility in a Competitive Electricity Market," Energy Economics, Vol. 30, p. 16251647 .

Wilson, Robert (2002) "Architecture of Power Markets," Econometrica, Vol. 70, No. 4, pp. 1299-1340.

Wolfram, Cathrine (1998) "Strategic Bidding in a Multiunit Auction: An Empirical Analysis of Bids to Supply Electricity in England and Wales," The RAND Journal of Economics, Vol. 29, No. 4, pp. 703-725. 


\title{
Real-time Pricing in Power Markets: Who Gains?
}

\author{
Anette Boom ${ }^{\mathrm{a}}$ \\ Copenhagen Business School, CIE and ENCORE \\ Sebastian Schwenen ${ }^{\mathrm{b}}$ \\ Copenhagen Business School
}

\begin{abstract}
We examine welfare effects of real-time pricing in electricity markets. Before stochastic energy demand is known, competitive retailers contract with final consumers who exogenously do not have real-time meters. After demand is realized, two electricity generators compete in a uniform price auction to satisfy demand from retailers acting on behalf of subscribed customers and from consumers with real-time meters. Increasing the number of consumers on real-time pricing does not always increase welfare since risk-averse consumers dislike uncertain and high prices arising through market power. In the Bertrand case, welfare is the same with all or no consumers on smart meters.
\end{abstract}

Keywords: Electricity, Real-time Pricing, Market Power, Efficiency. JEL-Classification: D42, D43, D44, L11, L12, L13

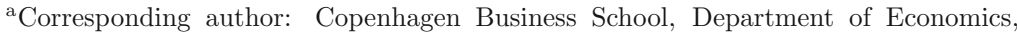
Porcelanshaven 16 A, DK-2000 Frederiksberg, e-mail: ab.eco@cbs.dk

${ }^{\mathrm{b}}$ Copenhagen Business School, Department of Economics, Porcelanshaven 16 A, DK2000 Frederiksberg, e-mail: ses.eco@cbs.dk
} 


\section{Introduction}

Real-time pricing of electricity for residential households and small businesses was for a long time technologically and economically not viable. Traditionally, final consumers had a meter that simply measured the total amount of electricity consumed without keeping track of when consumers actually consumed what amounts of electricity. For this reason it was not possible to differentiate prices to reflect the scarcity of electricity at each point in time, which made consumers unable to react to price signals. This lack of consumer response translates into highly inelastic market demand in electricity wholesale markets, which facilitates the exercise of market power especially in peak times, (see, e.g., Stoft, 2002, p.78f). In addition the absence of price signals prevents any consumption smoothing over time and thus aggravates the system operator's problem to constantly balance supply and demand. Since electricity is hardly storable, not achieving a balance results in costly blackouts and consumer rationing.

Recent technological developments and the rising need for more efficient power grids have however increased the attention on exploiting efficiency potentials through smarter metering. A number of firms have invented new meter technologies to reap such efficiency gains, which led to a drastic increase in venture capital for smart meter technologies. ${ }^{1}$ This new development of smart grids and smart meters aims at allowing electricity providers to transmit time varying price signals, that in turn enable even residential households and small businesses to adjust their consumption over the day accordingly. ${ }^{2}$ However, the installation of smart meters and smart grids changes the design of all current transmission networks and is extremely costly. Thus, there is considerable uncertainty in the welfare effects and the profitability of real-time metering technology. We ask how the introduction of real-time

\footnotetext{
${ }^{1}$ See The Economist (2009b).

${ }^{2}$ See The Economist (2009a).
} 
metering will benefit consumers, producers and overall welfare.

That prices should fluctuate if capacities cannot easily be adapted to fluctuating and uncertain demand is an insight gained from the peak-load pricing literature that started already in the fifties (for a survey see Crew et al. (1995)). More recently, Borenstein and Holland (2005) developed a model where firms invest in electricity generating capacity in the first stage and then compete in a perfectly competitive electricity market for a certain number of periods with a time-varying demand. They show that the market outcome is not efficient if not all consumers are on real time pricing schedules. Furthermore, the market outcome is less than second-best efficient, even if one takes into account that some consumers are priced only according to the average wholesale costs of serving them with a time-invariant price instead of paying the time-variant wholesale price in each single period. However, increasing the number of customers on real-time pricing does not necessarily increase social welfare, although having all customers on real-time pricing is always Pareto superior to having some of them on time-invariant rates. ${ }^{3}$

We derive efficiency effects of real-time pricing when generating firms have market power in the electricity wholesale market and consumers are riskaverse. We explicitly distinguish between the wholesale and the retail market of electricity, and assume market power in the wholesale market with only two firms generating and selling electricity. The retail sector is perfectly competitive. Like in Borenstein and Holland (2005), we assume that consumers who are on real-time pricing schedules can express their demand on the wholesale market either directly or indirectly via their competitive retailer. The consumers who are not on real-time meters need to contract with retailers before their own and the aggregate level of demand is known. Therefore they will finally pay the same price no matter what the level of de-

\footnotetext{
${ }^{3}$ Holland and Mansur (2006) simulate the short-run efficiency gains without capacity investments from increasing the share of customers on real-time pricing in a model close to Borenstein and Holland (2005) for the PJM market and can only identify moderate efficiency increases for this case.
} 
mand will be. Joskow and Tirole (2006) and Joskow and Tirole (2007) both mainly focus on the retail market without taking into account repercussions to the potentially non-competitive wholesale market. ${ }^{4}$ Contrary to the former and in line with the latter we abstract from monopoly distribution and assume that all retailers compete on a level playing field. Like Borenstein and Holland (2005), we model uniform retail prices whereas Joskow and Tirole (2006) and Joskow and Tirole (2007) allow for two-part tariffs.

Neither Borenstein and Holland (2005) nor the empirical studies that try to estimate the welfare effects of existing real-time pricing initiatives for large industrial customers (see Taylor et al. (2005)) take into account the insurance effect of fixed prices. Most analyses implicitly assume that the volatile demand is certain and therefore sum up the consumer surplus for all different time periods to determine consumer welfare. We instead assume demand uncertainty and consider concave surplus functions for our costumers when deriving welfare statements. Taking this risk aversion into account explicitly allows us to check whether the positive efficiency effects of realtime electricity pricing are potentially counteracted by the increase in price risks that risk-averse consumers dislike.

Our model is based on Boom and Buehler (2007). We introduce real time pricing and differentiated consumers, that is, each consumer demands a different quantity of electricity although they are all exposed to the same demand shock. Motivated by the observation that in most electricity markets larger consumers, e.g. private businesses, installed smart meters before smaller customers such as private households did, we assume that consumers with the highest demand will be served with real-time metering and pricing first. ${ }^{5}$ As

\footnotetext{
${ }^{4}$ Joskow and Tirole (2007) derive optimal retail prices, rationing rules and capacity investments with price-sensitive and price-insensitive consumers.

${ }^{5}$ Empirical studies of existing real time pricing programs with the exception of Allcott (2009) focus only on large industrial customers (see Patrick and Wolak (2001), Taylor et al. (2005), Boisvert et al. (2007), and Zarnikau and Hallett (2008)). Allcott (2009) is the only one who reports on a small scale real-time pricing experiment with residential households in Chicago in 2003.
} 
the degree of real-time pricing increases, the consumers that enter real-time pricing in our model will have a lower demand than those already in the program. Hence, our model set up also allows us to conclude whether real-time pricing is more beneficial for large or small customers.

The next section presents the modeling framework. Section three derives the model outcome and presents wholesale and retail market equilibria. In section four, we present comparative statics in the level of real-time pricing and derive welfare statements. Section five concludes.

\section{The model}

In a mass of $N$ consumers with $N=1$, each consumer can be of a different type $\alpha$ which is drawn from a uniform distribution on $\left[\frac{1}{2}, \frac{3}{2}\right]$. The preferences of a consumer of type $\alpha$ are represented by the consumer surplus function

$$
V(x, \alpha, \varepsilon, p)=\alpha(x-\varepsilon)-\frac{(x-\varepsilon)^{2}}{2}-p x,
$$

where $p$ is the electricity price, $x$ the electricity consumed and $\varepsilon$ a shock that affects all consumers alike and is drawn from a uniform distribution on $[0,1]$. Maximizing the surplus with respect to the consumed electricity $x$ yields the consumer's individual demand ${ }^{6}$

$$
x(p, \alpha, \varepsilon)=\max \{\alpha+\varepsilon-p, 0\} .
$$

We assume that the consumers with small demand, meaning $\alpha \leq \tilde{\alpha}$, do not have a smart meter and need to contract with one of the retailers and pay the retail price $p=r$. Consumers with a relatively large demand, defined by

\footnotetext{
${ }^{6}$ The demand is modeled similarly to Boom and Buehler (2007) and Boom (2009). However, there all consumers have $\alpha=1$ and thus identical demand.
} 
$\alpha>\tilde{\alpha}$ are on real-time meters and purchase their electricity directly on the wholesale market at the wholesale price $p=p^{*} .{ }^{7}$ The threshold separating large and small consumers, i.e. consumers with and without real-time meters, has to lie within the support of $\alpha$, that is, $\frac{1}{2} \leq \tilde{\alpha} \leq \frac{3}{2}$.

There are $n \geq 2$ retailers who compete à la Bertrand. Consumers without a smart meter subscribe to the retailer with the lowest retail price $r$ while their actual level of demand is still uncertain. For the sake of simplicity we assume zero retail costs. Retailers' marginal costs then equal the wholesale price for which they buy electricity. The retailers announce their customers' demand for electricity to the wholesale auction after they have observed the actual level of demand, that is the realization of $\varepsilon$. Retailers with supply obligations go out of business as soon as their marginal costs, the wholesale market price $p^{*}$, exceeds the retail price $r$. Then their customers will not be served with electricity, but the system operator is able to ration retail consumers and a blackout does not occur. ${ }^{8}$

Electricity is only produced by two electricity generating firms $A$ and $B$. Each generator $i=A, B$ is capacity constrained and owns capacity $K_{i}$. Both generators use an identical technology with constant marginal costs $c$ which are normalized to zero. Generating firms can produce up to their capacity $K_{i}$ but not beyond that quantity. They can sell their electricity only via the wholesale market, run by the system operator as a uniform price auction. Before each firm submits its supply bid to the wholesale market, the total demand, meaning the level of $\varepsilon$, is publicly known. In the auction each firm only announces a price $p_{i}$ at and above which they are willing to produce up

\footnotetext{
${ }^{7}$ Note that it does not matter whether customers on real-time meters bid their demand directly into the wholesale auction or whether they have a contract with a perfectly competitive retailer without retail costs. Borenstein and Holland (2005), Joskow and Tirole (2006) and (2007) also assume that consumers on real-time pricing pay the wholesale price.

${ }^{8}$ The latter assumption means that the system operator has perfect control over the grid and can selectively take customers off-line. This assumption is in line with Joskow and Tirole (2007) and will finally lead to efficient rationing. In the perfect smart grid scenario, efficient rationing is possible. However, today it is not implementable.
} 
to their total capacity. Fabra and von der Fehr (2006) show in their analysis that despite different optimal bidding strategies the market outcome would not change if we allowed for a finite but larger number of steps in the bidding function of the generators.

The system operator runs a uniform price auction. ${ }^{9}$ To clear the auction, the system operator first aggregates all submitted capacity at each price bid, and then finds the market clearing price, that equates supply and the level of demand stemming from the consumers on smart-meters and the ones that contract with a retailer and pay the retail price $r$. Three situations can occur:

1. The capacity of the low-bidding generator is sufficient to satisfy all demand at this low price. The wholesale price $p^{*}=p_{i}$ with $p_{i} \leq p_{j}$ and $i, j=A, B$ and only the low bidding firm is called to generate the amount of electricity necessary to satisfy demand $D\left(p^{*}, r, \tilde{\alpha}, \varepsilon\right)$.

2. The capacity of the low-bidding firm is insufficient to satisfy demand at this low price, but the total capacity of both firms is sufficient to satisfy the demand at the higher of the two prices. The wholesale price is $p^{*}=p_{j}$ with $p_{i} \leq p_{j}$ and $i, j=A, B$. The low-bidding firm can deliver its total capacity $K_{i}$ whereas the high-bidding firm is rationed to the amount of electricity that is necessary to satisfy residual demand $\left(D\left(p^{*}, r, \tilde{\alpha}, \varepsilon\right)-K_{i}\right)$.

3. The capacity of the low-bidding firm is insufficient to satisfy demand at this low price and total capacity is also insufficient to satisfy the demand at the higher of the two prices. The wholesale price $p^{*}$ is the price at which total demand satisfies total capacity $\left(D\left(p^{*}, r, \tilde{\alpha}, \varepsilon\right)=\right.$ $\left.K_{A}+K_{B}\right)$. Both firms generate electricity at their capacity constraint.

\footnotetext{
${ }^{9}$ Multi-unit uniform price auctions are used in most major electricity markets in Europe and the US. The other alternative is a discriminatory auction format, to which the UK market switched in 2001 when introducing the New Electricity Trading Arrangements (NETA). For a theoretical comparison of both auction formats see Fabra and von der Fehr (2006).
} 
All generators are paid the equilibrium price $p^{*}$ for all the electricity they deliver no matter what their price bid was. Before this wholesale auction is held, retailers contract with the final consumers. Figure 1 illustrates the timing of the model.

\begin{tabular}{|c|c|c|c|c|c|}
\hline Retailers & $\begin{array}{l}\text { Consumers } \\
\text { not on } \\
\text { RTM }\end{array}$ & Nature & $\begin{array}{c}\text { Consumers } \\
\text { on RTM } \\
\text { and } \\
\text { retailers }\end{array}$ & $\begin{array}{c}\text { Generators } \\
A \text { and } B\end{array}$ & $\begin{array}{c}\text { System } \\
\text { Operator }\end{array}$ \\
\hline \multirow{2}{*}{$\begin{array}{l}\text { compete } \\
\text { in retail } \\
\text { prices }\end{array}$} & \multirow{2}{*}{$\begin{array}{l}\text { subscribe } \\
\text { to the } \\
\text { cheapest } \\
\text { retailer }\end{array}$} & \multirow{2}{*}{$\begin{array}{c}\text { draws } \\
\text { demand } \\
\text { shock } \\
\varepsilon\end{array}$} & \multirow[t]{2}{*}{$\begin{array}{l}\text { bid their } \\
\text { demand }\end{array}$} & $\begin{array}{l}\text { bid their } \\
\text { prices }\end{array}$ & \multirow{2}{*}{$\begin{array}{c}\text { determines } \\
\text { wholesale price } \\
p^{*}\end{array}$} \\
\hline & & & & $p_{A}$ and $p_{B}$ & \\
\hline
\end{tabular}

Figure 1: Timing of the model

In the first stage of the game before the level of demand is known retailers set their retail prices for customers without real time meters. These customers contract with the retailer who offers the lowest price. ${ }^{10}$ Then, nature draws the demand shock $\varepsilon$ and demand is known to the generators, the retailers, the consumers with real-time metering and the system operator. Consumers with real-time metering bid their demand, and non-bankrupt retailers the demand of their contracted customers. The two generators bid the prices at which they are willing to produce up to their total capacity, and finally the system operator determines the wholesale electricity price $p^{*}$ as described above. We search for the subgame perfect equilibrium of this game.

\footnotetext{
${ }^{10}$ The contract is a service contract and implies that the costumers are provided with as much electricity as they want as long as the retailer does not go out of business. Rationing rules as discussed in Joskow and Tirole (2007) are not part of the contract and are also not very common for residential households.
} 


\section{Analysis of the model}

Since we are looking for a subgame-perfect equilibrium of this game we start the analysis with the last stage of the game, the wholesale market. After deriving the market outcome of the wholesale market for given retail prices, capacities and levels of smart metering we determine the retail price for those customers who do not have a smart meter for given capacities and levels of smart metering.

\subsection{The wholesale market}

By the time the wholesale market clears, the demand shock $\varepsilon \in[0,1]$ is known to all market participants. The threshold $\tilde{\alpha} \in\left[\frac{1}{2}, \frac{3}{2}\right]$ defines the mass of consumers who are on pre-determined fixed retail prices and the mass of consumers who have a smart meter and can directly participate in the wholesale market. This threshold is exogenous and known to all market participants.

The group with $\alpha \leq \tilde{\alpha}$ buys electricity via their retailers and pays the predetermined retail price $r$. Given $r$, their retailers demand a fixed volume of electricity which is derived from aggregating their individual demand, given in (2). The retailers' demand from consumers without a smart meter is represented by

$$
D^{R}\left(r, \tilde{\alpha}, \varepsilon, p^{*}\right)= \begin{cases}\int_{\frac{1}{2}}^{\tilde{\alpha}} \alpha+\varepsilon-r d \alpha & \text { if } p^{*} \leq r \leq \frac{1}{2}+\varepsilon \\ \int_{r-\epsilon}^{\tilde{\alpha}} \alpha+\varepsilon-r d \alpha & \text { if } \max \left\{p^{*}, \frac{1}{2}+\varepsilon\right\} \leq r \leq \\ & \tilde{\alpha}+\varepsilon, \\ 0 & \text { if either } r<p^{*} \text { or } r>\tilde{\alpha}+\varepsilon .\end{cases}
$$


Retail demand is completely inelastic in the wholesale price $p^{*}$. As soon as the wholesale price exceeds the retail price, $r>p^{*}$, retailers stop demanding and serving their retail customers, because otherwise retailers suffer losses. The level of fixed retail demand depends on the pre-determined retail price $r$. For the retail price, we have to distinguish three cases: In the first case the retail price is small enough such that all customers with $\alpha<\tilde{\alpha}$ have a positive demand $r \leq \frac{1}{2}+\varepsilon$. With $\frac{1}{2}+\varepsilon<r \leq \tilde{\alpha}+\varepsilon$ some consumers without smart metering do not buy any electricity anymore because it is too costly and with $r>\tilde{\alpha}+\varepsilon$ no customer on traditional meters demands electricity.

Consumers with smart meters directly take part in the wholesale market. Aggregating their individual demand from (2) yields

$$
D^{W}\left(p^{*}, \tilde{\alpha}, \varepsilon\right)= \begin{cases}\int_{\tilde{\alpha}}^{\frac{3}{2}} \alpha+\varepsilon-p^{*} d \alpha & \text { if } 0 \leq p^{*} \leq \tilde{\alpha}+\varepsilon \\ \int_{p^{*}-\varepsilon}^{\frac{3}{2}} \alpha+\varepsilon-p^{*} d \alpha & \text { if } \tilde{\alpha}+\varepsilon<p^{*} \leq \frac{3}{2}+\varepsilon \\ 0 & \text { if } \frac{3}{2}+\varepsilon<p^{*}\end{cases}
$$

Demand from consumers with smart meters is elastic in the wholesale price $p^{*}$. Again, we have to distinguish the three cases where all smart meter customers have a positive demand $\left(0 \leq p^{*} \leq \tilde{\alpha}+\varepsilon\right)$, where some of them stop buying $\left(\tilde{\alpha}+\varepsilon<p^{*} \leq \frac{3}{2}+\varepsilon\right)$, and where the price exceeds the reservation price and all of them stop buying electricity $\left(p^{*}>\frac{3}{2}+\varepsilon\right)$.

Aggregate total demand then is the sum of the demand from the consumers with a predetermined retail price and from those on smart metering and is given by

$$
D\left(p^{*}, r, \tilde{\alpha}, \varepsilon\right)=D^{R}\left(r, \tilde{\alpha}, \varepsilon, p^{*}\right)+D^{W}\left(p^{*}, \tilde{\alpha}, \varepsilon\right) .
$$

Total demand in the wholesale market is sketched in figure 2 .

Total demand is discontinuous at $p^{*}=r$ if $r<\tilde{\alpha}+\varepsilon$, has the same constant slope for $0 \leq p^{*}<r$ and for $r<p^{*}<\tilde{\alpha}+\varepsilon$ and is convexly decreasing for $\tilde{\alpha}+\varepsilon \leq p^{*} \leq \frac{3}{2}+\varepsilon$. 


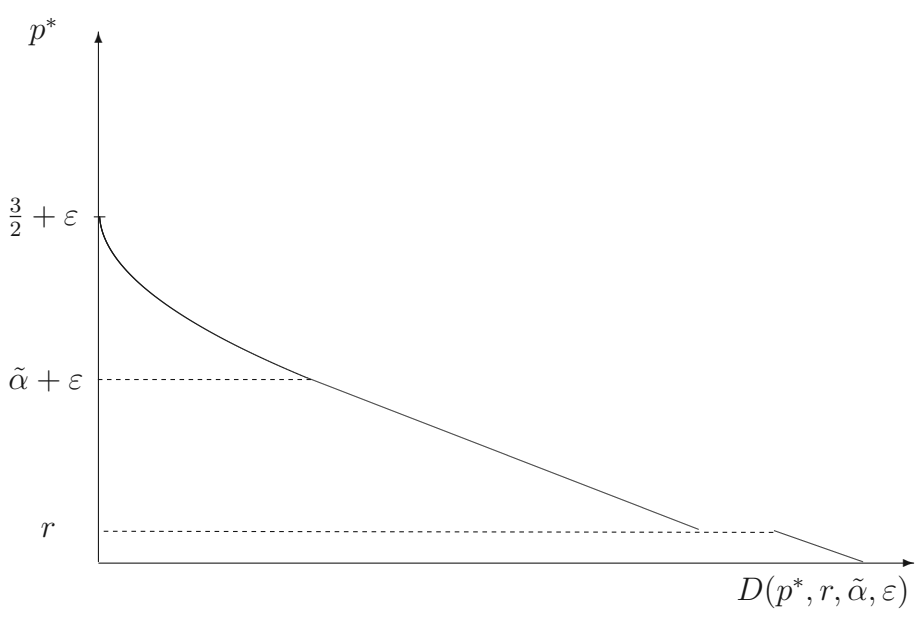

Figure 2: Total Demand in the Wholesale Market with $r<\tilde{\alpha}+\varepsilon$

The two generators $A$ and $B$ know the total realized demand when they bid their price into the market. Their optimal bidding strategies depend on their own and their rival's capacity $K_{A}$ and $K_{B}$, on the retail price $r$, on the level of smart metering determined by $\tilde{\alpha}$ and on the level of the demand shock $\varepsilon$.

Proposition 1 With regard to the market equilibria on the wholesale market we can distinguish five cases.

(i) If $K_{i} \geq D(0, r, \tilde{\alpha}, \varepsilon)$ and $K_{j} \geq D(0, r, \tilde{\alpha}, \varepsilon)$ with $i, j=A, B$ the firms bid in the unique equilibrium $p_{i}=0$ and $p_{j}=0$ resulting in the uniform auction price of $p^{*}=0$.

(ii) If $0 \leq K_{i}<D(0, r, \tilde{\alpha}, \varepsilon)$ and $K_{j}>D(0, r, \tilde{\alpha}, \varepsilon)$ with $i, j=A, B$ there 
are multiple equilibria. In all these equilibria the firms bid $p_{j}=p_{j}^{*}$ with

$$
p_{j}^{*}=\arg \max _{p}\left\{p\left[D(p, r, \tilde{\alpha}, \varepsilon)-K_{i}\right]\right\}
$$

and $0 \leq p_{i}<\bar{p}_{i}<p_{j}^{*}$ where $\bar{p}_{i}$ is implicitly defined by (17). The unique auction price is $p^{*}=p_{j}^{*}$.

(iii) If $0 \leq K_{i} \leq K_{j}<D(0, r, \tilde{\alpha}, \varepsilon)$ and $D\left(p_{j}^{*}, r, \tilde{\alpha}, \varepsilon\right)-K_{j} \leq K_{i}<\underline{K_{i}}$ we have the same equilibria as in (ii). $\underline{K}_{i}$ is either defined in equation (34), (35) or (36).

(iv) If $K_{i} \leq K_{j}<D(0, r, \tilde{\alpha}, \varepsilon)$ and $\underline{K_{i}}<K_{i} \leq K_{j}$ with $i, j=A, B$ the uniform price auction has two types of equilibria, one type is identical with the one in (ii), in the other one the firms bid $p_{i}=p_{i}^{*}$ with

$$
p_{i}^{*}=\arg \max _{p}\left\{p\left[D(p, r, \tilde{\alpha}, \varepsilon)-K_{j}\right]\right\} \leq p_{j}^{*}
$$

and $0 \leq p_{j}<\bar{p}_{j}<p_{i}^{*}$ where $\bar{p}_{j}$ is implicitly defined by the equivalent to (17). The auction price in the latter type of equilibrium is $p^{*}=p_{i}^{*}$.

(v) If $K_{i}<K_{j}$ and $K_{i}+K_{j}<D\left(p_{j}^{*}, r, \tilde{\alpha}, \varepsilon\right)$ with $i, j=A, B$ there are multiple equilibria in which the two firms bid $p_{i} \leq \hat{p}$ and $p_{j} \leq \hat{p}$ with

$$
\hat{p}=\left\{p \mid K_{i}+K_{j}=D(p, r, \tilde{\alpha}, \varepsilon)\right\}>p_{j}^{*} \geq p_{i}^{*} .
$$

The auction price is nevertheless unique and given by $p^{*}=\hat{p}$.

Proof: See Appendix A.

Note that multiple equilibria occur as soon as firms are capacity constrained (cases (ii)-(v) of proposition 1). The multiplicity only leads to different equilibrium wholesale prices and different profits for the two generators if their capacities are of a relatively similar size and satisfy case (iv) of proposition 
1. In this case there exist two types of equilibria where either the high capacity firm or the low capacity firm bids the high price in equilibrium. The high price maximizes the monopoly profit on the residual demand. If the firms' capacities differ more (cases (ii) and (iii)) it is always the firm with the larger capacity that bids high and serves the residual demand whereas the small firm bids low and sells its total capacity. In case (v) the market does not clear at the monopoly price on the residual demand. The demand cannot be served by the two firms at this price. The low capacity firm never has an incentive to bid a higher price than the large capacity firm and the system operator needs to increase the large capacity firm's bid to balance the market.

Whenever multiple equilibria occur, we select the equilibrium in which the larger firm is bidding the high price. For completely inelastic demand Boom (2008) argues that the equilibria with the large firm bidding the high price and the small firm undercutting it, risk-dominate the equilibria where the roles are reversed. It is beyond the scope of this paper to verify whether this selection can also be supported with elastic demand. Empirical findings by Wolfram (1998), however, show that for the UK electricity market it indeed is the larger firm that is the pivotal bidder and submits the market clearing price. With identical capacities we assume that each of the two firms is equally likely to choose the high price in equilibrium.

Figure 3 illustrates all equilibria of proposition 1. For a given demand shock $\varepsilon$, a given level of real time pricing $\tilde{\alpha}$ and a given retail price $r$ the equilibrium auction price is a function of the capacity levels of the two firms. The equilibrium prices depend on each firm's capacities. As derived in Appendix A, the borders for which the large and high pricing firm finds it optimal to price above, at or below the retail price are denoted as $K_{1}$ and $K_{2}$, respectively. Whenever both firms can serve the entire market on their own and have capacities larger than $D_{0}$ the equilibrium price equals zero which is the Bertrand outcome. Figure 3 is drawn for relatively low retail prices because 


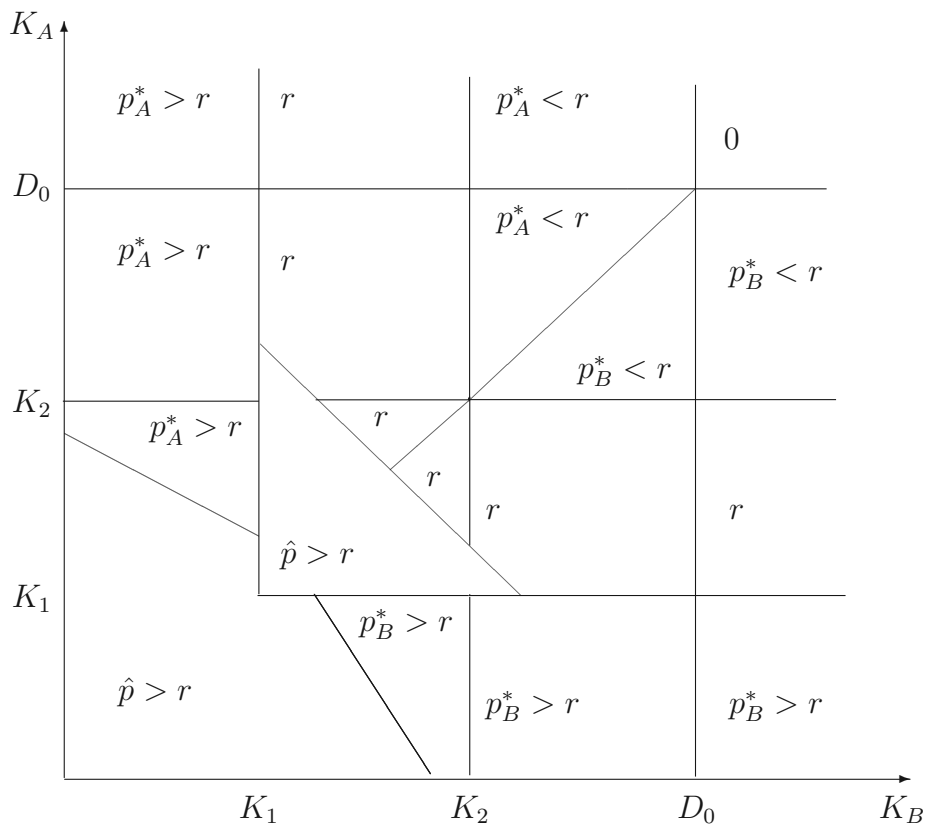

Figure 3: The Auction Prices in the Wholesale Market for Low Retail Prices

there exist capacity combinations $0<\min \left\{K_{A}, K_{B}\right\}<K_{1}$ for which the equilibrium prices are above the retail price level $r$. For this case to be true $K_{1}$ as defined in (20) in Appendix A.2 needs to be positive which is equivalent to $0<r<r_{1}$, where $r_{1}=\left\{r \mid K_{1}=0\right\}$ is depicted in figure 4 . If $K_{1}<0$, wholesale prices above the retail price cannot be an equilibrium, unless the system operator has to set the wholesale price. In the south west corner of figure 3 we always find an area where the system operator needs to set the price above the highest price bid to clear the market. ${ }^{11}$ The discontinuity of

\footnotetext{
${ }^{11}$ Borders for these areas are given by $S_{i}$ in (31), (32) or (33) in Appendix A.3. As the retail price increases these borders shift inward for those areas with $\min \left\{K_{A}, K_{B}\right\}>K_{1}$. Higher retail prices reduce demand and therefore the system operator needs to interfere less often to ensure market clearing. When the market outcome is determined by capac-
} 
the system operator price regions at $\min \left\{K_{A}, K_{B}\right\}=K_{1}$ is due to the jump of the potential wholesale price from $p^{*}>r$ to $p^{*}=r$, which is induced by the kink in the demand curve due to the sudden inclusion of the customers without real time pricing (see the demand in figure 2). The overall pricing pattern described in figure 3 is intuitive. The larger the capacities the smaller is the wholesale price.

Considering the specific equilibrium prices, given in (19), (24) and (28) Appendix A.2, it becomes clear that the wholesale price depends only on the capacity of the smaller firm. This is because the smaller firm's capacity determines the residual demand for the larger and pivotal firm that decides on the wholesale price in all cases where at least one firm is capacity constrained. For higher demand shocks capacities are relatively scarcer and hence the borders defining the equilibrium prices shift outwards. On the contrary for increasing retail prices, the borders shift inwards. Figure 4 shows which wholesale price regimes are relevant given the retail price and the level of smart metering. For $r<r_{1}$ all three wholesale price regimes depicted in figure 3 exist. For intermediate retail prices $r_{1}<r<r_{2}$ figure 3 would simplify and wholesale prices above the retail price would no longer be possible. For $r_{2}<r<\tilde{\alpha}+\varepsilon$ the critical capacity level $K_{2}$ or $K_{2}^{\prime}$, as defined in equation (21) or (25), respectively, are no longer positive. ${ }^{12}$ In that case figure 3 simplifies even further and $0 \leq p^{*}<r$ must hold in equilibrium. Note that for $r>\tilde{\alpha}+\varepsilon$ the retail price does not matter any more for the level of the wholesale price because at these retail prices no retail customer has a positive demand. Figure 3 would have only one horizontal and vertical line, which would no longer be defined by $\min \left\{K_{A}, K_{b}\right\}=D_{0}^{\prime}$ with $D_{0}^{\prime}$ defined in (26), but by $\min \left\{K_{A}, K_{b}\right\}=D_{0}^{\prime \prime}$ with $D_{0}^{\prime \prime}$ defined in (29) in Appendix A.2.

ities that satisfy $\min \left\{K_{A}, K_{B}\right\}<K_{1}$, increases in the retail price are irrelevant, because retailers have left the market.

${ }^{12}$ The critical retail price $r_{2}$ is defined by either $r_{2}=\left\{r \mid K_{2}=0\right\}$ or $r_{2}=\left\{r \mid K_{2}^{\prime}=0\right\}$ depending on whether it exceeds the level $r=\varepsilon+\frac{1}{2}$ or not, so on whether all retail customers have still a positive demand or not. The critical retail price $r_{2}$ increases and is continuous in $\tilde{\alpha}$ as is sketched in figure 4 . 
Depending on whether $0<\min \left\{K_{A}, K_{b}\right\}<D_{0}^{\prime \prime}$ holds or $\min \left\{K_{A}, K_{b}\right\}>D_{0}^{\prime \prime}$ we would either have $p^{*}>0$ or $p^{*}=0 .{ }^{13}$

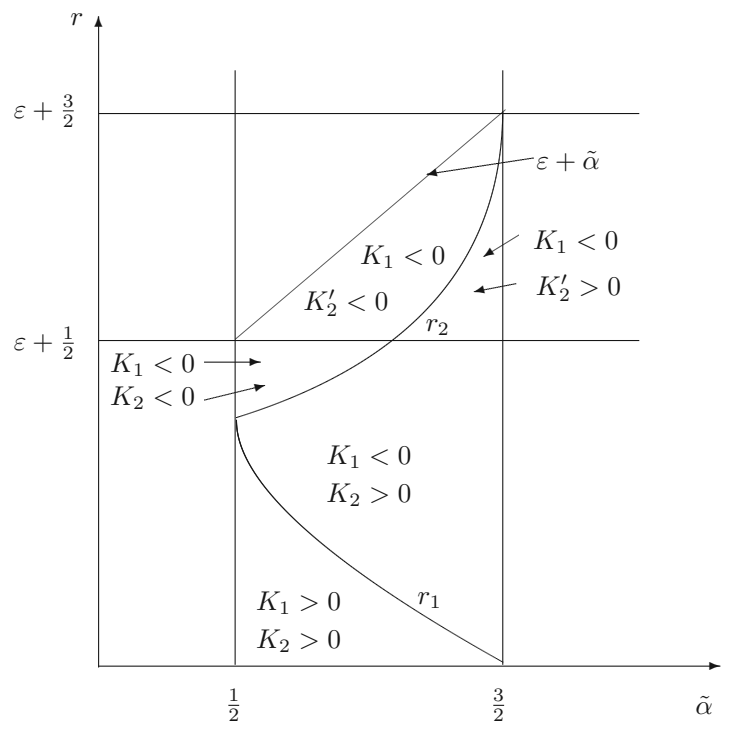

Figure 4: Critical Retail Price Levels

\subsection{The retail market}

Retailers compete in prices and do not have any other retail costs than the price they need to pay for electricity on the wholesale market. Therefore all retailers compete the price down to a level where they do not generate positive profits any more. Retailers have zero profits if they find themselves for every potential demand induced by $\varepsilon$ in a situation where the wholesale

\footnotetext{
${ }^{13}$ With completely inelastic demand, as in Boom and Buehler (2007), $p^{*}>0$ or $p^{*}=0$ always are the only possible outcomes.
} 
price satisfies $p^{*} \geq r$. Looking at the lattice pattern in figure 3 it becomes obvious that this condition is satisfied if $K_{2}>\min \left\{K_{A}, K_{B}\right\}$ or, if it becomes relevant, $K_{2}^{\prime}>\min \left\{K_{A}, K_{B}\right\}$ for all $\varepsilon \in[0,1]$. Retailers compete in the retail price until the generating firms' capacities ensure a wholesale price that equals the retail price at a demand shock of $\varepsilon=0$. This condition guarantees zero profits for retailers for all $\varepsilon \in[0,1]$ and all $p^{*} \geq r$. From this idea we can derive the following proposition which describes the retail price in equilibrium.

Proposition 2 Assume $K_{i} \leq K_{j}$, then there is a unique subgame perfect equilibrium in which all retailers set $r=\bar{r}=0$, if $K_{i}>1$. If $K_{i} \leq 1$ then there are multiple subgame perfect Nash equilibria. In all these equilibria the retailers charge their customers retail prices which satisfy $0 \leq r \leq \bar{r}$. The level of $\bar{r}$ depends on the capacity levels $K_{i}$ and $K_{j}$ and on the level of smart metering reflected in $\tilde{\alpha}$. The definition of $\bar{r}$ is given by

$$
\bar{r}= \begin{cases}\frac{3}{2}-\sqrt{2\left(K_{i}+K_{j}\right)} & \text { if } 0 \leq K_{i}< \\ 3-\tilde{\alpha}-\frac{1}{2} \sqrt{27-4 \tilde{\alpha}(6-\tilde{\alpha})+8 K_{i}} & \text { if } \left.\min \left\{\frac{9}{8}-\frac{2 K_{j}\left(9-(9-2 \tilde{\alpha}) \tilde{\alpha}-K_{j}\right)}{(3-2 \tilde{\alpha})^{2}}, \frac{1-2 K_{j}}{2}\right\} \frac{2 K_{j}\left(9-(9-2 \tilde{\alpha}) \tilde{\alpha}-K_{j}\right)}{(3-2 \tilde{\alpha})^{2}}, 0\right\} \\ & \leq K_{i}<\min \left\{\frac{1}{2}\left(\tilde{\alpha}-\frac{1}{2}\right), K_{j}\right\} \\ 1-K_{i}-K_{j} & \text { if } \frac{1-2 K_{j}}{2} \leq K_{i} \leq \min \left\{1-\frac{(5-2 \tilde{\alpha}) K_{j}}{3-2 \tilde{\alpha}}\right. \\ & \left.K_{j}\right\}, \\ \frac{2\left(1-K_{i}\right)}{5-2 \tilde{\alpha}} & \text { if } \max \left\{\frac{1}{2}\left(\tilde{\alpha}-\frac{1}{2}\right), 1-\frac{(5-2 \tilde{\alpha}) K_{j}}{3-2 \tilde{\alpha}}\right\} \\ & \leq K_{i}<\min \left\{1, K_{j}\right\} \\ 0 & \text { if } 1 \leq K_{i} \leq K_{j} .\end{cases}
$$

Proof: See Appendix B.

Note that we potentially have multiple equilibria. We follow the convention in economics that we assume that firms stop undercutting each others prices 
as soon as they generate zero profits. For retailers this condition translates into all retailers setting $r=\bar{r}$ if $0 \leq \min \left\{K_{A}, K_{B}\right\}<1$ and $r=\bar{r}=0$ otherwise. The relationship between the different capacity levels and the retail price is characterized in figure 5 .

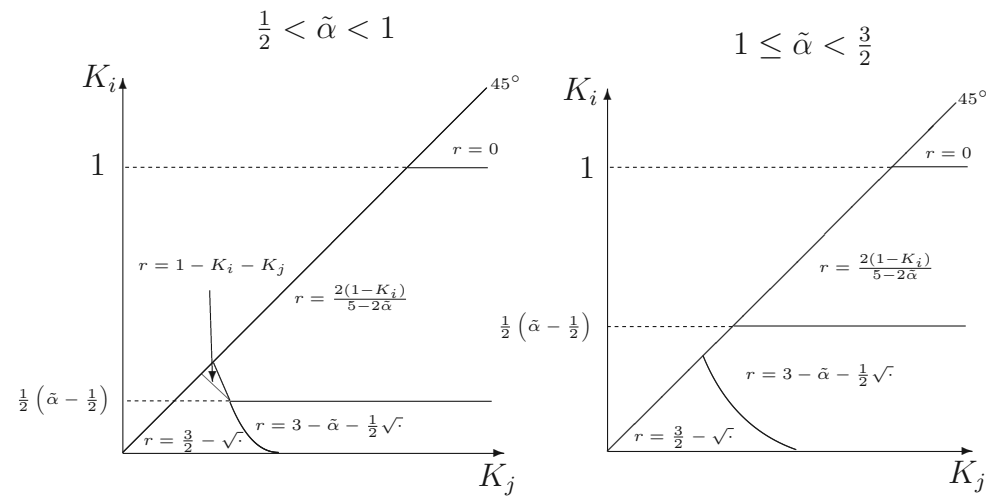

Figure 5: Retail Price with Different Capacities for $K_{i} \leq K_{j}$

From proposition 2 it becomes clear that the retail price $\bar{r}$ only changes marginally in the level of smart metering if we are in the cases represented by the second and fourth line of its definition. These are the cases where the generating firms' capacities are sufficient such that the system operator does not need to interfere with the generators' price bidding on the electricity wholesale market for the smallest demand shock $\varepsilon=0$. For these cases the retail price decreases if the level of smart metering increases because $\frac{\partial \bar{r}}{\partial \tilde{\alpha}}>0$ and a lower $\tilde{\alpha}$ means more customers with smart meters. A larger number of smart meters decreases the retail demand and hence the retail price is lowered. In addition, because of the lower retail demand the retail market is now for more combinations of $K_{A}$ and $K_{B}$ fully covered instead of only partially covered. Thus, for the capacities for which $\frac{\partial \bar{r}}{\partial \tilde{\alpha}}>0$ holds consumers without smart meters will always benefit from more (other) consumers having a smart 
meter and taking part directly in the wholesale market. The same effect has been found by Borenstein and Holland (2005). Since in their analysis all consumers were identical and more smart metering did not imply reducing the willingness to pay of the customers without a smart meter, this result is not simply driven by the lower willingness to pay of the customers without real time prices. Retail prices are determined by fierce price competition by the retailers who cannot just expropriate the consumers' rent.

If the capacities of the electricity generating firms are so low that the system operator needs to interfere with the price bidding of the generators for all possible levels of the demand shock $\varepsilon \in[0,1]$ then the retail price does marginally not respond to a higher degree of metering. The main reason for this is that how consumers are split and how price responsive the wholesale demand is on the margin, does not influence the wholesale prices. Instead, wholesale prices are always determined by equalizing total demand with total capacity. Then, given that the retail price is determined by the lowest possible wholesale price being below or equal to the retail price, also the retail price solely depends on the firms' capacities. The higher the firms' total capacity is, the lower is the lowest possible wholesale and the resale price.

\section{Comparative statics in the level of smart metering}

Retailers always have zero profits and therefore do not have an impact on welfare as the level of smart metering changes. Only their competitive retail price and the wholesale market price effect welfare. Thus, we consider how a change in the level of smart metering changes retail and wholesale prices for all possible states of demand realizations. We use these prices to derive expected profits, consumer surplus and welfare ex ante of the demand realization. For the sake of tractability we only look at the cases in which the 
retail prices are indeed determined by $\tilde{\alpha}$ and the SO does not have to intervene in the market. This in turn assumes that the firms are always investing sufficiently in their capacity endowments and the market always clears at the residual monopoly price of the high bidding firm.

We use the consumer surplus function and the three equilibrium retail prices in proposition 2 that depend on $\tilde{\alpha}$ (cases (i), (ii) and (iv)) to calculate expected welfare. From the consumer surplus function in equation (1) we know that those consumers who are served will achieve a surplus of

$$
V(\alpha+\varepsilon-p, \alpha, \varepsilon, p)=\alpha(\alpha-p)-\frac{(\alpha-p)^{2}}{2}-p(\alpha+\varepsilon-p),
$$

where due to our assumption that the SO never has to intervene $\mathrm{p}$ is either the wholesale price $p^{*}=p_{j}^{*}>r$ that varies according to the state of demand $\varepsilon$ or the predetermined retail price $r$ that does not change with the demand realization. Those consumers who are either not served or who decide themselves that they do not want to consume realize a surplus of

$$
V(0, \alpha, \varepsilon, p)=-\alpha \varepsilon-\frac{\varepsilon^{2}}{2} .
$$

Customers on traditional meters always pay their contracted retail price and hence we have $p=r$ in equation (6) for all $\frac{1}{2}<\alpha<\tilde{\alpha}$. The wholesale price that consumers with smart meters pay can be either $p^{*}=p_{j}^{*}$ or $p^{*}=r$. We can have both prices for consumers with $\tilde{\alpha}<\alpha<\frac{3}{2}$. The level of the wholesale price depends on whether $K_{i}$ is smaller or greater than $K_{1}$. If $K_{i} \geq K_{1}$ the residual monopoly price equals the retail price, while for $K_{i}<K_{1}$ the residual monopoly price lies on the linear downward sloping part of the demand curve above the retail price. To account for the different wholesale market prices in the welfare calculations we define a critical demand 
shock, $\varepsilon^{*}$. Whenever the demand shock is larger than

$$
\varepsilon^{*}=\left\{\varepsilon \mid K_{i}=K_{1}\right\}
$$

the low bidding firm's capacity is relatively scarce and the wholesale price becomes $p^{*}=p_{j}^{*}$. For lower demand shocks than $\varepsilon^{*}$ the wholesale market price remains equal to the retail price. The critical shock $\varepsilon^{*}$ depends on the retail price. In the following we distinguish between equilibrium retail prices of zero (case (i) in proposition 2), intermediate equilibrium retail prices (case (ii)) and high equilibrium retail prices (case (iv)).

\subsection{Equilibrium retail prices of zero}

When capacities satisfy $1 \leq K_{i} \leq K_{j}$ the retail price is zero. In this scenario the SO never has to intervene, because $K_{i}+K_{j} \geq 2 \geq D_{0}$ holds and the two firms can cover all demand at each price for all demand realizations. Figure 3 simplifies because $K_{2}=D_{0}$, and the wholesale price can be either $p^{*}=p_{j}^{*}$ or $p^{*}=r=0$. For $r=0$ the critical demand shock in equation (8) becomes

$$
\varepsilon_{z}^{*}=\frac{8 K_{i}+4 \tilde{\alpha}^{2}-9}{12-8 \tilde{\alpha}}
$$

In Appendix C.1 we derive $\varepsilon_{z}^{*}$. If the demand shock is larger than $\varepsilon_{z}^{*}$ the wholesale price becomes $p^{*}=p_{j}^{*}$, while for lower demand shocks the wholesale market price is zero. Wholesale prices of $p^{*}=p_{j}^{*}$ never occur as long as $\varepsilon_{z}^{*}>1$, which holds as long as $K_{i}>\max \left\{1, \frac{1}{8}(3-2 \tilde{\alpha})(7+2 \tilde{\alpha})\right\}$. If $K_{i}$ exceeds this threshold the highest demand shock cannot be so large to make it optimal for the high bidding firm to price above the retail price. Then all consumers always pay a price of zero no matter whether they have a smart meter and participate in the wholesale market or whether they have a retail contract with a predetermined price. Therefore welfare is identical with aggregate 
consumer surplus which is defined by

$$
C S=W=\int_{0}^{1} \int_{\frac{1}{2}}^{\frac{3}{2}} \frac{\alpha^{2}}{2} d \alpha d \varepsilon=\frac{13}{24} .
$$

Generators do not earn any profits. If however $1<K_{i} \leq \frac{1}{8}(3-2 \tilde{\alpha})(7+2 \tilde{\alpha})$ and $\varepsilon_{z}^{*} \leq 1$ then wholesale customers have to pay a positive price for some states of demand. In these states retail customers are not served because $p^{*}>r$. This happens if $\varepsilon^{*}=\varepsilon_{z}^{*} \leq \varepsilon \leq 1$. The consumer surplus is now

$$
\begin{aligned}
C S= & \int_{0}^{\varepsilon^{*}} \int_{\frac{1}{2}}^{\frac{3}{2}} \frac{\alpha^{2}}{2} d \alpha d \varepsilon+\int_{\varepsilon^{*}}^{1} \int_{\frac{1}{2}}^{\tilde{\alpha}}-\alpha \varepsilon-\frac{\varepsilon^{2}}{2} d \alpha d \varepsilon \\
& +\int_{\varepsilon^{*}}^{1} \int_{\tilde{\alpha}}^{\frac{3}{2}} \alpha\left(\alpha-p^{*}\right)-\frac{\left(\alpha-p^{*}\right)^{2}}{2}-p^{*}\left(\alpha+\varepsilon-p^{*}\right) d \alpha d \varepsilon .
\end{aligned}
$$

Substituting the relevant price which is always given by $p_{j}^{*}$ from (19) we can show that $\frac{\partial C S}{\partial \tilde{\alpha}}>0$ holds. Aggregate consumer surplus decreases if the level of smart metering increases (meaning that $\tilde{\alpha}$ decreases). While wholesale costumers face price risks in potentially having to pay positive duopoly prices, retail customers are not served for some demand realizations. By increasing the number of wholesale customers the first effect aggravates, whereas the second is softened. Since consumer surplus is reduced the first effect dominates the second. The producer surplus is given by

$$
P S=\pi_{i}+\pi_{j}=\int_{\varepsilon_{1}}^{1} \int_{\tilde{\alpha}}^{\frac{3}{2}} p^{*}\left(\alpha+\varepsilon-p^{*}\right) d \alpha d \varepsilon .
$$

The producer surplus increases with the level of smart metering since $\frac{\partial P S}{\partial \tilde{\alpha}}<$ 0 holds. This is not surprising because more smart metering means more demand situations in which wholesale customers pay a positive price and, on top of it, there are more wholesale customers who have to pay the higher price. Because of the opposing nature of consumer and producer surplus, 
welfare is U-shaped in the level of smart metering. For small $\tilde{\alpha}$ we have $\frac{\partial W}{\partial \tilde{\alpha}}<0$ while for larger we have $\frac{\partial W}{\partial \tilde{\alpha}}>0$. Obviously the effect on the profits dominates welfare for small $\tilde{\alpha}$, whereas for large $\tilde{\alpha}$ the effect on consumer surplus dominates. Figure 6 depicts the welfare results for retail prices of zero and a given capacity of the low bidding firm.

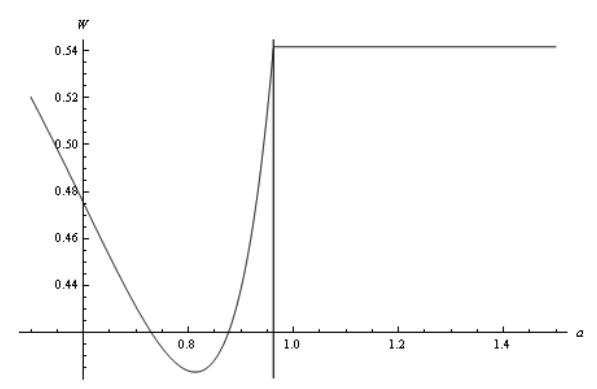

Figure 6: Welfare depending on $\tilde{\alpha}$ for retail prices of zero.

An increase in the level of smart metering from no smart metering at all $\left(\tilde{\alpha}=\frac{3}{2}\right)$ does first not have an effect on welfare, consumer surplus or profits. Welfare is constant as long as the degree of smart metering is low enough and $\tilde{\alpha}$ is above a certain threshold $\left(\tilde{\alpha}>\frac{\sqrt{25-8 K_{i}}}{2}-1\right)$ that ensures that $\varepsilon_{z}^{*}>1$ and $p *=r=0$ always hold. Above this threshold the retail market is so large that the residual monopoly profit is always maximized at the retail price. For degrees of smart metering below this threshold the high bidding firm maximizes its profits by clearing the market above the retail price for at least some states of demand realization. Then consumer surplus and welfare decrease. The loss of consumer surplus due to uncertain prices above the marginal cost level cannot be compensated by the larger producer surplus and by the fact that fewer retail customers are sometimes not served. When smart metering is further extended, the two latter effects start dominating the first and finally, if all customers are on smart meters the wholesale price is approaching zero again. In the Bertrand case, when $K_{j}>K_{i}>2=D_{0}$, 
welfare is the same with all consumers on smart meters or none at all.

\subsection{Intermediate equilibrium retail prices}

When the two firms' capacities become scarcer the retail price is $\frac{2\left(1-K_{i}\right)}{5-2 \tilde{\alpha}}$, as described in proposition 2. This retail price is always lower than $\frac{1}{2}+\varepsilon$, and hence all retail customers demand electricity. The SO might have to intervene, because $K_{i}+K_{j}<D(r)$ is possible for some states of the demand realization. To focus on the case where firms clear the market at their bid and the wholesale price can be either $p^{*}=p_{j}^{*}$ or $p^{*}=\frac{2\left(1-K_{i}\right)}{5-2 \tilde{\alpha}}$ we introduce the following condition. As long as

$$
K_{i} \geq D(r \mid \varepsilon=1)-K_{j}=\frac{8+2 \tilde{\alpha}\left(K_{j}-2\right)-5 K_{j}}{3-2 \tilde{\alpha}}
$$

holds, the SO never has to set the price at $\hat{p}>r$. Equation (13) ensures that the two firms can cover the market at the retail price even for the highest demand shock. We derive this condition in Appendix C.2 and show that under this condition firms are also able to cover all possible states of demand at the optimal price above the retail price, $p^{*}=p_{j}^{*}$. Similarly to the case of zero retail prices we can now argue that whenever the demand shock is larger than $\varepsilon_{i}^{*}$ the wholesale price becomes $p^{*}=p_{j}^{*}$, while for lower demand shocks the wholesale market price is $p^{*}=r=\frac{2\left(1-K_{i}\right)}{5-2 \tilde{\alpha}}$. For the derivation of the critical shock with intermediate retail prices, $\varepsilon_{i}^{*}$, see Appendix C.1. Consumer surplus and profits can then be calculated equivalently to equations (11) and (12) respectively. Figure 7 illustrates the welfare results for a given capacity of the low bidding firm.

Again, for a large enough $\tilde{\alpha}$ such that only $p^{*}=r$ applies, all consumers are always served and pay the same price no matter whether they are on smart metering or not. In this case all effects of a variation of $\tilde{\alpha}$ are driven by the change in the price. Due to $\frac{\partial \bar{r}}{\partial \tilde{\alpha}}>0$, contrary to the case for zero retail 


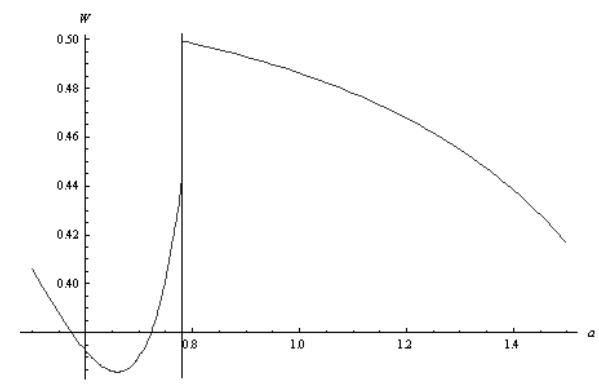

Figure 7: Welfare depending on $\tilde{\alpha}$ for intermediate retail prices.

prices, consumers like an increase in smart metering because they consume more and pay less $\left(\frac{\partial C S}{\partial \tilde{\alpha}}<0\right)$. We find that $\frac{\partial P S}{\partial \tilde{\alpha}}>0$ and that producer surplus reduces as the level of smart metering increases because despite their increased electricity consumption consumers pay less. More smart metering increases welfare $\left(\frac{\partial W}{\partial \tilde{\alpha}}<0\right)$ because it reduces market power without any consumer being forced to leave the market. When the degree of smart metering is above the threshold the pivotal firm, depending on the demand shock, clears the market at or above the retail price. In this case more smart metering means a decrease in the consumer surplus $\left(\frac{\partial C S}{\partial \tilde{\alpha}}>0\right)$ and an increase in the producer surplus $\left(\frac{\partial P S}{\partial \tilde{\alpha}}<0\right)$. The level of welfare is U-shaped again. The same arguments that explain the U-shaped effect for zero retail prices also apply for intermediate retail prices.

\subsection{High equilibrium retail prices}

The retail price becomes $3-\tilde{\alpha}-\frac{1}{2} \sqrt{27-4 \tilde{\alpha}(6-\tilde{\alpha})+8 K_{i}}$ for relatively scarce capacities. Again, if $K_{i} \geq D(r \mid \varepsilon=1)-K_{j}$ holds, the wholesale market always clears at the optimal bid of the pivotal firm. We only have wholesale prices equal to the retail price for low shocks that satisfy $\varepsilon<\varepsilon_{h}^{*}$. For demand shocks $\varepsilon_{h}^{*}<\varepsilon<1$ the wholesale price is above the retail price. In Appendix 
C.1 and C.2 we derive $\varepsilon_{h}^{*}$ and the functional form of the market clearing condition $K_{i} \geq D(r \mid \varepsilon=1)-K_{j}$, for which the SO does not have to intervene and set scarcity prices. Opposing to the case of intermediate retail prices, for high retail prices we can have $r>\frac{1}{2}+\varepsilon$ and some retail consumers do not demand electricity. Given the retail price, whether all or only some retail customers demand electricity depends on the demand shock. Hence for $\varepsilon<\varepsilon_{h}^{*}$ we now derive consumer surplus as

$$
\begin{aligned}
C S= & \int_{0}^{\varepsilon^{f}} \int_{\frac{1}{2}}^{r-\varepsilon}-\alpha \varepsilon-\frac{\varepsilon^{2}}{2} d \alpha d \varepsilon \\
& +\int_{0}^{\varepsilon^{f}} \int_{r-\varepsilon}^{\tilde{\alpha}} \alpha(\alpha-r)-\frac{(\alpha-r)^{2}}{2}-r(\alpha+\varepsilon-r) d \alpha d \varepsilon \\
& +\int_{\varepsilon^{f}}^{1} \int_{\frac{1}{2}}^{\tilde{\alpha}} \alpha(\alpha-r)-\frac{(\alpha-r)^{2}}{2}-r(\alpha+\varepsilon-r) d \alpha d \varepsilon \\
& +\int_{0}^{1} \int_{\tilde{\alpha}}^{\frac{3}{2}} \alpha(\alpha-r)-\frac{(\alpha-r)^{2}}{2}-r(\alpha+\varepsilon-r) d \alpha d \varepsilon
\end{aligned}
$$

where $\varepsilon^{f}$ decides on wheter $r>\frac{1}{2}+\varepsilon$ or $r<\frac{1}{2}+\varepsilon$, so on whether the retail market is partially or fully covered. Since $\varepsilon<\varepsilon_{h}^{*}$ and $p^{*}=r$ for all demand shocks, only the effects of $\frac{\partial \bar{r}}{\partial \tilde{\alpha}}$ determine welfare. We again find $\frac{\partial C S}{\partial \tilde{\alpha}}<0$ and $\frac{\partial W}{\partial \tilde{\alpha}}<0$. More smart metering lowers the market price and increases consumer surplus and welfare. Producer surplus, that is derived within the same integrals as in equation (14), decreases as smart metering increases, however only if the negative effect on profits of the lowered retail price is offset by the positive effect that for lower retail prices the retail market is fully covered for more demand realizations. For high $K_{i}$, that lead to high retail prices and relatively greater losses if the retail market is not fully covered, the latter effect starts dominating and producer surplus becomes inverted U-shaped in the level of smart metering.

Whenever $\varepsilon_{h}^{*}<\varepsilon<1$ and the wholesale price changes with the demand 
shock we derive consumer surplus as

$$
\begin{aligned}
C S= & \int_{0}^{\varepsilon^{f}} \int_{\frac{1}{2}}^{r-\varepsilon}-\alpha \varepsilon-\frac{\varepsilon^{2}}{2} d \alpha d \varepsilon \\
& +\int_{0}^{\varepsilon^{f}} \int_{r-\varepsilon}^{\tilde{\alpha}} \alpha(\alpha-r)-\frac{(\alpha-r)^{2}}{2}-r(\alpha+\varepsilon-r) d \alpha d \varepsilon \\
& +\int_{\varepsilon^{f}}^{\varepsilon_{h}^{*}} \int_{\frac{1}{2}}^{\tilde{\alpha}} \alpha(\alpha-r)-\frac{(\alpha-r)^{2}}{2}-r(\alpha+\varepsilon-r) d \alpha d \varepsilon \\
& +\int_{\varepsilon_{h}^{*}}^{1} \int_{\frac{1}{2}}^{\tilde{\alpha}}-\alpha \varepsilon-\frac{\varepsilon^{2}}{2} d \alpha d \varepsilon \\
& +\int_{0}^{1} \int_{\tilde{\alpha}}^{\frac{3}{2}} \alpha\left(\alpha-p^{*}\right)-\frac{\left(\alpha-p^{*}\right)^{2}}{2}-p^{*}\left(\alpha+\varepsilon-p^{*}\right) d \alpha d \varepsilon .
\end{aligned}
$$

Then like for intermediate retail prices $\frac{\partial C S}{\partial \tilde{\alpha}}>0$ holds and consumers dislike smart metering. Producer surplus is increasing in the amount of smart metering, unless the retail price is very high (for low $K_{i}$ ). If $K_{i}$ is very low, the retail price is very high and producer surplus becomes slightly U-shaped, because a sufficient number of customers have to be on smart meters to level out the losses of retailers that pay high prices whenever $p=r$ but leave the market whenever the demand shock is high and $p>r$ holds. In line with the case of intermediate retail prices we find that welfare is U-shaped whenever the market outcome changes with the demand realization, while welfare is increasing if the wholesale market price equals the retail price for all demand shocks. Overall, the comparative statics of smart metering on welfare for high retail prices follow the patterns for intermediate retail prices. 


\section{Conclusion}

This paper derives welfare effects of real-time pricing in electricity markets. When electricity generating firms have market power in the wholesale market and consumers are risk-averse, we show that real-time pricing does not have to be efficiency enhancing. Overall welfare implications depend on the level of firms' capacities and on the magnitude of stochastic demand shocks. With large capacities that always lead to Bertrand prices, we find no difference in welfare when all or no consumers are on smart meters. When firms' capacities are smaller such that market power arises, firms can price relatively high in times of high demand shocks. When this is the case, we show that for the main cases in which the system operator does not need to intervene and set prices, real-time pricing decreases consumer surplus, because risk-averse consumers dislike high and uncertain prices. At the same time real-time metering increases producer surplus, because more smart metering means more demand situations in which more wholesale customers pay a price above marginal costs. These two opposing effects lead to a U-shaped welfare in smart metering whenever the demand shock can change equilibrium prices. If however firms capacities are relatively large and the demand shock does not change the wholesale price, smart metering can increase consumer surplus and welfare. Our findings suggest that, before investing in smart meters and smart grids, dominant firm behavior and the welfare gain of fixed retail prices that insure risk-averse consumers against price fluctuations should be taken into consideration. 


\section{Appendix}

\section{A Proof or proposition 1}

\section{A.1 Case (i): $K_{i}>D(0, r, \tilde{\alpha}, \varepsilon), K_{j}>D(0, r, \tilde{\alpha}, \varepsilon)$}

This is the usual Bertrand case because non of the firms is effectively capacity constrained. If firm $i$ bids $p_{i}=0$ and firm $j$ bids $p_{j}=0$ with $i, j=A, B$, none of the two firms has an incentive to deviate because they could not improve on their profit of 0 . If the firms bid $p_{i}=p_{j}=p>0$ firm $i$ 's and firm $j$ 's profit would be identical and given by $\pi_{i}=\pi_{j}=$ $\frac{1}{2} p D(p, r, \tilde{\alpha}, \varepsilon)$. Then each firm has an incentive to slightly undercut its rival because then it could realize instead $\pi_{i, j}=(p-\epsilon) D(p-\epsilon, r, \tilde{\alpha}, \varepsilon)$ with $\epsilon \rightarrow 0$. If the firms bid $p_{i}>p_{j} \geq 0$ then firm $i$ 's profit is zero and firm j's profit is $\pi_{j}=p_{j} D\left(p_{j}, r, \tilde{\alpha}, \varepsilon\right)$. Here firm $i$ has again an incentive to slightly undercut firm $j$ in order to realize $\pi_{i}=\left(p_{j}-\epsilon\right) D\left(p_{j}-\epsilon, r, \tilde{\alpha}, \varepsilon\right)$ with $\epsilon \rightarrow 0$ instead. Thus $p_{i}=p_{j}=0$ is the only Nash equilibrium.

\section{A.2 Case (ii): $K_{i}<D(0, r, \tilde{\alpha}, \varepsilon), K_{j}>D(0, r, \tilde{\alpha}, \varepsilon)$}

Here only firm $i$ is capacity constrained. Suppose both firms bid $p_{i}=p_{j}=0$ and have therefore zero profits, then only firm $j$ has an incentive to deviate to a higher price $p_{j}>0$. If it deviates it would serve the residual demand and would realize $\pi_{j}=p_{j}\left(D\left(p_{j}, r, \tilde{\alpha}, \varepsilon\right)-\right.$ $\left.K_{i}\right)>0$ if $p_{j}$ were not too high. The optimal deviation would be to choose

$$
p_{j}^{*}=\arg \max _{p}\left\{p\left[D(p, r, \tilde{\alpha}, \varepsilon)-K_{i}\right]\right\} .
$$

The same price $p_{j}^{*}$ would also be a best response of firm $j$ if firm $i$ chooses $p_{i}$ with $0 \leq p_{i}<p_{j}^{*}$ such that

$$
\left(p_{i}-\epsilon\right) \min \left\{D\left(p_{i}-\epsilon, r, \tilde{\alpha}, \varepsilon\right), K_{j}\right\} \leq p_{j}^{*}\left[D\left(p_{j}^{*}, r, \tilde{\alpha}, \varepsilon\right)-K_{i}\right]
$$

with $\epsilon \rightarrow 0$. The capacity constrained firm $i$ does never want to deviate to $p_{i}>p_{j}$ because it could not generate any positive demand for itself this way. The low-bidding firm $j$ would serve the whole market and firm $i$ would not increase its profits.

In order to determine $p_{j}^{*}$ we need to take into account the different cases of the demand in equation (5) resulting from the situation on the retail market. We need to distinguish three cases: 
Fully Covered Retail Market $\left(0 \leq r \leq \frac{1}{2}+\varepsilon\right)$ : All consumers without real-time pricing have a positive demand. The demand function is

$$
D\left(p^{*}, r, \tilde{\alpha}, \varepsilon\right)= \begin{cases}1+\varepsilon-\left(\frac{3}{2}-\tilde{\alpha}\right) p^{*}-\left(\tilde{\alpha}-\frac{1}{2}\right) r & \text { if } 0 \leq p^{*} \leq r, \\ \left(\frac{3}{2}-\tilde{\alpha}\right)\left(\frac{1}{2}\left(\frac{3}{2}+\tilde{\alpha}\right)+\varepsilon-p^{*}\right) & \text { if } r<p^{*} \leq \tilde{\alpha}+\varepsilon, \\ \frac{1}{2}\left(\varepsilon-p^{*}+\frac{3}{2}\right)^{2} & \text { if } \tilde{\alpha}+\varepsilon \leq p^{*} \leq \varepsilon+\frac{3}{2}, \\ 0 & \text { if } p^{*}>\varepsilon+\frac{3}{2} .\end{cases}
$$

Solving for $p_{j}^{*}$ yields the following solution

$$
p_{j}^{*}= \begin{cases}\frac{3+2 \tilde{\alpha}+4 \varepsilon}{8}-\frac{K_{i}}{3-2 \tilde{\alpha}} & \text { if } 0 \leq K_{i}<K_{1}, \\ r & \text { if } \max \left\{0, K_{1}\right\} \leq K_{i}<K_{2}, \\ \frac{2+2 \varepsilon-2 K_{i}-r(2 \tilde{\alpha}-1)}{6-4 \tilde{\alpha}} & \text { if } \max \left\{0, K_{2}\right\}<K_{i}<D_{0},\end{cases}
$$

where $K_{1}, K_{2}$ and $D_{0}$ are defined as

$$
\begin{aligned}
K_{1}= & \left(\frac{3}{2}-\tilde{\alpha}\right)\left(\frac{3+2 \tilde{\alpha}}{4}+\varepsilon-2 r\right) \\
& -\frac{\sqrt{r(4(2-\tilde{\alpha}) \tilde{\alpha}-3)(1+2 \tilde{\alpha}+4 \varepsilon-4 r)}}{2}, \\
& K_{2}=1+\varepsilon-\left(\frac{5}{2}-\tilde{\alpha}\right) r \text { and } \\
D_{0}= & D(0, r, \tilde{\alpha}, \varepsilon)=1+\varepsilon-\left(\tilde{\alpha}-\frac{1}{2}\right) r .
\end{aligned}
$$

Partially Covered Retail Market $\left(\frac{1}{2}+\varepsilon<r \leq \tilde{\alpha}+\varepsilon\right)$ : Some of the consumers without real-time pricing are priced out of the market. The demand function is

$$
D\left(p^{*}, r, \tilde{\alpha}, \varepsilon\right)= \begin{cases}\left(\frac{3}{2}-\tilde{\alpha}\right)\left(\frac{1}{2}\left(\frac{3}{2}+\tilde{\alpha}\right)+\varepsilon-p^{*}\right) & \\ +\frac{1}{2}(\tilde{\alpha}+\varepsilon-r)^{2} & \text { if } 0 \leq p^{*} \leq r \\ \left(\frac{3}{2}-\tilde{\alpha}\right)\left(\frac{1}{2}\left(\frac{3}{2}+\tilde{\alpha}\right)+\varepsilon-p^{*}\right) & \text { if } r<p^{*} \leq \tilde{\alpha}+\varepsilon \\ \frac{1}{2}\left(\varepsilon-p^{*}+\frac{3}{2}\right)^{2} & \text { if } \tilde{\alpha}+\varepsilon \leq p^{*} \leq \varepsilon+\frac{3}{2}, \\ 0 & \text { if } p^{*}>\varepsilon+\frac{3}{2}\end{cases}
$$


Solving for $p_{j}^{*}$ here yields the following

$$
p_{j}^{*}= \begin{cases}r & \text { if } 0 \leq K_{i}<K_{2}^{\prime}, \\ \frac{1}{2}\left(\frac{1}{2}\left(\frac{3}{2}+\tilde{\alpha}\right)+\varepsilon+\frac{(\tilde{\alpha}+\varepsilon-r)^{2}-2 K_{i}}{3-2 \tilde{\alpha}}\right) & \text { if } \max \left\{0, K_{2}^{\prime}\right\}<K_{i} \\ & <D_{0}^{\prime},\end{cases}
$$

where $K_{2}^{\prime}$ and $D_{0}^{\prime}$ are defined as

$$
\begin{gathered}
K_{2}^{\prime}=\frac{1}{2}\left(\left(\frac{3}{2}+\varepsilon\right)^{2}-2 r(3-\tilde{\alpha}+\varepsilon)+r^{2}\right) \text { and } \\
D_{0}^{\prime}=D(0, r, \tilde{\alpha}, \varepsilon)=\frac{1}{2}\left(\frac{3}{2}-\tilde{\alpha}\right)\left(\frac{3}{2}+\tilde{\alpha}+2 \varepsilon\right)+(\tilde{\alpha}+e-r)^{2} .
\end{gathered}
$$

Uncovered Retail Market $(r>\tilde{\alpha}+\varepsilon)$ : All consumers without real-time prices are priced out of the market. The Demand function is

$$
D\left(p^{*}, r, \tilde{\alpha}, \varepsilon\right)= \begin{cases}\left(\frac{3}{2}-\tilde{\alpha}\right)\left(\frac{1}{2}\left(\frac{3}{2}+\tilde{\alpha}\right)+\varepsilon-p^{*}\right) & \text { if } 0<p^{*} \leq \tilde{\alpha}+\varepsilon, \\ \frac{1}{2}\left(\varepsilon-p^{*}+\frac{3}{2}\right)^{2} & \text { if } \tilde{\alpha}+\varepsilon \leq p^{*} \leq \varepsilon+\frac{3}{2} \\ 0 & \text { if } p^{*}>\varepsilon+\frac{3}{2} .\end{cases}
$$

Solving for the the optimal $p_{j}^{*}$ yields

$$
p_{j}^{*}=\frac{3+2 \tilde{\alpha}+4 \varepsilon}{8}-\frac{K_{i}}{3-2 \tilde{\alpha}} \text { if } 0<K_{i}<D_{0}^{\prime \prime},
$$

with $p_{j}^{*}<\tilde{\alpha}+\varepsilon<r$. $D_{0}^{\prime \prime}$ is defined as

$$
D_{0}^{\prime \prime}=D(0, r, \tilde{\alpha}, \varepsilon)=\frac{1}{8}(3-2 \tilde{\alpha})(3+2 \tilde{\alpha}+4 \varepsilon) .
$$

Note that independent of the specific case that we are looking at $p_{j}^{*}<\tilde{a}+\varepsilon$ and $\frac{\partial p_{j}^{*}}{\partial K_{i}}<0$ always holds. Thus, all consumers with real-time pricing have a positive demand at $p_{j}^{*}$ and it is never located at the non-linear part of the demand function, see figure 2 . The equilibrium $\left(p_{i}, p_{j}\right)=\left(0, p_{j}^{*}\right)$ does always exist for this case. In addition condition (17) is usually satisfied for a range of $0 \leq p_{i} \leq \bar{p}_{i}$ where $p_{i}=\bar{p}_{i}$ satisfies the condition with equality. $\bar{p}_{i}$ is unique because one can show that the left-hand side of (17) is a convex increasing or single peaked function with at most one point of discontinuity at $p_{i}=r$ for all $p_{i}<p_{j}^{*}$. Given that the condition is never satisfied for $p_{i}=p_{j}^{*}$ and always for $p_{i}=0$ 
there exists a unique $0 \leq \bar{p}_{i}<p_{j}^{*}$ such that condition (17) is satisfied for all $0 \leq p_{i} \leq \bar{p}_{i}$. Thus we have multiple Nash equilibria with $\left(p_{i}, p_{j}\right)=\left(p_{i}, p_{j}^{*}\right)$ and $0 \leq p_{i} \leq \bar{p}_{i}$. They are all pay-off equivalent and result in a unique auction price $p^{*}=p_{j}^{*}$.

\section{A.3 Case (iii), (iv) and (v): $K_{i} \leq K_{j}<D(0, r, \tilde{\alpha}, \varepsilon)$}

Here both firms are capacity constrained and both firms have an incentive to deviate from $p_{i}=p_{j}=0$ because both firm can benefit from a positive residual demand. Given that the rival sticks to a price of zero each firm has an incentive to set

$$
p_{j}^{*}=\arg \max _{p}\left\{p\left[D(p, r, \tilde{\alpha}, \varepsilon)-K_{i}\right]\right\} \text { or } p_{i}^{*}=\arg \max _{p}\left\{p\left[D(p, r, \tilde{\alpha}, \varepsilon)-K_{j}\right]\right\} .
$$

Like in case (ii) in subsection A.2 this might even be a best response for a positive price of one's rival as long as (17) or the equivalent condition for firm $i$ choosing $p_{i}^{*}$ holds. Since both firms are capacity constrained, bidding a price above $p_{j}^{*}$ or $p_{i}^{*}$ is potentially profitable for both firms. Therefore the Nash equilibria with either $\left(p_{i}, p_{j}\right)=\left(p_{i}, p_{j}^{*}\right)$ with $p_{i} \leq \bar{p}_{i}<p_{j}^{*}$ and $\bar{p}_{i}$ implicitly defined in $(17)$ or $\left(p_{i}, p_{j}\right)=\left(p_{i}^{*}, p_{j}\right)$ with $p_{j} \leq \bar{p}_{j}<p_{i}^{*}$ and $\bar{p}_{j}$ implicitly defined in the equivalent to (17) can only exist as long as the low-bidding firm does not have an incentive to bid above the high-bidding firms price level.

Note that $p_{j}^{*}$ and $p_{i}^{*}$ are still defined by either (19), (24), or (28) or the equivalent equations for $p_{i}^{*}$ depending on the retail price level. And no matter which definition applies we can show that $p_{j}^{*} \geq p_{i}^{*}$ as long as $K_{j} \geq K_{i}$. If $\left(p_{i}, p_{j}\right)=\left(p_{i}, p_{j}^{*}\right)$ with $p_{i} \leq \bar{p}_{i}<p_{j}^{*}$ holds and the total capacity in the market is sufficient to satisfy $D\left(p_{j}^{*}, r, \tilde{\alpha}, \varepsilon\right)$, the best $p_{i}>p_{j}^{*}$ would be $p_{i}=p_{j}^{*}+\epsilon$ with $\epsilon \rightarrow 0$ for the low-capacity firm. Then firm $i$ 's profit would be $\left(p_{j}^{*}+\epsilon\right)\left[D\left(p_{j}^{*}+\epsilon, r, \tilde{\alpha}, \varepsilon\right)-K_{j}\right]$ and this does never exceed the profit $p_{j}^{*} K_{i}$ that it would achieve with $p_{i} \leq \bar{p}_{i}<p_{j}^{*}$. Thus the equilibrium with the low-capacity firm bidding low with $p_{i} \leq \bar{p}_{i}$ and the high-capacity firm bidding high with $p_{j}=p_{j}^{*}>\bar{p}_{i}$ always exist for $K_{i} \leq K_{j}<D(0, r, \tilde{\alpha}, \varepsilon)$ as long as $K_{i}+K_{j} \geq D\left(p_{j}^{*}, r, \tilde{\alpha}, \varepsilon\right)$ holds. The latter condition is equivalent to $K_{i}>S_{i}$ with

$$
S_{i}= \begin{cases}\frac{1}{4}\left(\frac{3}{2}-\tilde{\alpha}\right)(3+2 \tilde{\alpha}+4 \varepsilon)-2 K_{j} & \text { if } 0 \leq K_{j}<K_{1}, \\ 1+\varepsilon-r-K_{j} & \text { if } \max \left\{0, K_{1}\right\} \leq K_{j}<K_{2}, \\ 1+\varepsilon-\left(\tilde{\alpha}-\frac{1}{2}\right) r-2 K_{j} & \text { if } \max \left\{0, K_{2}\right\} \leq K_{j}<D_{0},\end{cases}
$$


if $0 \leq r \leq \frac{1}{2}+\varepsilon$

$$
S_{i}=\left\{\begin{array}{lc}
\frac{(3+2 \varepsilon-2 r)^{2}}{8}-K_{j} & \text { if } 0 \leq K_{j}<K_{2}^{\prime}, \\
\frac{1}{8}\left(9+12 \varepsilon+4 \varepsilon^{2}+4 r^{2}-8(\tilde{\alpha}+\varepsilon) r\right) & \\
-2 K_{j} & \text { if } \max \left\{0, K_{2}^{\prime}\right\} \leq K_{j} \\
& <D_{0}^{\prime},
\end{array}\right.
$$

if the retail price fulfills $\frac{1}{2}+\varepsilon<r \leq \tilde{\alpha}+\varepsilon$ and

$$
S_{i}=\frac{1}{8}\left(\frac{3}{2}-\tilde{\alpha}\right)(3+2 \tilde{\alpha}+4 \varepsilon)-2 K_{j} \text { if } 0 \leq K_{j}<D_{0}^{\prime \prime},
$$

if $\tilde{\alpha}+\varepsilon<r$.

If we now consider the other potential equilibrium with $\left(p_{i}, p_{j}\right)=\left(p_{i}^{*}, p_{j}\right)$ with $p_{j} \leq \bar{p}_{j}<$ $p_{i}^{*}$, this equilibrium only exists if the high capacity firm $j$ does not have an incentive to deviate to a price with $p_{j}>p_{i}^{*}$. Since $p_{j}^{*} \geq p_{i}^{*}$ holds, the optimal deviation for the high capacity firm is given by its $p_{j}^{*}$ that is defined in (19), (24), or (28), depending on the relevant retail price level. Checking the profits from choosing $p_{j}^{*}>p_{i}^{*}$ reveals that this deviation is not beneficial if $K_{i} \geq \underline{K_{i}}$ with

$$
\underline{K_{i}}=\left\{\begin{array}{cc}
\frac{1}{8}(9+12 \varepsilon-4 \tilde{\alpha}(\tilde{\alpha}+2 \varepsilon) & \\
\left.-4 \sqrt{K_{j}\left(9+12 \varepsilon-8 K_{j}-4 \tilde{\alpha}(\tilde{\alpha}+2 \varepsilon)\right)}\right) & \text { if } 0 \leq K_{j}<K_{1} \\
\max \left\{\frac{1}{8}(9+12 \varepsilon-4 \tilde{\alpha}(\tilde{\alpha}+2 \varepsilon)\right. & \\
\left.\left.-8 \sqrt{2 K_{j} r(3-2 \tilde{\alpha})}\right), 1+\varepsilon-K_{j}-r\right\} & \text { if } \min \left\{0, K_{1}\right\} \\
\max \left\{\frac{1}{8}(3-2 \tilde{\alpha})(3+2 \tilde{\alpha}+4 \varepsilon)\right. & \leq K_{j}<K_{2} \\
-\sqrt{K_{j}\left(2+2 \varepsilon-2 K_{j}-r(2 \tilde{\alpha}-1)\right)}, & \\
\left.\frac{2 K_{j}^{2}+2(3-2 \tilde{\alpha})(1+\varepsilon-r) r-K_{j}(2+2 \varepsilon-r(\tilde{\alpha}-1))}{2 r(3-2 \tilde{\alpha})}\right\} & \text { if } \min \left\{0, K_{2}\right\} \\
& \leq K_{j}<D_{0}
\end{array}\right.
$$


if $0 \leq r<\frac{1}{2}+\varepsilon$,

$$
\underline{K_{i}}=\left\{\begin{array}{lc}
\frac{3+2 \varepsilon-2 r}{8}-K_{j} & \text { if } 0 \leq K_{j}<K_{2}^{\prime} \\
\frac{8 K_{j}^{2}+(3-2 \tilde{\alpha})(3+2 \varepsilon-2 r)^{2} r-K_{j}\left((3+2 \varepsilon)^{2}-8 r(\tilde{\alpha}+\varepsilon)+4 r^{2}\right)}{2 r(3-2 \tilde{\alpha})} & \text { if } K_{2}^{\prime} \leq K_{j}<K_{3} \\
\frac{1}{8}\left\{9-8 \tilde{\alpha} r+4\left[\varepsilon(3+\varepsilon)-2 \varepsilon r+r^{2}\right]\right. & \\
& +4 \sqrt{K_{j}}\left(9+12 \varepsilon+4 \varepsilon^{2}-8 K_{j}+4 r^{2}\right. \\
\left.-8(\tilde{\alpha}+\varepsilon) r)^{1 / 2}\right\} & \text { if } \max \left\{K_{2}^{\prime}, K_{3}\right\} \\
& \leq K_{j}<D_{0}^{\prime}
\end{array}\right.
$$

if $\frac{1}{2}+\varepsilon \leq r<\tilde{\alpha}+\varepsilon$ and

$$
\begin{aligned}
\underline{K_{i}}=\frac{1}{8} & (9+12 \varepsilon-4 \tilde{\alpha}(\tilde{\alpha}+2 \varepsilon) \\
& \left.-4 \sqrt{K_{j}\left(9+12 \varepsilon-8 K_{j}-4 \tilde{\alpha}(\tilde{\alpha}+2 \varepsilon)\right)}\right) \text { if } 0 \leq K_{j}<D_{0}^{\prime \prime},
\end{aligned}
$$

if $r>\tilde{\alpha}+\varepsilon$. The parameter $K_{3}$ in (35) is only relevant as long as $K_{2}>K_{3}>D_{0}^{\prime}$ holds and is defined as

$$
\begin{aligned}
K_{3}=\frac{1}{16} & \left(9+12 \varepsilon+4 \varepsilon^{2}-8 \tilde{\alpha} r-8 \varepsilon r+4 r^{2}\right. \\
& \left.+\sqrt{-128(3-2 \tilde{\alpha})^{2} r^{2}+\left((3+2 \varepsilon)^{2}-8(\tilde{\alpha}+\varepsilon) r+4 r^{2}\right)^{2}}\right) .
\end{aligned}
$$

One can also show that $S_{i} \leq \underline{K_{i}}$ for the relevant ranges of $K_{j}$. Thus, the two types of equilibrium with either $\left(p_{i}, p_{j}\right)=\left(p_{i}, p_{j}^{*}\right)$ and $p_{i} \leq \bar{p}_{i}<p_{j}^{*}$ or $\left(p_{i}, p_{j}\right)=\left(p_{i}^{*}, p_{j}\right)$ and $p_{j} \leq \bar{p}_{j}<p_{i}^{*}$ exist for $K_{j} \geq K_{i} \geq \underline{K_{i}}$. For $\min \left\{K_{j}, \underline{K_{i}}\right\}>K_{i} \geq S_{i}$ only the equilibria with $\left(p_{i}, p_{j}\right)=\left(p_{i}, p_{j}^{*}\right)$ and $p_{i} \leq \bar{p}_{i}<p_{j}^{*}$ exist. For $K_{i}<S_{i}$ the total capacity in the market does not satisfy the total demand at $p_{j}^{*}$ any more. The system operator will set the market clearing price $\hat{p}$. Both firms bid a price that does not exceed the anticipated market clearing price because this would reduce their profit.

\section{B Proof of proposition 2}

The retailers will always compete the retail price down to a level where $r \leq p^{*}$ is ensured for all $\varepsilon \in[0,1]$ due to the Bertrand competition among them. From equations (19), (24) and (28) and the definition of $\hat{p}$ from case (v) in Proposition 1 it is obvious that $\frac{\partial p^{*}}{\partial \varepsilon} \geq 0$ 
for all $\varepsilon \in[0,1]$ if $p^{*} \geq 0$. Thus $r \leq p^{*}$ for all $\varepsilon$ implies that $r \leq p^{*}$ for $\varepsilon=0$.

If $K_{i}<K_{2}$ or $K_{i}<K_{2}^{\prime}$ holds for $\varepsilon=0$, then the retail price will always satisfy $r \leq p^{*}$. Alternatively, $r \leq p^{*}$ might also occur for either $K_{2} \leq K_{i}<S_{i}$, or $K_{2}^{\prime} \leq K_{i}<S_{i}$, if the system operator needs to set the price $\hat{p}$ such that it exceeds the retail price for $\varepsilon=0$.

Let us first assume that $K_{i}$ and $K_{j}$ are large enough that the system operator does not need to set a price $\hat{p}$ for $K_{i}>K_{2}$ or $K_{i}>K_{2}^{\prime}$ such that it exceeds the retail price, then $K_{i} \leq K_{2}$ or $K_{i} \leq K_{2}^{\prime}$ for the smallest $\varepsilon=0$ is sufficient to ensure that $r \leq p^{*}$ for all $\varepsilon \in[0,1]$. Taking into account $p^{*}$ from either (19) or (24) and solving these inequalities for $r$ yields

$$
r<r^{\prime}= \begin{cases}3-\tilde{\alpha}-\frac{1}{2} \sqrt{27-4 \tilde{\alpha}(6-\tilde{\alpha})+8 K_{i}} & \text { if } 0 \leq K_{i}<\frac{1}{2}\left(\tilde{\alpha}-\frac{1}{2}\right) \\ \frac{2\left(1-K_{i}\right)}{5-2 \tilde{\alpha}} & \text { if } \frac{1}{2}\left(\tilde{\alpha}-\frac{1}{2}\right) \leq K_{i}<1 .\end{cases}
$$

The split occurs because for $K_{i}<\frac{1}{2}\left(\tilde{\alpha}-\frac{1}{2}\right)$ the retail price threshold $r_{1}$ exceeds $\frac{1}{2}$ where, given $\varepsilon=0$, the retail market is no longer fully covered and the parameter $K_{2}^{\prime}$ instead of $K_{2}$ becomes relevant. For $K_{j} \geq K_{i} \geq 1$ the only possible outcome for the retail competition is $r=0$.

Let us now assume that $K_{i}$ and $K_{j}$ are not large enough to avoid the case that the system operator needs to set a price $\hat{p} \geq r$ for some $K_{2}<K_{i} \leq K_{j}$ or $K_{2}^{\prime}<K_{i} \leq K_{j}$ if $\varepsilon=0$. The system operator price, given a fully covered retail market, is

$$
\hat{p}=\frac{2\left(1-K_{i}-K_{j}-r\left(\tilde{\alpha}-\frac{1}{2}\right)\right)}{3-2 \tilde{\alpha}} .
$$

The system operator price, given a partially covered retail market, is

$$
\hat{p}=\frac{9-8 K_{i}-8 K_{j}-8 \tilde{\alpha} r+4 r^{2}}{12-8 \tilde{\alpha}} .
$$

In order to ensure $\hat{p} \geq r$

$$
r \leq r^{\prime \prime}= \begin{cases}\frac{3}{2}-\sqrt{2\left(K_{i}+K_{j}\right)} & \text { if } 0 \leq K_{i}<\frac{1}{2}-K_{j}, \\ 1-K_{i}-K_{j} & \text { if } \frac{1}{2}-K_{j} \leq K_{i}<1-K_{j}\end{cases}
$$

must hold.

Note that we do not need to consider the case where the retail market is uncovered for $\varepsilon=0$ because this implies that the retail price is too high for a positive demand of the retail consumers and would be competed downward by the retail firms. In addition $r^{\prime \prime}$ is 
only relevant if $r^{\prime}<r^{\prime \prime}$ for the given $K_{i} \leq K_{j}$. Checking for which $K_{i} \leq K_{j}$ the inequality holds yields the definition of $\bar{r}$ in Proposition 2.

\section{Welfare derivation}

\section{C.1 Critical shocks}

The critical demand shock, $\varepsilon^{*}$, that decides on whether the wholesale price is at or above the retail price can de derived as follows. Because $\varepsilon^{*}$ determines if $K_{i}$ is smaller or larger than $K_{1}$, we set $K_{1}$ from equation (20) equal to $K_{i}$ and solve for $\varepsilon$. This yields

$$
\varepsilon^{*}=-\frac{\tilde{\alpha}}{2}+\frac{2\left(K_{i}+2 r\right)}{3-2 \tilde{\alpha}}+\frac{\sqrt{2} \sqrt{(3-2 \tilde{\alpha})^{2}(2 \tilde{\alpha}-1) r\left(2 \tilde{\alpha}+4 K_{i}+4 r-3\right)}}{(3-2 \tilde{\alpha})^{2}}-\frac{3}{4} .
$$

For zero retail prices the critical shock is then

$$
\varepsilon_{z}^{*}=\frac{8 K_{i}+4 \tilde{\alpha}^{2}-9}{12-8 \tilde{\alpha}}
$$

Inserting the intermediate and the high retail prices from proposition 2 in equation (43) yields the respective critical shocks $\varepsilon_{i}^{*}$ and $\varepsilon_{h}^{*}$.

\section{C.2 Conditions for market clearing}

For the welfare analysis to be tractable, we assume that the firms can always clear the market and the SO never has to intervene. For retail prices of zero this is given through the capacity requirements that have to hold for the retail prices to be zero.

For intermediate and high retail prices capacities can be too low and the SO has to set the market clearing price for some demand shocks. To calculate welfare when the firms clear the market at their bids we define minimum capacity endowments such that the firms are able to play $p^{*}=r$ or $p^{*}=p_{j}^{*}$.

Intermediate retail price are always below $\frac{1}{2}$ and hence below $\frac{1}{2}+\varepsilon$ and therefore the retail market is always fully covered. Capacities have to fulfill $K_{i}+K_{j} \geq D(r \mid \varepsilon=1)$, where $r<\frac{1}{2}+\varepsilon$, and $K_{i}+K_{j} \geq D\left(p_{j}^{*} \mid \varepsilon=1\right)$. Rearranging the first condition yields

$$
K_{i} \geq \frac{8+2 \tilde{\alpha}\left(K_{j}-2\right)-5 K_{j}}{3-2 \tilde{\alpha}} .
$$


Because $r<p_{j}^{*}$ and hence $D(r \mid \varepsilon=1)>D\left(p_{j}^{*} \mid \varepsilon=1\right)$, whenever equation (45) is satisfied, the firms can also cover the market at all optimal prices higher than the retail price.

Likewise, for high retail prices, capacities have to fulfill $K_{i}+K_{j} \geq D(r \mid \varepsilon=1)$ and $K_{i}+K_{j} \geq D\left(p_{j}^{*} \mid \varepsilon=1\right)$. When $\varepsilon=1, r<\frac{1}{2}+\varepsilon=\frac{3}{2}$ always holds for high retail prices and the retail market is always fully covered. When $r<\frac{1}{2}+\varepsilon$ and all retail customers demand electricity the firms capacities have to satisfy $K_{i}+K_{j} \geq D(r \mid \varepsilon=1)$ what implies

$$
K_{i} \begin{cases}\geq \tilde{\alpha}-K_{j}+\frac{1}{2} \sqrt{4(\tilde{\alpha}-4) \tilde{\alpha}-8 K_{j}+23} & \text { if } K_{i}>-\frac{1}{2}(\tilde{\alpha}-6) \tilde{\alpha}-\frac{23}{8} \\ \leq \tilde{\alpha}-K_{j}-\frac{1}{2} \sqrt{4(\tilde{\alpha}-4) \tilde{\alpha}-8 K_{j}+23} & \text { if } K_{i}<-\frac{1}{2}(\tilde{\alpha}-6) \tilde{\alpha}-\frac{23}{8}\end{cases}
$$

If the firms can cover all demand at the retail price when the retail market is fully covered, they can also cover the reduced demand for a partially covered retail market and the wholesale market at optimal prices above the retail price. Figure 8 illustrates the area that equations (45) and (46) define.

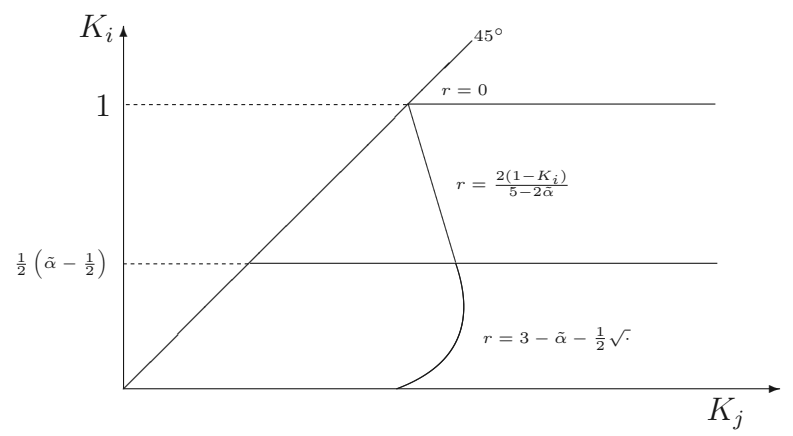

Figure 8: Combinations of $K_{i}$ and $K_{j}$ that ensure $p=r$ or $p=p_{j}^{*}$. 


\section{References}

Allcott, Hunt (2009) "Rethinking Real Time Electricity Pricing," Working Paper 09-15, Center for Energy and Environmental Policy Research, MIT Energy Initiative and Sloan School of Management.

Boisvert, Richard N., Peter Cappers, Charles Goldman, Bernie Neenan, and Nicole Hopper (2007) "Customer Response to RTP in Competitive Markets: A Study of Niagara Mohawk's Standard Offer Tariff," The Energy Journal, Vol. 28, No. 1, pp. 53-74.

Boom, Anette (2008) "Equilibrium Selection with Risk Dominance in a Multiple-unit Unit Price Auction," Working Paper 2-2008, Department of Economics, Copenhagen Business School.

(2009) "Vertically Integrated Firms' Investments in Electricity Generating Capacities," International Journal of Industrial Organization, Vol. 27, pp. 544-551.

Boom, Anette and Stefan Buehler (2007) "Restructuring Electricity Markets when Demand is Uncertain: Effects on Capacity Investments, Prices and Welfare," Discussion Paper 2007-09, Centre for Industrial Economics, Department of Economics, University of Copenhagen.

Borenstein, Severin and Stephen Holland (2005) "On the Efficiency of Competitive Electricity Markets with Time-invariant Retail Prices," The Rand Journal of Economics, Vol. 36, No. 3, pp. 469-493.

Crew, Michael A., Chitru S. Fernando, and Paul R. Kleindorfer (1995) "The Theory of Peak-load Pricing: A Survey," Journal of Regulatory Economics, Vol. 8, pp. 215-248.

Fabra, Natalia and Nils-Hendrik von der Fehr (2006) "Designing Electricity Auctions," The Rand Journal of Economics, Vol. 37, No. 1, pp. 23-46.

Holland, Stephen P. and Erin T. Mansur (2006) "The Short-run Effects of Time-Varying Prices in Competitive Electricity Markets," The Energy Journal, Vol. 27, No. 4, pp. $127-155$.

Joskow, Paul and Jean Tirole (2006) "Retail Electricity Competition," The Rand Journal of Economics, Vol. 37, No. 4, pp. 799-815.

(2007) "Reliability and Competitive Elextricity Markets," The Rand Journal of Economics, Vol. 38, No. 1, pp. 60-84. 
Patrick, Robert and Frank Wolak (2001) "Estimating the Customer-level Demand for Electricity under Real-time Market Prices," Working Paper 8213, National Bureau of Economic Research, Cambridge, MA.

Stoft, Steven (2002) Power System Economics-Designing Markets for Electricity, New York: IEEE Press and John Wiley \& Sons.

Taylor, Thomas N., Peter M. Schwarz, and James E. Cochell (2005) "24/7 Hourly Response to Electricity Real-Time Pricing with up to Eight Summers of Experience," Journal of Regulatory Economics, Vol. 27, No. 3, pp. 235-262.

The Economist (2009a) "Building the Smart Grid," June 4th.

— (2009b) "Wiser wires," October 8th.

Wolfram, Cathrine (1998) "Strategic Bidding in a Multiunit Auction: An Empirical Analysis of Bids to Supply Electricity in England and Wales," The RAND Journal of Economics, Vol. 29, No. 4, pp. 703-725.

Zarnikau, Jay and Ian Hallett (2008) "Aggregate Industrial Energy Consumer Response to Wholesale Prices in the Restructured Texas Electricity Market," Energy Economics, Vol. 30, pp. 1798-1808. 


\title{
Strategic Bidding in Multiunit Auctions with Capacity Constrained Bidders: The New York Capacity Market
}

\author{
Sebastian Schwenen ${ }^{\mathrm{a}}$ \\ Copenhagen Business School
}

\begin{abstract}
This paper employs a simple model to describe bidding behavior in multiunit uniform price procurement auctions when firms are capacity constrained. Using data from the New York City capacity auctions, I find that capacity constrained firms use simple bidding strategies to co-ordinate on an equilibrium that extracts high rents for all bidders. I show theoretically and empirically that the largest bidder submits the auction clearing bid, while all other bidders submit inframarginal bids that are low enough to not be profitably undercut. Inframarginal bidders react to capacity endowments and decrease their bids as the largest firm's capacities and its profits of undercutting increase.
\end{abstract}

Keywords: Auctions, Electricity, Market Design. JEL-Classification: D43, D44, L11, L13

${ }^{a}$ Copenhagen Business School, Department of Economics, Porcelanshaven 16 A, DK2000 Frederiksberg, e-mail: ses.eco@cbs.dk 
Strategic Bidding in Multiunit Auctions with Capacity Constrained Bidders: The New York Capacity Market

\section{Introduction}

The volume of goods traded through auctions in the economy has been drastically increasing over the last decades. This increased use of auctions raises the need to better understand and predict economic behavior in bid based selling mechanisms. To address this challenge, an increasing strand of literature tests and expands existing auction models. Because electricity is a completely homogeneous good and produced by a small number of firms, restructured power markets have become a major field of applied auction analysis. Multiunit auctions are the main auction format used in electricity markets. This paper contributes to the literature by demonstrating that a simple model of multiunit uniform price auctions is consistent with observed bidding data from capacity auctions in electricity markets. Harbord and Von der Fehr (1993), LeCoq (2002), Crampes and Creti (2005), Fabra et al. (2006) and more recently Fabra et al. (2011) developed a multiunit auction framework in which capacity constrained bidders with constant marginal costs compete in electricity auctions. I focus on an extended version of Fabra et al. (2006) and, using data from the New York Independent System Operator (NYISO) capacity auctions, find that these models are sufficient to predict economic bidding behavior in multiunit auctions when bidders are capacity constrained.

By tailoring a multiunit auction model to the NYISO capacity market this paper also reveals design flaws in this market and contributes to the discussion on supply security and electricity market design. Generating firms in the NYISO capacity market co-ordinated on an equilibrium play that was extracting the highest possible rents for the supply side between 2003 and 2008. The capacity market was always clearing at the price cap and thus set incorrect price signals for entry and profitability of new peaking units.

The economic theory of multiunit auctions dates back to the auctions of share framework by Wilson (1979). Klemperer and Meyer (1989) increased 
Strategic Bidding in Multiunit Auctions with Capacity Constrained Bidders: The New York Capacity Market

the predictive power of Wilson's model by introducing demand uncertainty thereby reducing the multiplicity of equilibria substantially. Green and Newberry (1992) were the first to tailor a multiunit auction model to electricity markets and designed the model to describe the UK spot market for electricity. Early tests of these models by Wolfram (1998) and Green and Newberry (1992) confirmed the models' predictions. More recent structural empirical work by Hortacsu and Puller (2008) and Oren and Sioshansi (2007) and also by Wolak (2000) provided additional support for the main models, extended them by including forward markets, and introduced non-parametric tests. So far, empirical findings for simple multiunit auction models in the style of Fabra et al. (2006) are not documented, which is partly due to the stylized nature of these models. Capacity auctions take place in an environment very close to the one assumed in Fabra et al. (2006) and are ideal to deliver empirical insights on the predictions of such models.

The remainder is organized as follows. Section 2 presents the market structure in the New York electricity market. Section 3 introduces a model for multiunit uniform price procurement auctions with capacity constrained firms that reflects the market design discussed in section 2. Section 4 discusses the empirical findings. I compare the optimal bids generated by the model to observed bids in the auction, assess deviations from the model, and present estimates of the best response functions. Section 6 concludes on the contribution and limitations of my empirical findings and draws policy recommendations for future market designs of capacity markets.

\section{The New York capacity market}

This section sketches the market design of the New York ISO energy market. The New York power market consists of an energy market and a capacity market. In virtually all other markets, pricing the commodity only is sufficient to promote long run investment. Hence most markets do not need to 
Strategic Bidding in Multiunit Auctions with Capacity Constrained Bidders: The New York Capacity Market

price capacity. In electricity markets, the existence of dominant firms and the absence of a robust demand response requires that in times of shortage the market price is set administratively. When this price cap is set just above marginal costs (for mostly political reasons this is the case is in all major US electricity markets), electricity prices are a weak signal for promoting efficient long run investment. Capacity markets, as they are installed in most markets along the US east coast, supplement the lost revenues, termed 'missing money', that result from the price cap in the energy market. By allowing firms to obtain revenue from holding capacity, regulators get to keep electricity shortage prices at a politically acceptable level and to secure long run investment in electricity generation at the same time. ${ }^{1}$

Capacity markets are artificially created markets that signal the scarcity of aggregate generation capacities relative to future projected power demand. Projected demand for generating capacity is estimated, announced and procured by the system operator, who finances the costs of procurement by passing them on to retailers. When generation capacities are scarce, capacity market rents are high. When there is relatively large market capacity, the capacity market price is low and does not promote further investment. Firms who earn capacity payments must offer to produce power, that is, they must supply a bid below the energy market price cap in the electricity wholesale auction. In the purest form the energy price cap is set at the marginal cost of peaking units, so all rents for peaking units are made in the capacity market. Off-peak units with lower marginal costs earn revenues in the energy and the capacity market. The capacity market imitates the revenues for peaking units that would be earned in an energy-only market in times when the market price would be above the price cap. The overarching policy goal of capacity markets is to protect consumers from market power, while maintaining sufficient peak production and investment incentives in

\footnotetext{
${ }^{1}$ This market design is highly debated. For an analysis of energy-only markets see Hogan (2005).
} 
Strategic Bidding in Multiunit Auctions with Capacity Constrained Bidders: The New York Capacity Market

new peak capacity despite the price cap.

The New York state electricity market serves about 20 million final customers and had a peak demand of about $33 \mathrm{GW}$ in 2010, whereas total generating capacity was at about $41 \mathrm{GW} .^{2}$ The New York state wide wholesale electricity exchange is organized by the NYISO, who in addition administers a monthly capacity market. Each month firms bid their available capacity into the capacity market and thereby, if they are procured, oblige themselves to offer energy in the energy market during the following month. If generation capacity is scarce relative to the ISO's demand for generating and reserve capacity, these markets then generate rents for firms to cover fixed costs of currently running peakers and signal the profitability of new entry.

To set locationally different signals, the ISO runs three separate capacity markets with different demand curves for New York City, Long Island, and the remaining area of New York state. The data used to empirically assess the auction model comes from the capacity market in New York City. To account for different summer and winter peak demand, the ISO fixes the demand for capacity every six month, while the procurement takes place each month. Each month the New York City capacity spot market clears around 8.5 GW at a capacity price of $7 \$ / \mathrm{kw}$-month during winter months and at around 12 $\$ / \mathrm{kw}$-month during the summer period. Retailers are the final consumers of capacity rights. The ISO obliges retailers to hold capacity rights according to the projected electricity demand of their retail customers. Retailers can also buy capacity rights on bilateral and institutional forward markets. Retailers buy capacity in the forward markets, notify their position to the ISO, who then procures the missing capacity as a single buyer in the final spot auction and resells the capacity rights to the retailers at the auction clearing price.

Winning firms in the capacity market have to bid into the energy market

\footnotetext{
${ }^{2}$ See www.nyiso.com. After several years of high capacity prices and new investment in capacities before 2010, this reserve margin is projected to be sufficient until 2018 according to the 2009 Reliable Need Assessment of NYISO.
} 
Strategic Bidding in Multiunit Auctions with Capacity Constrained Bidders: The New York Capacity Market

and deliver at the prevailing energy market price. The NYISO's energy market software employs an automated market power mitigation procedure for energy market bids that are significantly higher than previously submitted bids from the same generation unit during, for example, competitive low demand periods. Hence it is not possible for firms to earn capacity payments and withhold rewarded capacity in the energy market by bidding above the clearing price of the electricity wholesale auction.

The model introduced in the next section is built upon a full information framework to describe the spot market capacity auction run by the NYISO. The model assumes that firms know their rival's forward position resulting from bilateral or institutional forward trading of capacity rights. Hence what we observe in the spot market are best response functions to what firms already sold forward. Given the repeated nature of the auction, this assumption seems realistic. ${ }^{3}$ In 2009, the NYISO estimated that approximately $45 \%$ of the capacity requirements are transacted through the NYISO administered capacity auctions, at an annual volume of over $\$ 850$ million. The remaining requirements were met through forward contracts that hedge around the spot market capacity price. A look at the forward and spot prices for capacity reveals that the law of one price holds with respect to all forward market transactions. ${ }^{4}$

\section{The model}

To analyze the data I use a simple model of bidding behavior in multiunit uniform price procurement auctions. The model builds on the auction

\footnotetext{
${ }^{3}$ Between 2006 and 2008 a financial hedge between two participants in the auction existed. This agreement changed their forward market behavior and was judged to violate the Sherman Act by the Department of Justice. However, the agreement was common information and is in line with the assumption that each firm know its rivals forward position.

${ }^{4}$ See the ICAP summary section at www.nyiso.com.
} 
Strategic Bidding in Multiunit Auctions with Capacity Constrained Bidders: The New York Capacity Market

framework in Fabra et al. (2006), who derive equilibrium outcomes in a variety of multiunit auction settings. The NYISO market clears as a multiunit uniform price procurement auction, where the ISO announces the demand schedule and generating firms submit supply bids. The auctioneer, the ISO, announces a linear downward sloping demand function, $D(p)$, that is known to all bidders prior to the auction. ${ }^{5}$ I assume that all bidders $i=1, \ldots, N$ are capacity constrained so that no bidder has enough available capacity, $\bar{k}_{i}$, to serve entire demand at a price of zero. Firms can bid a discrete, possibly stepwise, supply function $s_{i}(b)$, that specifies how much capacity a firm is willing to sell at a price of $b$. Hence, if firms submit just one bid step, their supply function $s_{i}(b)$ would be $\left(b, \bar{k}_{i}\right)$. If a firm submits two or more steps, the supply function would split up $\bar{k}_{i}$ and submit this capacity at two or more different price bids. I assume that firms submit all their available constrained capacities, $\bar{k}_{i}$, and provide the condition for which it is indeed optimal to offer all capacity up to the constraint in Appendix A.1. The auctioneer orders all bids, independent of who submitted them, in increasing order and finds the market clearing price, $p^{c}$, which satisfies the condition

$$
\sum_{j=1}^{M} S_{j}\left(p^{c}\right)=D\left(p^{c}\right),
$$

where the index $j$ denotes on bid step $j=1, \ldots, M$ in the aggregate bid function $S_{j}(b)$. The auctioneer sums up all capacity submitted at each price bid and finds the market clearing price. All bids that are lower than the market clearing price will be procured and paid the market clearing price. I drop time indices for each auction. For each auction, firm $i$ 's profits are

$$
\pi_{i}=s_{i}\left(p^{c}\right) p^{c} .
$$

\footnotetext{
${ }^{5}$ In practice, this spot demand function is the total demand for capacity minus all quantities that retailers contracted bilaterally or on forward auctions.
} 
Strategic Bidding in Multiunit Auctions with Capacity Constrained Bidders: The New York Capacity Market

Marginal costs are assumed to be constant and zero. Firms do not face notable costs of offering their capacity on the capacity market. Cramton and Stoft (2005) show that for all firms that plan to sell electricity in the energy market, it is not costly to commit to that in the capacity market. Furthermore, Stoft (2002) shows that capacity markets clear at market prices close to zero in times of overcapacity, which indicates that marginal costs are insignificant. These two features, capacity constraints and constant marginal costs, have significant impact on the firms' strategy choice. When firms are unconstrained or face increasing marginal costs, firms maximize profits by bidding upward sloping supply functions against all residual demand situations. However, when firms are capacity constrained and do not face increasing marginal costs (that force them to bid upward sloping bid functions), simpler strategies suffice. Inframarginal firms cannot serve their residual demand and only one pivotal firm clears the auction on the margin against its residual demand. Then, profits of the inframarginal bidders do not change whether they submit upward sloping supply functions or simply submit all their available capacity at some price below the market clearing price, and are rewarded at the clearing price. Only one high and pivotal bidder clears the market in each auction.

Firm's strategies can be described as follows. For the auction to clear, the auctioneer sorts all price bids $b_{j}$, where $j=1, \ldots, M$, in increasing order. Accordingly, denote the bid ranking such that $b_{1}<b_{2}<\ldots<b_{M}$. At each $b_{j}$ a cumulated capacity of $K_{j}=\sum_{s=1}^{j} k_{j}$ is offered, where $k_{j}$ is the capacity offered at each $b_{j}$. There is one pivotal, marginal bidder, $i=m$, who offers the marginal bid, $b_{j}=b_{m}$, that clears the auction and $K_{m-1}<$ $D\left(b_{m-1}\right) \wedge K_{m} \geq D\left(b_{m}\right)$ holds. The pivotal bidder $m$ maximizes over the residual demand that all other inframarginal and low bidding capacity constrained firms leave unsatisfied. In the NYISO capacity market a price cap is imposed and therefore the pivotal bidder maximizes profits by finding: 
Strategic Bidding in Multiunit Auctions with Capacity Constrained Bidders: The New York Capacity Market

$$
b_{m}^{*}=\min \left\{\arg \max _{b} b\left(D(b)-K_{m-1}\right), b^{c a p}\right\} .
$$

The pivotal bidder submits the optimal residual monopoly bid, if not bound by the bid cap, and will earn profits of $\pi_{m}$. These profits are considered by the low bidding firms when choosing their strategy. They choose, $s_{i}(b)$, their inframarginal bids, such that they are low enough to not be undercut by the pivotal bidder. We can derive upper bounds for all bids of the low bidding firms, $b_{j}<b_{m}$. Each bid $j$ faces an upper bound, $\bar{b}_{j}$, that solves

$$
\bar{b}_{j}:= \begin{cases}b_{j}\left(D\left(b_{j}\right)-K_{j-1}\right)=\pi_{m} & \text { if } \bar{k}_{m}>D\left(b_{j}\right)-K_{j-1} \\ \hat{b}_{j} \bar{k}_{m}=\pi_{m} & \text { if } D\left(b_{j}\right)-K_{j-1}>\bar{k}_{m} \text { and } b_{j} \leq \hat{b}_{j} .\end{cases}
$$

The first case in equation (4) describes all bids that, when sligthly underbid by the pivotal firm, are pushed out of the market. In this case the pivotal firm stays pivotal. The second case defines upper bounds for bids that, when slightly underbid by the pivotal firm, stay in the market. It is possible that auctions clear and bids only face upper bounds according to the first case. This happens when the pivotal bidder's capacity, $\bar{k}_{m}$, is large enough to push all bids out of the market. If the pivotal bidder cannot push all bids out of the market, then there is at most one bid, $\hat{b}_{j}$, that, when undercut, becomes pivotal and clears the auction. All bids $b_{j} \leq \hat{b}_{j}$ then face the same upper bound as the highest bid for which $D\left(b_{j}\right)-K_{j-1}>\bar{k}_{m}$ holds, because if the pivotal firm does not want to underbid that particular bid (and sell all its capacity $\bar{k}_{m}$ ), then the pivotal firm also does not want to underbid lower bids $b_{j} \leq \hat{b}_{j}$, still sell $\bar{k}_{m}$, and potentially decrease the auction price.

Not defined in equation (4) are cases in which the auction does not clear, $K_{m}<D\left(b_{m}\right)$, because capacity constraints are too tight. The auctioneer then would find the auction price that ensures $K_{m}=D(p)$. In this case there is no strategic relation in the firms' bids. As described, there is, if 
Strategic Bidding in Multiunit Auctions with Capacity Constrained Bidders: The New York Capacity Market

at all, only one bid (the highest for which $D\left(b_{j}\right)-K_{j-1}>\bar{k}_{m}$ holds) that determines the bound for all bids that cannot be pushed out of the market by the pivotal firm. In the remainder, such bids are denoted $b_{j}^{I}$. In each auction there are, if at all, one or more bids for which $\bar{k}_{m}>D\left(b_{j}\right)-K_{j-1}$ holds. Bids that fall into this category will be denoted by $b_{j}^{I I}$. If they exist, lower bids for which $D\left(b_{j}\right)-K_{j}>\bar{k}_{m}$ holds are optimal by definition if the bid $b_{j}^{I}$ is below its bound.

Figure 1 describes an example of the equilibrium play described above. This example has four bids, meaning maximum four firms but potentially less if one or more firms submitted a stepwise function. The pivotal firm, $i=m$, submits the highest bid and sets the auction clearing price. The pivotal firm simply clears the market by optimizing as a monopolist over its residual demand, see equation (3). The high bidding firm is bound however by the price cap and chooses the minimum out of the optimal residual monopoly price and the price cap. All low bidding firms submit bids, $b_{j} \in\left[0, \bar{b}_{j}\right]$, such that they will not be undercut, according to equation (4). The second highest bid, $b_{3}$, has an upper bound that solves $b_{j}\left(D\left(b_{j}\right)-K_{j-1}\right)=\pi_{m}$. In this case the capacity of the pivotal bidder is large enough to completely push bid three out of the market. However, already the second lowest bid, $b_{2}$, given its position in the merit order in this example, will still be among the winning bids when undercut by the pivotal firm. When the pivotal firm underbids and submit $b_{2}-\epsilon$ it cannot cover the whole residual demand and bid $b_{2}$ will set the auction clearing price. Firm $m$ then would sell all its capacity, hence for $b_{2}$ the upper bound is $\bar{b}=\frac{\pi_{m}}{k_{m}}$. For, $b_{1}$, the bound is the same bound as for $b_{2}$. All bids below $b_{2}$ will never be underbid, because if they are, the underbidding pivotal firm will potentially decrease the market price and still sell all its capacity, compared to the price it obtains when only underbidding $b_{2}$.

Last, what is not graphed above is the case when the auction does not clear. This happens in the data, because the capacity constraints are very tight 


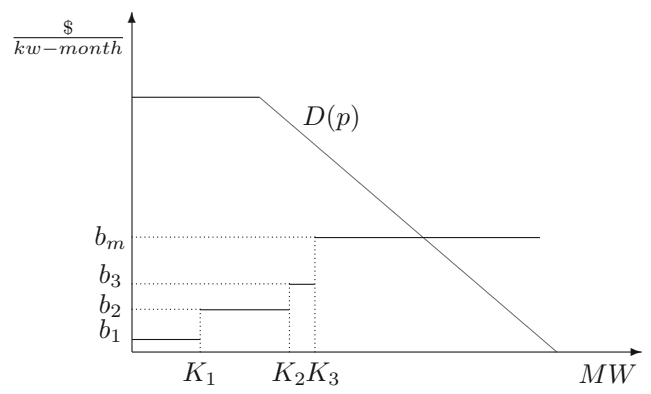

Figure 1: Example of the auction clearing.

in some auctions. Since the system operator would set the price such that $D(p)=K_{M}$, firms then just have to bid below that price, otherwise they would not be procured at all. The equilibria described above are summarized by the first proposition.

Proposition 1 In the multiunit uniform price procurement auction with capacity constrained firms, the equilibrium in pure strategies is characterized by one pivotal firm who submits the auction clearing bid, while all other bidders submit low inframarginal bids $b_{j} \in\left[0, \bar{b}_{j}\right]$, if $D\left(b_{M}^{*}\right) \leq K_{M}$.

Proof. See equations (3) and (4) and note that the pivotal bidder does not want to deviate by construction. If low bidders want to deviate and overbid, these particular equilibria do not exist.

There exist multiple equilibria, in which different firms can be the pivotal bidder. The multiplicity of equilibria is common to the general supply function framework and also to Fabra et al. (2006). In Appendix A.2, I show 
Strategic Bidding in Multiunit Auctions with Capacity Constrained Bidders: The New York Capacity Market

that equilibria in which the largest firm is the pivotal bidder always exist and smaller bidders never want to overbid. Furthermore, in Appendix A.3 I prove that for very asymmetric firm capacities the largest firm never wants to be among the low bidding firms and becomes the pivotal bidder, as stated in the following proposition.

Proposition 2 When capacity endowments are sufficiently asymmetric, only equilibria exist, in which the largest firm is the pivotal bidder and submits $b_{m}^{*}$, while all smaller firms submit low bids $b_{j} \in\left[0, \bar{b}_{j}\right]$ and do not find it profitable to overbid $b_{m}^{*}$.

Proof: See Appendix A.3.

The intuition behind proposition 2 is straightforward. Suppose the by far largest firm is bidding a low inframarginal price. Then, the residual demand is relatively low and therefore also the auction clearing residual monopoly price that one of the smaller firms would bid. Hence, the largest firm increases its profits by overbidding and increasing the market price, even if it then might not sell all its capacity. In the case of two firms, a firm that owns enough capacities to act as a monopolist would not mind an infinitesimal small firm entering the auction, and would still bid close to its monopoly price. In turn, the small firm would never overbid the large firms monopoly price. ${ }^{6}$

To empirically analyze how the best response functions are describing the low bids, $b_{i}<b_{m}$, I employ equation (4). Changing the inequality of the bound to an equality and taking the log yields:

\footnotetext{
${ }^{6}$ Note that for this equilibrium structure introducing stochastic quantity offers of the firms and hence stochastic residual demand can only be done for a relatively low support of random capacity offers. When the support of the residual demand becomes too large, low bidding firm's might find themselves setting the market price and in this event like to price high and increase profits. This effect leads to mixed strategies, see Fabra et al. (2006). Mixed strategies complicate the analysis significantly. This observation together with the existence of common and zero marginal costs further support the simple full information framework.
} 
Strategic Bidding in Multiunit Auctions with Capacity Constrained Bidders: The New York Capacity Market

$$
\ln \left(b_{j}\right)=\ln \left(\pi_{m}\right)-\ln \left(\bar{k}_{m}\right)
$$

for all bids for which $D\left(b_{j}\right)-K_{j-1}>\bar{k}_{m}$ holds and

$$
\ln \left(b_{j}\right)=\ln \left(\pi_{m}\right)-\ln \left(D\left(b_{j}\right)-K_{j-1}\right)
$$

if $\bar{k}_{m}>D\left(b_{j}\right)-K_{j-1}$ holds. Versions of these equations will be estimated to see how low bids react to changing pivotal capacity. The model suggests that inframarginal bids increase as pivotal profits become larger, while inframarginal bids decrease if the larger firms profits of undercutting, that is its sold quantity when undercutting, $\bar{k}_{m}$ or $D\left(b_{j}\right)-K_{j-1}$, increases.

The next section, section 3, presents the data. Section 4 tests the two propositions derived above. Like in Hortacsu and Puller (2008), the analysis starts by simply deriving the percentage of cases in which firms behaved as predicted by the model. I first asses the optimality of the pivotal firms profits, and then count how often inframarginal bidders violated their bounds. Last, I present the results for the estimations of the best response functions in equations (5) and (6).

\section{Data and method}

This section presents the data and describes the implementation of the model. The data consist of 56 monthly procurement auctions for installed capacity in the New York City ISO electricity market from June 2003 to March $2008 .^{7}$ We do not consider auctions after summer 2008, because in May 2008 the NYISO implemented a new regulatory regime that introduced the possibility for the ISO to buy from the pivotal bidder withheld capacity at a default

\footnotetext{
${ }^{7}$ Bid data from November 2003 was not available. Auction 1 is June 2003, auction 56 is the February 2008 capacity auction for making capacity available in March 2008.
} 
Strategic Bidding in Multiunit Auctions with Capacity Constrained Bidders: The New York Capacity Market

price. For each capacity auction, the functional form of the demand curve, all bids and a unique bidder ID are available. Table 1 shows selected descriptive auction statistics.

\begin{tabular}{l|ccc} 
& mean & $\min$ & $\max$ \\
\hline \hline number of bidders & 15.3 & 3 & 35 \\
number of bids & 19.7 & 4 & 63 \\
offer share largest firm & $66.8 \%$ & $35.8 \%$ & $85.3 \%$ \\
offer share two largest firms & $88.0 \%$ & $66.2 \%$ & $99.8 \%$ \\
offer share three largest firms & $93.7 \%$ & $83.7 \%$ & $100 \%$ \\
\hline \hline
\end{tabular}

Table 1: Auction statistics.

On average 15.3 bidders participated in each auction and submitted around 20 bids (where firm individual stepwise bid functions are decomposed into separate bids at each price). The number of bidders rises over time. In the first auctions, only a few firms, among them the overall larger bidders, participated. The new bidders were small bidders, potentially retailers, who bought too many capacity rights in the forward markets and then sold their excess capacity rights. As table 1 illustrates the largest offer per bidder in each auction was on average $66.8 \%$ of all offered capacity. Together with the second largest bidder, the offer share of the two largest firms already cover on average $88 \%$ of all offers. The three largest firms nearly account for all offered capacity. These numbers indicate that the auction outcome will be determined in the game with two or three bidders. ${ }^{8}$ For ten auctions the ISO had to clear the market, because available capacity was not large enough to clear the auction.

The implementation of the model proceeds in several steps. ${ }^{9}$ First, I check

\footnotetext{
${ }^{8}$ During the period of this study, the major players in the New York electricity market have been Keyspan, NRG, ConEd and Reliant. The largest bidder is with very high probability Keyspan.

${ }^{9} \mathrm{I}$ used matlab to program each step and apply it to the data.
} 
Strategic Bidding in Multiunit Auctions with Capacity Constrained Bidders: The New York Capacity Market

each auction to see if inframarginal bidders are indeed capacity constrained, and if it is optimal for them to submit all their capacity, as derived in Appendix A.1. Then, for each auction, I find the pivotal bidder, subtract all capacity offered by lower bids than the pivotal bid from the demand curve, and calculate the optimal residual monopoly price. I compare this theoretically optimal price to the observed market clearing bid. This comparison shows how close the pivotal firm was to its profit maximizing market clearing bid. I use the theoretically optimal auction clearing bid to calculate the high bidders profits in each auction. I use these profits to back out upper bounds for the low bids as characterized in equation (4). Then I discuss how these bounds describe the observed low bidding patterns. Last, I use the generated data on the pivotal firms profits and the observed data on the demand curve, the capacity and bid offers to estimate different versions of the best response functions in equations (5) and (6).

\section{$5 \quad$ Results}

This section presents the results. I look ex post at the equilibria in each auction, implement the model, and compare the model to the observed bids. In other words, I check if deviation was profitable for some bidders and hence if the firms did not play within the equilibrium as outlined above.

\subsection{Capacity constraints}

Only the offers and not the endowment of capacity (that remains from their forward capacity market commitments) are observable in the data. Therefore Appendix A.1 derives a theoretical limit on the optimal aggregate capacity that would be bid by all inframarginal bidders. If all capacity submitted by the inframarginal bidders is less than this limit, each firm could gain by increasing its capacity offer. In the data, aggregate inframarginal capacity is 
Strategic Bidding in Multiunit Auctions with Capacity Constrained Bidders: The New York Capacity Market

always below the limit, which shows that each inframarginal firm could gain by offering more capacity. This fact allows us to focus on the price game as described in the model section without modeling a capacity market stage prior to the price game. The fact that low bidding firms must be capacity constrained also becomes visible when looking at the optimal pivotal bid discussed below.

\subsection{The pivotal bidder}

As theoretically derived in proposition 2 , the pivotal firm bids the largest amount of capacity. This also holds in the data, in each auction over all years. The largest bidder in table 1 is the pivotal bidder. Hence, firms played an equilibrium as described in proposition 2. When assessing the bidding strategy of the pivotal bidder, the price cap constrains the analyses. When the optimal price is above the price cap, we cannot compare the optimal bid to the observed bid, but only state that the firm behaved optimally in submitting the price cap. This lowers the value of the comparison. Since the price cap was indeed binding, the pivotal firm always submitted the price cap in all auctions. This is in line with the model's prediction. Figure 2 shows that the unconstrained optimal price was (with four minor exceptions) above the price cap, and hence the pivotal bidder maximized profits by submitting a bid at the price cap. In the early years of the market optimal residual monopoly prices were significantly above the price cap. As the market capacity increased over time, the optimal high bid declines and during summer months almost equaled the price cap in the later auctions. Figure 2 also reveals the constrained nature of the low bidding firms. Especially in the early auctions bids below the pivotal bid could have offered more capacity without decreasing the auction price.

Figure 2 also shows that the regulatory bid cap, which was around $7 \$ / \mathrm{kw}-$ month during winter months and at around $12 \$ / \mathrm{kw}$-month during the sum- 
Strategic Bidding in Multiunit Auctions with Capacity Constrained Bidders: The New York Capacity Market

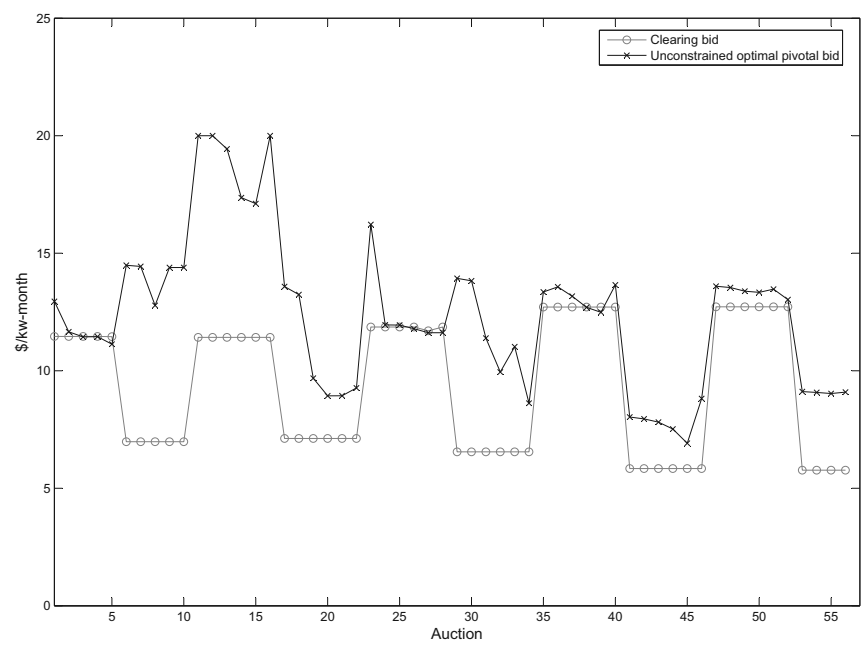

Figure 2: Modeled and observed high bids for auctions June 2003 to March 2008.

mer period, is significantly constraining the bid in the first auctions, while in the later auctions it did not substantially constrain the high bidder. The strategic importance of the price cap also adds to the debate among policymakers on whether capacity market demand should be linear and price elastic or completely inelastic, see e.g. The Brattle Group (2009). The above results illustrate that clearing prices for capacity do not necessarily change depending on whether demand is elastic or completely inelastic, if the price cap is binding in both cases. 
Strategic Bidding in Multiunit Auctions with Capacity Constrained Bidders: The New York Capacity Market

\subsection{Inframarginal bids}

This subsection compares to what extent the observed bids fall into the bounds derived in equation (4). Bids for which $D\left(b_{j}\right)-K_{j-1}>\bar{k}_{m}$ holds are denoted by $b_{j}^{I}$, while the bound for those bids is denoted by $\bar{b}^{I}$. Bids for which $D\left(b_{j}\right)-K_{j-1} \leq \bar{k}_{m}$ holds are denoted by $b_{j}^{I I}$, while the bounds for those bids are denoted by $\bar{b}_{j}^{I I}$. The comparison shows that the bounds fit the observed low bids to a high degree. In total, in the 56 auctions 1100 bids were submitted. Not accounting for 239 bids that were submitted when capacities were very scarce and the ISO had to set the price, 861 bids were submitted in total when the auction was cleared. Of these 861 bids, 96 bids came from the pivotal firm, leaving 765 inframarginal bids. Eventually, of these 765 inframarginal bids, 346 are bids that follow bounds $\bar{b}_{j}^{I I}$ and 40, that follow bounds $\bar{b}^{I}$, while 379 bids were bids below $b_{j}^{I}$, that all face the same bound determined by $\bar{b}^{I}$. As the next table shows, only the bids $b_{j}^{I}$ show significant deviations from the model. In $15 \%$ of all cases, the firms bid above the bound $\bar{b}^{I}$. However, $12.5 \%$ percentage points of those violations come from the first five auction rounds. It can be conjectured that firms learned over time, and lowered their bid accordingly. Neglecting the first five auction rounds, more than $95 \%$ of all strategic inframarginal bids can be explained by the model. Table 2 lists the percentage of observed bids that are higher than their modelled bounds.

\begin{tabular}{ccc} 
Bound & Frequency & Violations in \% \\
\hline \hline $\bar{b}^{I}$ & 40 & $15 \%$ \\
$\bar{b}_{j}^{I I}$ & 346 & $4.6 \%$ \\
\hline $\bar{b}^{I}$ and $\bar{b}_{j}^{I I}$ & 386 & $5.6 \%$ \\
\hline \hline
\end{tabular}

Table 2: Frequencies and violations of bounds.

While in some auctions many firms simply bid the lowest possible bid of zero, in other auctions a lot of capacity is offered at higher prices close to 
Strategic Bidding in Multiunit Auctions with Capacity Constrained Bidders: The New York Capacity Market

the bounds. Figure 3 shows the example of auction number 40, and plots the bounds and the optimal high bid.

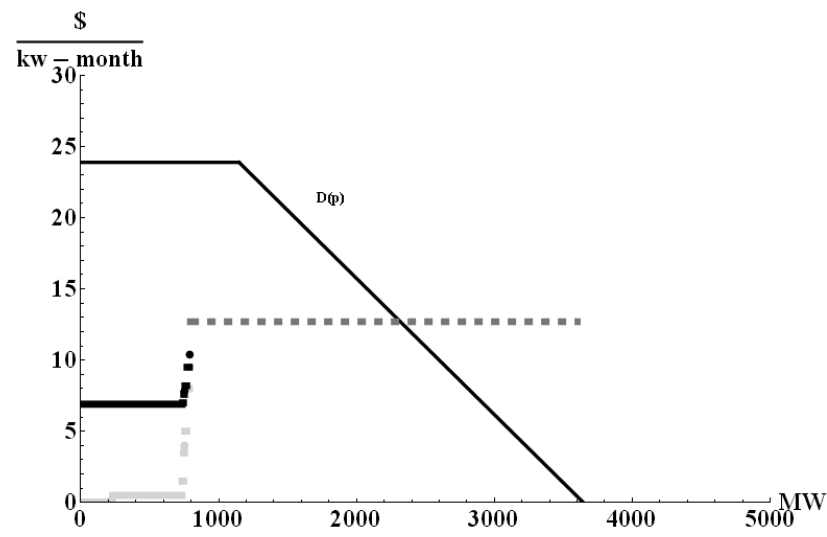

Figure 3: Auction 40 and calculated bounds for the bids.

In this auction the optimal monopoly price and the observed firm's bid (the dashed line) were the price cap. The gray lines are the low bids. A lot of capacity was submitted at prices close to zero. The thick black lines plot the bounds for inframarginal capacities. In this particular auction all firms submitted bids below the bounds. The largest inframarginal bid, in terms of capacity, was submitted at a price of $0.5 \$ / \mathrm{kw}$-month, whereas this bid could have been submitted up to a bid of around $7 \$ / \mathrm{kw}-$ month to not be profitably undercut by the pivotal firm.

\subsubsection{Best response function regressions}

While like in auction 40 most of the low bids were submitted at relatively low levels below the bound, over all auctions a lot of bids were submitted just below the bound. Figure 4 shows a histogram of each bids' difference to 
Strategic Bidding in Multiunit Auctions with Capacity Constrained Bidders: The New York Capacity Market

its bound. At 0 , the bid was zero, while at 100, the submitted bid was equal to its bound. Values above 100 signal the percentage of bids that violated their bound, as described in table 2 .

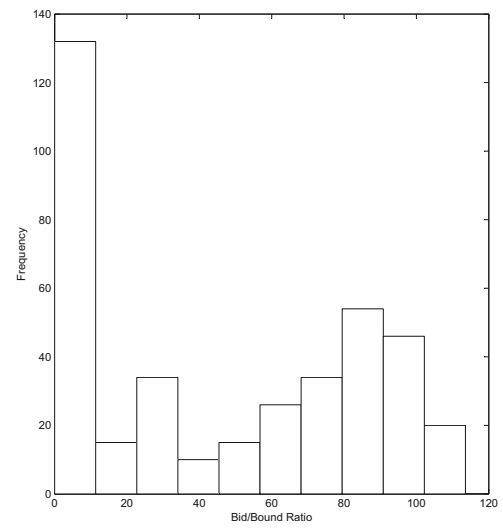

Figure 4: Density bid-bound ratio.

The histogram in figure 4 only depicts bids that fall in the categories of $\bar{b}^{I}$ and $\bar{b}^{I I}$, and shows that firms chose to submit bids at the ends of the support of its allowed interval $b_{j} \in\left[0, \bar{b}_{j}\right]$. In the following I use the fact that a number of bids were submitted just below the bound.

I use the best response functions in equations (5) and (6) with the observed bids instead of their modeled bounds. Note that in each auction, there can only be one bid that satisfies the conditions for $b_{j}^{I}$, and thus we only have a very small number of observations to estimate equation (5). However, results for estimating $b_{j}^{I}$ are supported by the estimation results for the model in equation (6), which are presented below and are based on a sufficient number of observations. For testing equation (5), I regress the $\log$ of the bid $b_{j}^{I}$ on the 
Strategic Bidding in Multiunit Auctions with Capacity Constrained Bidders: The New York Capacity Market

$\log$ of pivotal bidders profits and the $\log$ of the pivotal bidders capacity in each auction. ${ }^{10}$ I add the reservation price, denoted by $p(0)$, of each auction and a dummy for winter months to control for the level of demand, because otherwise a higher demand would simply inflate profits and bids alike. For equation (5) I estimate

$$
\ln \left(b_{j}^{I}\right)=\beta_{0}+\beta_{1} \ln \left(\pi_{m}\right)+\beta_{2} \ln \left(k_{m}\right)+\beta_{3} \ln (p(0))+\beta_{4} D_{W} .
$$

Column one in table 3 presents the regression results. The coefficients show a significant and positive relation of low bids, $\ln \left(b_{j}^{I}\right)$, to pivotal profits, $\ln \left(\pi_{m}\right)$. When the pivotal bidder earns more profits, undercutting becomes less attractive, and the low bidding firms can submit higher prices. The regression also shows that the more capacity the high bidder has available, $\ln \left(k_{m}\right)$, the lower is the bid by inframarginal bidders. When the high bidder holds large capacities, undercutting is more profitable and inframarginal bidders decrease their bids.

Similar results are shown in the results for bids that belong to the bound $\bar{b}^{I I}$. Here, in each auction several bids could have a bound according to $\bar{b}^{I I}$. Besides the variables derived from equation (6) I add the reservation price again. The dummy is excluded since all these bids occur in summer months. I estimate

$$
\ln \left(b_{j}^{I I}\right)=\beta_{0}+\beta_{1} \ln \left(\pi_{m}\right)+\beta_{2} \ln \left(D\left(b_{j}\right)-K_{j-1}\right)+\beta_{3} \ln (p(0)) .
$$

Results can be found in the second column in the regression table 3 in the tables section. Again, now with a sufficient number of observations, the intuition is confirmed. When the large bidder has relatively higher residual demand when underbidding, $\ln \left(D\left(b_{j}\right)-K_{j-1}\right)$, low bids are decreasing to make underbidding less profitable. To confirm the validity I re-run the second model only with bids that were submitted at above $70 \%$ of their bound. These

\footnotetext{
${ }^{10}$ Because bids can be exactly zero, I normalize the $\log$ of the bids to $\log$ (bids +2 ).
} 
Strategic Bidding in Multiunit Auctions with Capacity Constrained Bidders: The New York Capacity Market

\begin{tabular}{|c|c|c|}
\hline & $\begin{array}{c}(1) \\
\ln \left(b_{j}^{I}\right)\end{array}$ & $\begin{array}{c}(2) \\
\ln \left(b_{j}^{I I}\right)\end{array}$ \\
\hline $\ln \left(\pi_{m}\right)$ & $\begin{array}{c}2.046^{* * *} \\
(11.14)\end{array}$ & $\begin{array}{c}0.923^{* * *} \\
(31.87)\end{array}$ \\
\hline $\ln \left(k_{m}\right)$ & $\begin{array}{c}-2.150^{* * *} \\
(-12.33)\end{array}$ & \\
\hline $\ln (p(0))$ & $\begin{array}{c}0.596^{* *} \\
(3.06)\end{array}$ & $\begin{array}{c}0.160^{* *} \\
(2.96)\end{array}$ \\
\hline$D_{W}$ & $\begin{array}{c}0.696^{* * *} \\
(5.09)\end{array}$ & \\
\hline $\ln \left(D\left(b_{j}\right)-K_{j-1}\right)$ & & $\begin{array}{c}-1.521^{\text {*** }} \\
(-34.39)\end{array}$ \\
\hline _cons & $\begin{array}{c}-3.780^{* * *} \\
(-3.70)\end{array}$ & $\begin{array}{c}4.099^{* * *} \\
(10.21)\end{array}$ \\
\hline$N$ & 40 & 346 \\
\hline
\end{tabular}

Table 3: Regression results for low bidders' best response functions.

regressions support the above results and can be found in Appendix B.

\subsubsection{Profit equivalence of low bids}

As shown in the model section multiple equilibria exist, in which $b_{j} \in\left[0, \bar{b}_{j}\right]$ holds and inframarginal firms can bid any bid in between zero and their bound. Low bidding firms' profits are independent of their own bid as long as they bid low enough to not be undercut. The model disregards other strategic behavior among inframarginal bidders. To confirm the strategic independence among inframarginal bidders there should be no difference in the level of the bid depending on other bidder characteristics such as firm 
Strategic Bidding in Multiunit Auctions with Capacity Constrained Bidders: The New York Capacity Market

size. Figure 5 plots the bid-bound ratio over submitted capacity. Firms that submitted relatively small capacity might be retailers reselling capacity rights. Observations to the far out on the $\mathrm{x}$-axis are bids submitted by larger firms.

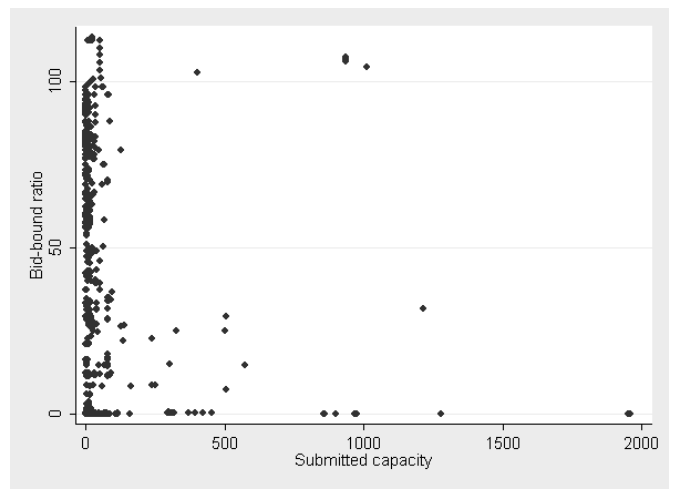

Figure 5: Bid-bound ratio over submitted capacity.

As figure 5 shows, there is no relation between the level of the bid and the submitted capacity, supporting the model and the profit equivalence among bids between zero and their bound.

\subsection{Counterfactuals}

\subsubsection{No capacity withholding}

Capacity markets should reward the true aggregate market capacity. As shown, gaming in this auction leads to significant withholding by the pivotal bidder. The auction price is too high relative to the actual capacity scarcity. As a counterfactual I calculate the auction price that would occur if all capacity was submitted to the auction, and the pivotal player would not withhold any capacity. I find the hypothetical auction price, $p^{h}$, that fulfills 
Strategic Bidding in Multiunit Auctions with Capacity Constrained Bidders: The New York Capacity Market

$D\left(p^{h}\right)=K_{M}$. Then I apply this hypothetical price on the full demand curve (spot and forward markets). Subtracting the 'no withholding market volume' from the real and observed market volume yields the potential savings. If the market would have rewarded capacity according to the true capacity scarcity the cumulative firms' rents would decrease on average by about $\$ 415$ million a year. The ISO would then procure the full market capacity at about $40 \%$ less of the costs. ${ }^{11}$ A comparison of the realized auction price and the calculated auction price if all capacity was submitted is shown in figure 6 .

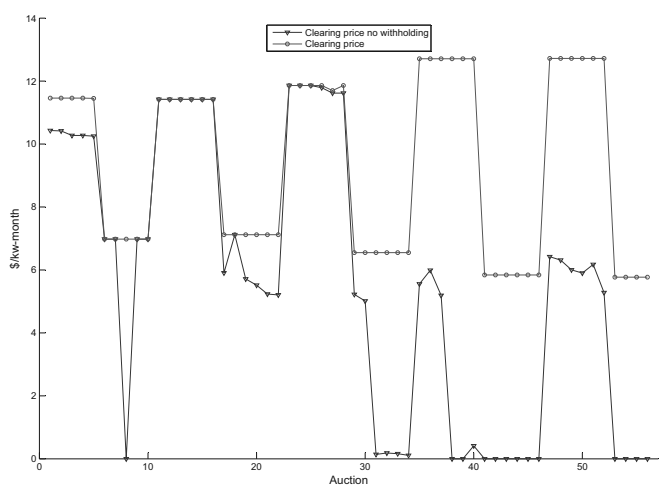

Figure 6: Real and counterfactual clearing price.

From figure 6 we can conjecture that high capacity prices in the early years of the market resulted in an increase in capacity over the years and hence the hypothetical market price without withholding falls over time, taking into account different demand in summer and winter periods. ${ }^{12}$

\footnotetext{
${ }^{11}$ This counterfactual is robust to the assumption of zero costs as long as the hypothetical market clearing price is above the marginal costs.

${ }^{12}$ I do not have an explanation for auction 8, in which compared to other auctions in that year more capacity entered the auction and could have resulted in a clearing price of
} 
Strategic Bidding in Multiunit Auctions with Capacity Constrained Bidders: The New York Capacity Market

\subsubsection{Bid floors}

New regulations in April 2008 introduced a bidding floor for newly participating resources and a pivotal supplier test including a must offer of all capacity for pivotal firms. The bid floor was implemented at 0.75 times of the estimated net cost of entry (Net Cone). All new built capacity participating for the first time had to bid above this floor. The bid floor was introduced to prevent uneconomic entry. Opposing to the NYISO regulations, this counterfactual assumes that a bid floor is implemented for all participating units. A bid floor for all capacity bids can change the equilibrium price if the bid floor is higher than at least one bound derived in equation (4). Firms are forced to bid higher and it becomes profitable to undercut for the pivotal firm. In this way a bid floor can lower the equilibrium price. For the counterfactual I use a bid floor of 0.75 times Net Cone like it is required for the new resources that entered the market after April 2008. The results show that under this bid floor regime the pivotal firm would have profitably undercut and the equilibrium price would have been lower for 12 out of 56 auctions. When the pivotal firm undercuts and also prices at the bid floor, the ISO can effectively use a well adjusted bid floor to lower the market price. Generally the ISO faces a trade-off between the frequency and the amount of price reductions. If the bid floor is too low, the equilibria as described in equations (3) and (4) are still feasible. If the bid floor is too high, the market price becomes higher than without the bid floor. Calculations using a bid floor of only 0.5 times Net Cone show that then the outcome of only 7 auctions would change, but therefore yielding lower auction prices.

zero. One possibility is that the pivotal bidder did not sell enough capacity on the forward market and submitted all remaining capacity to the spot auction. 
Strategic Bidding in Multiunit Auctions with Capacity Constrained Bidders: The New York Capacity Market

\section{Conclusion}

This paper developed a simple multiunit uniform price auction model and applied it to data from the NYISO capacity auctions. The results show that the model describes the behavior in the auction to a high degree. The pivotal bidder offers the largest capacity and submits the clearing price in each auction. In this way the firms co-ordinate on an equilibrium that extracts high rents from the auctioneer. Modeled bounds for inframaginal bids describe around $95 \%$ of the observed bid patterns. Where bounds were violated and bids could have profitably been undercut by the pivotal firm, bidders seem to learn over time. A majority of bids that could have been profitably underbid were submitted in the first five auctions, and the magnitude of non-optimal low bids decreases after the first five auctions. Inframarginal firms reacted to the pivotal firm's profits and its profits of undercutting by adjusting their inframarginal bids. During the period studied from 2003 to 2008, the capacity market in New York did not clear as intended and was rewarding capacity at too high prices. Capacity markets, if designed in the form studied here, are a costly tool to overcome the problem of supply security and supply adequacy in electricity markets. Counterfactual calculations show that bid floors have the potential to lower capacity market prices.

\section{A Appendix}

\section{A.1 Capacity offers by inframarginal bidders}

I derive a limit on the optimal aggregate capacity submitted by all inframarginal bidders, $K_{m-1}$. The residual monopoly price that optimizes equation (3) can be rewritten as $\min \left\{\frac{a-\sum_{i=1}^{m-1} k_{i}}{2 d}, b^{c a p}\right\}$, where $b^{c a p}$ is the bid cap and $a$ and $d$ are demand at a price of zero and the demand slope respectively. Profits of inframarginal firms become $\pi_{i \neq m}=$ $\min \left\{\frac{a-\sum_{i=1}^{m-1} k_{i}}{2 d}, b^{c a p}\right\} k_{i}$. If the bid cap is not binding, $\min \left\{\frac{a-\sum_{i=1}^{m-1} k_{i}}{2 d}, b^{c a p}\right\}=\frac{a-\sum_{i=1}^{m-1} k_{i}}{2 d}$, taking the F.O.C with respect to $k_{i}, \frac{\partial \pi_{i \neq m}}{\partial k_{i}}$, yields $k_{i}^{*}=a-\sum_{i=1}^{m-1} k_{i}$. Summing up all 
optimal capacity offers of each firm $i$ and assuming symmetry of low bidding firms we arrive at an aggregate optimal capacity offer of all inframarginal firms of $\sum_{i=1}^{m-1} k_{i}=$ $\frac{(m-1) a}{m}$, which is increasing in $\mathrm{m}$. Observing less aggregate capacity by inframarginal bidders in one auction means that each bidder could have gained by increasing its capacity offer and hence must be constrained. If the pivotal firm is constrained by the bid cap, $\min \left\{\frac{a-\sum_{i=1}^{m-1} k_{i}}{2 d}, b^{c a p}\right\}=b^{c a p}$, the limit on the optimal aggregate inframarginal capacity can be found by solving $\frac{a-\sum_{i=1}^{m-1} k_{i}}{2 d}=b^{c a p}$, which yields $\sum_{i=1}^{m-1} k_{i}=a-2 d b^{c a p}$. The bid cap increases the optimal aggregate inframarginal capacity until the residual monopoly price equals the price cap.

\section{A.2 Equilibria in wich the largest firm is pivotal}

All equilibria in which the largest firm is the pivotal bidder and all smaller firms bid inbetween zero and their bound always exist, because smaller firms never have an incentive to overbid the pivotal firm. If small bidders overbid, the largest bidder will be among the inframarginal bidders and aggregate inframarginal capacity increases. This results in a lower residual demand for the overbidding small firm, than the residual demand the largest firm was facing. The auction price decreases, compared to the situation in which the largest firm is pivotal. Hence, all smaller firms always sell all their capacity at the highest possible price, when being among the low bidders. Overbidding the pivotal and largest firm decreases the auction price, and potentially also the sold quantity for the overbidding small firm.

\section{A.3 Conditions for the largest firm to be pivotal}

When firm sizes are sufficiently asymmetric, the multiplicity of equilibria in the auction outcome reduces to a smaller set of equilibria, in which the largest firm is the pivotal bidder and all smaller firms submit bids between zero and their upper bounds. Suppose all but the largest firms have an aggregate capacity of $K_{m-1}$, while the largest pivotal bidder has a capacity of $k_{m}$. If $k_{m}$ is sufficiently larger than the sum of all the small firms' capacities $K_{m-1}$, the large firm always would like to overbid smaller pivotal bidders and maximize its profits by submitting the market clearing high bid. To see this, note that the simple residual monopoly price is $\frac{a-K_{m-1}}{2 d}$, where $a$ is the demand at a price of zero and $d$ is the demand slope. Residual monopoly profits of the large firm can be derived 


\section{Strategic Bidding in Multiunit Auctions with Capacity Constrained} Bidders: The New York Capacity Market

as $\frac{\left(a-K_{m-1}\right)^{2}}{4 d}$. When not being the pivotal bidder but among the low bidders, the largest firm can earn the highest profits when beeing the lowest bidder, and leaving the highest possible residual demand for smaller and auction clearing firms. These highest profits for the large firm, when being inframarginal, are the profits when the next highest bid by a smaller firm is alrady the pivotal bid. In this case the large firm earns profits of $\frac{a-k_{m}}{2 d} k_{m}$. Hence, for $\frac{a-k_{m}}{2 d} k_{m}<\frac{\left(a-K_{m-1}\right)^{2}}{4 d}$, the largest firm will always overbid all smaller pivotal bidders. Rearranging yields the sufficient but not neccessary condition of firm sizes for which the largest player would never be among the low bidders. For all $k_{m}$ and $K_{m-1}$ that satisfy

$$
K_{m-1} \leq \sqrt{2\left(a-k_{m}\right) k_{m}}
$$

there is only one set of equilibria in which the largest firm with capacity $k_{m}$ is the pivotal bidder.

When the bid cap is binding for the pivotal firm, $\min \left\{\frac{a-\sum_{i=1}^{m-1} k_{i}}{2 d}, b^{c a p}\right\}=b^{c a p}$, condition (9) changes. Profits of the pivotal firm $m$ are now $\left(D\left(b^{c a p}\right)-K_{m-1}\right) b^{c a p}$, while if among the low bidders, with a similar reasoning as above, profits are at $\operatorname{most} \min \left\{\frac{a-k_{m}}{2 d}, b^{\text {cap }}\right\} k_{m}$. Whenever $\min \left\{\frac{a-k_{m}}{2 d}, b^{c a p}\right\}=b^{c a p}$, and we compare pivotal and low bidding profits, $\left(D\left(b^{c a p}\right)-K_{m-1}\right) b^{c a p}=b^{c a p} k_{m}$, the largest firm never wants to overbid and become pivotal when being among the low bidders, unless $D\left(b^{c a p}\right)-K_{m-1}>k_{m}$ holds and the auction does not clear. When however $\min \left\{\frac{a-k_{m}}{2 d}, b^{c a p}\right\}=\frac{a-k_{m}}{2 d}$, what happens as long as

$$
k_{m}>a-2 d b^{c a p},
$$

we compare pivotal and low bidding profits $\left(D\left(b^{c a p}\right)-K_{m-1}\right) b^{c a p}=\frac{a-k_{m}}{2 d} k_{m}$ and find that as long as

$$
K_{m-1}<D\left(b^{c a p}\right)-\frac{a-k_{m}}{2 d b^{c a p}} k_{m}
$$

holds, the largest firm always wants to be the pivotal bidder. Hence, whenever the price cap is not binding and condition (9) holds, or whenever the price cap is binding for the largest firm when being pivotal and conditions (10) and (11) hold, there is only one set of equilibria in which the largest firm with capacity $k_{m}$ is the pivotal bidder. 
Strategic Bidding in Multiunit Auctions with Capacity Constrained Bidders: The New York Capacity Market

\section{B Tables}

Table 1: Model for equation (6) with bid bound ratio larger than 0.7.

\begin{tabular}{lc}
\hline \hline & $(1)$ \\
& $\ln \left(b_{j}^{I I}\right)$ \\
\hline $\ln \left(\pi_{m}\right)$ & $(30.16)$ \\
& $-0.699^{* * * *}$ \\
$\ln \left(D\left(b_{j}\right)-K_{j-1}\right)$ & $(-12.01)$ \\
& 0.0276 \\
& $(0.77)$ \\
$\ln (p(0))$ & 0.180 \\
& $(0.68)$ \\
ccons & 133 \\
\hline$N$ & \\
\hline \hline$t$ statistics in parentheses \\
$* p<0.05,{ }^{* *} p<0.01,{ }^{* * *} p<0.001$
\end{tabular}

\section{References}

Crampes, Claude and Anna Creti (2005) "Capacity Competition in Electricity Markets," Economia delle Fonti di Energia e dell'Ambiente.

Cramton, Peter and Steven Stoft (2005) "A Capacity Market that Makes Sense," The Electricity Journal, Vol. 18, No. 7, pp. 43-54.

Fabra, Natalia, Nils-Henrik Von der Fehr, and Maria-Angeles de Frutos (2011) "Market Design and Investment Incentives," The Economic Journal, Vol. Doi: 10.1111.

Fabra, Natalia, Nils-Henrik Von der Fehr, and David Harbord (2006) "Designing Electricity Auctions," RAND Journal of Economics, Vol. 37, No. 1, pp. 23-46. 
Strategic Bidding in Multiunit Auctions with Capacity Constrained Bidders: The New York Capacity Market

Green, Richard and David Newberry (1992) "Competition in the British Electricity Spot Market," Journal of Political Economy, Vol. 100, No. 5.

Harbord, David and Nils-Henrik Von der Fehr (1993) "Spot Market Competition in the UK Electricity Industry," The Economic Journal, Vol. 103, No. 418, pp. 531-546.

Hogan, William (2005) "On an Energy Only Electricity Market Design for Resource Adequacy," Harvard University, Mimeo.

Hortacsu, Ali and Steven Puller (2008) "Understanding strategic bidding in multi-unit auctions: a case study of the Texas electricity spot market," Rand Journal of Economics, Vol. 39, No. 1, p. 86114.

Klemperer, Paul D. and Margaret A. Meyer (1989) "Supply Function Equilibria in Oligopoly under Uncertainty," Econometrica, Vol. 57, No. 6.

LeCoq, Chloé (2002) "Strategic Use of Available Capacity in the Electricity Spot Market," SSE/EFI Working Paper, Series in Economics and Finance, No. 496.

Oren, Samuel and Feiredon Sioshansi (2007) "How Good are Supply Function Equilibrium Models: An Empirical Analysis of the ERCOT Balancing Market," Journal of Regulatory Economics, Vol. 31, No. 1, pp. 1-35.

Stoft, Steven (2002) "Power System Economics," IEEE Press and Wiley-Interscience.

The Brattle Group (2009) "Cost-Benefit Analysis of Replacing the NYISOs Existing ICAP Market with a Forward Capacity Market," Report prepared for the New York Independent System Operator.

Wilson, Robert (1979) "Auctions of Shares," The Quarterly Journal of Economics, Vol. 93, No. 4 .

Wolak, Frank A. (2000) "An Empirical Analysis of the Impact of Hedge Contracts on Bidding Behavior in a Competitive Electricity Market," International Economic Journal, Vol. 14, No. 2.

Wolfram, Cathrine (1998) "Strategic Bidding in a Multiunit Auction: An Empirical Analysis of Bids to Supply Electricity in England and Wales," The RAND Journal of Economics, Vol. 29, No. 4, pp. 703-725. 


\section{Conclusion}

Security of supply in electricity markets is determined by power generating firms who decide on prices and production capacities while facing stochastic demand and intermittent production technologies. This dissertation consists of three chapters that each deal with the effects of market design on the firms' decision to produce and the consumers' choice to consume electricity, and how their actions combine to determine security of supply.

The first chapter asks to what extent a duopolistic power market can solve efficiency and supply security requirements. I show that in a duopoly market the wholesale auction is characterized by prices above marginal costs and that blackout probabilities can arise through capacity withholding rather than capacity scarcity. In equilibrium, one larger firm prices higher and sells power at the margin, while the smaller firm bids lower energy prices and withholds inframarginal capacity. Only the larger firm has an incentive to maintain balanced grids and supply all stochastic demand. The smaller firm risks blackouts when maximizing profits. When the system operator faces high demand that leads to a shortage of supply, and thus has to buy more energy, the smaller firm then becomes a monopolist for out of market purchases.

Then I analyze how markets can be designed to support secure supply and minimize blackouts through bid based capacity remuneration mechanisms. When regulators implement capacity remuneration mechanisms, available peak capacity increases, however only if capacity is remunerated above its marginal costs of being available. In that case, capacity mechanisms lower blackout probabilities, but increase energy price volatility. I find that energy price caps reduce price volatility without effecting system security in the short run. Hence, energy price caps and capacity mechanisms can mitigate market power in the energy market, but at high costs for available peak 
Conclusion

capacity. The choice of market design depends on regulatory preferences for supply security. That is, on how much costs regulators are willing to spend for secure supply and on how far regulators are willing to administer capacity mechanisms that distort energy price signals in the long run.

The second chapter analyzes how smart metering can soften the market design problem as discussed in the first chapter and increase market efficiency. The focus of the analysis lies on welfare effects of smart metering when consumers are risk-averse and generating firms have market power. Whether real-time pricing enhances welfare depends on the firms' capacities, the magnitude of the demand shock and on the proportion of consumers on real-time pricing schemes. With large firm capacities that always lead to Bertrand prices, there is no difference in welfare when all or no consumers are on realtime pricing. When firms' capacities are smaller such that market power arises, firms can price relatively high in times of high demand shocks. When this is the case, real-time pricing decreases consumer surplus, because risk averse consumers dislike high and uncertain prices. At the same time realtime pricing increases producer surplus, because more wholesale customers pay a real-time price above marginal costs. These two opposing effects lead to a U-shaped welfare in smart metering whenever the demand shock can change the equilibrium price. If however firms' capacities are relatively large and the demand shock does not change the wholesale price, smart metering can increase consumer surplus and welfare. The findings suggest that, before investing in smart meters and smart grids, aggregate market capacities, dominant firm behavior, and the welfare gain of insuring against price fluctuations through fixed retail prices should be taken into consideration.

The last chapter takes the market design discussion to data. I develop a simple multiunit uniform price auction model and apply it to data from the New York ISO capacity auctions. The results show that the simple model describes the behavior in the auction to a high degree. As predicted by the model, the pivotal bidder offers the largest amount of capacity and submits 
the clearing price in each auction. In this way the firms co-ordinate on an equilibrium that extracts high rents from the auctioneer. Where observed bids violated the model and could have profitably been undercut by the pivotal firm, bidders seem to learn over time. A majority of bids that according to the model could have been profitably underbid were submitted in the first five auctions, and the magnitude of non-optimal inframarginal bids decreases thereafter. Small firms adjusted their bids according to the largest firm's profits of undercutting, thereby making undercutting not profitable. During the period studied from 2003 to 2008, the capacity market in New York did not clear as intended by the system operator and was rewarding capacity at too high prices. Capacity remuneration mechanisms, if designed in the form of the capacity auctions studied here, are a costly tool to promote supply security and supply adequacy in electricity markets. 
TITLER I PH.D.SERIEN:

\section{4}

1. Martin Grieger

Internet-based Electronic Marketplaces and Supply Chain Management

2. Thomas Basbøll

LIKENESS

A Philosophical Investigation

3. Morten Knudsen

Beslutningens vaklen

En systemteoretisk analyse of mo-

derniseringen af et amtskommunalt

sundhedsvæsen 1980-2000

4. Lars Bo Jeppesen

Organizing Consumer Innovation

A product development strategy that is based on online communities and allows some firms to benefit from a distributed process of innovation by consumers

5. Barbara Dragsted

SEGMENTATION IN TRANSLATION

AND TRANSLATION MEMORY

SYSTEMS

An empirical investigation of cognitive segmentation and effects of integrating a TM system into the translation process

6. Jeanet Hardis

Sociale partnerskaber

Et socialkonstruktivistisk casestudie af partnerskabsaktørers virkelighedsopfattelse mellem identitet og legitimitet

7. Henriette Hallberg Thygesen

System Dynamics in Action

8. Carsten Mejer Plath

Strategisk Økonomistyring

9. Annemette Kjærgaard

Knowledge Management as Internal

Corporate Venturing
- a Field Study of the Rise and Fall of a Bottom-Up Process

10. Knut Arne Hovdal

De profesjonelle i endring

Norsk ph.d., ej til salg gennem

Samfundslitteratur

11. Søren Jeppesen

Environmental Practices and Greening

Strategies in Small Manufacturing

Enterprises in South Africa

- A Critical Realist Approach

12. Lars Frode Frederiksen

Industriel forskningsledelse

- på sporet af mønstre og samarbejde

i danske forskningsintensive virksom-

heder

13. Martin Jes Iversen

The Governance of GN Great Nordic

- in an age of strategic and structural transitions 1939-1988

14. Lars Pynt Andersen

The Rhetorical Strategies of Danish TV

Advertising

A study of the first fifteen years with special emphasis on genre and irony

15. Jakob Rasmussen

Business Perspectives on E-learning

16. Sof Thrane

The Social and Economic Dynamics

of Networks

- a Weberian Analysis of Three

Formalised Horizontal Networks

17. Lene Nielsen

Engaging Personas and Narrative

Scenarios - a study on how a user-

centered approach influenced the perception of the design process in the e-business group at AstraZeneca

18. S.J Valstad

Organisationsidentitet

Norsk ph.d., ej til salg gennem

Samfundslitteratur 
19. Thomas Lyse Hansen

Six Essays on Pricing and Weather risk in Energy Markets

20. Sabine Madsen

Emerging Methods - An Interpretive

Study of ISD Methods in Practice

21. Evis Sinani

The Impact of Foreign Direct Investment on Efficiency, Productivity Growth and Trade: An Empirical Investigation

22. Bent Meier Sørensen

Making Events Work Or,

How to Multiply Your Crisis

23. Pernille Schnoor

Brand Ethos

Om troværdige brand- og

virksomhedsidentiteter i et retorisk og

diskursteoretisk perspektiv

24. Sidsel Fabech

Von welchem Österreich ist hier die

Rede?

Diskursive forhandlinger og magtkampe mellem rivaliserende nationale identitetskonstruktioner i østrigske pressediskurser

25. Klavs Odgaard Christensen Sprogpolitik og identitetsdannelse $i$ flersprogede forbundsstater Et komparativt studie af Schweiz og Canada

26. Dana B. Minbaeva

Human Resource Practices and

Knowledge Transfer in Multinational

Corporations

27. Holger Højlund

Markedets politiske fornuft

Et studie af velfærdens organisering i perioden 1990-2003

28. Christine Mølgaard Frandsen

A.s erfaring

Om mellemværendets praktik i en transformation af mennesket og

subjektiviteten

29. Sine Nørholm Just

The Constitution of Meaning

- A Meaningful Constitution?

Legitimacy, identity, and public opinion

in the debate on the future of Europe

\section{5}

1. Claus J. Varnes

Managing product innovation through rules - The role of formal and structured methods in product development

2. Helle Hedegaard Hein

Mellem konflikt og konsensus

- Dialogudvikling på hospitalsklinikker

3. Axel Rosenø Customer Value Driven Product Innovation - A Study of Market Learning in New Product Development

4. Søren Buhl Pedersen

Making space

An outline of place branding

5. Camilla Funck Ellehave

Differences that Matter

An analysis of practices of gender and organizing in contemporary workplaces

6. Rigmor Madeleine Lond

Styring af kommunale forvaltninger

7. Mette Aagaard Andreassen

Supply Chain versus Supply Chain

Benchmarking as a Means to

Managing Supply Chains

8. Caroline Aggestam-Pontoppidan

From an idea to a standard

The UN and the global governance of accountants' competence

9. Norsk ph.d.

10. Vivienne Heng Ker-ni

An Experimental Field Study on the 
Effectiveness of Grocer Media

Advertising

Measuring Ad Recall and Recognition,

Purchase Intentions and Short-Term

Sales

11. Allan Mortensen

Essays on the Pricing of Corporate

Bonds and Credit Derivatives

12. Remo Stefano Chiari

Figure che fanno conoscere

Itinerario sull'idea del valore cognitivo e espressivo della metafora e di altri tropi da Aristotele e da Vico fino al cognitivismo contemporaneo

13. Anders Mcllquham-Schmidt

Strategic Planning and Corporate

Performance

An integrative research review and a meta-analysis of the strategic planning and corporate performance literature from 1956 to 2003

14. Jens Geersbro

The TDF - PMI Case

Making Sense of the Dynamics of

Business Relationships and Networks

15 Mette Andersen

Corporate Social Responsibility in

Global Supply Chains

Understanding the uniqueness of firm behaviour

16. Eva Boxenbaum

Institutional Genesis: Micro - Dynamic Foundations of Institutional Change

17. Peter Lund-Thomsen

Capacity Development, Environmental Justice NGOs, and Governance: The Case of South Africa

18. Signe Jarlov

Konstruktioner af offentlig ledelse

19. Lars Stæhr Jensen

Vocabulary Knowledge and Listening Comprehension in English as a Foreign Language
An empirical study employing data elicited from Danish EFL learners

20. Christian Nielsen

Essays on Business Reporting

Production and consumption of

strategic information in the market for information

21. Marianne Thejls Fischer

Egos and Ethics of Management

Consultants

22. Annie Bekke Kjær

Performance management i Proces-

innovation

- belyst i et social-konstruktivistisk

perspektiv

23. Suzanne Dee Pedersen

GENTAGELSENS METAMORFOSE

Om organisering af den kreative gøren

$i$ den kunstneriske arbejdspraksis

24. Benedikte Dorte Rosenbrink

Revenue Management

Økonomiske, konkurrencemæssige \&

organisatoriske konsekvenser

25. Thomas Riise Johansen

Written Accounts and Verbal Accounts The Danish Case of Accounting and Accountability to Employees

26. Ann Fogelgren-Pedersen

The Mobile Internet: Pioneering Users'

Adoption Decisions

27. Birgitte Rasmussen

Ledelse i fællesskab - de tillidsvalgtes fornyende rolle

28. Gitte Thit Nielsen

Remerger

- skabende ledelseskræfter i fusion og opkøb

29. Carmine Gioia

A MICROECONOMETRIC ANALYSIS OF MERGERS AND ACQUISITIONS 
30. Ole Hinz

Den effektive forandringsleder: pilot, pædagog eller politiker?

Et studie $i$ arbejdslederes meningstilskrivninger i forbindelse med vellykket gennemforelse af ledelsesinitierede forandringsprojekter

31. Kjell-Åge Gotvassli

Et praksisbasert perspektiv på dynamiske

læringsnettverk i toppidretten

Norsk ph.d., ej til salg gennem

Samfundslitteratur

32. Henriette Langstrup Nielsen

Linking Healthcare

An inquiry into the changing performances of web-based technology for asthma monitoring

33. Karin Tweddell Levinsen

Virtuel Uddannelsespraksis

Master i IKT og Læring - et casestudie i hvordan proaktiv proceshåndtering kan forbedre praksis i virtuelle læringsmiljøer

34. Anika Liversage

Finding a Path

Labour Market Life Stories of Immigrant Professionals

35. Kasper Elmquist Jørgensen

Studier i samspillet mellem stat og

erhvervsliv i Danmark under

1. verdenskrig

36. Finn Janning

A DIFFERENT STORY

Seduction, Conquest and Discovery

37. Patricia Ann Plackett

Strategic Management of the Radical Innovation Process

Leveraging Social Capital for Market Uncertainty Management

\section{6}

1. Christian Vintergaard

Early Phases of Corporate Venturing
2. Niels Rom-Poulsen

Essays in Computational Finance

3. Tina Brandt Husman

Organisational Capabilities,

Competitive Advantage \& Project-

Based Organisations

The Case of Advertising and Creative

Good Production

4. Mette Rosenkrands Johansen

Practice at the top

- how top managers mobilise and use non-financial performance measures

5. Eva Parum

Corporate governance som strategisk kommunikations- og ledelsesværktøj

6. Susan Aagaard Petersen

Culture's Influence on Performance

Management: The Case of a Danish

Company in China

7. Thomas Nicolai Pedersen

The Discursive Constitution of Organizational Governance - Between unity and differentiation

The Case of the governance of environmental risks by World Bank environmental staff

8. Cynthia Selin

Volatile Visions: Transactons in

Anticipatory Knowledge

9. Jesper Banghøj

Financial Accounting Information and Compensation in Danish Companies

10. Mikkel Lucas Overby

Strategic Alliances in Emerging HighTech Markets: What's the Difference and does it Matter?

11. Tine Aage

External Information Acquisition of Industrial Districts and the Impact of Different Knowledge Creation Dimensions 
A case study of the Fashion and

Design Branch of the Industrial District

of Montebelluna, NE Italy

12. Mikkel Flyverbom

Making the Global Information Society

Governable

On the Governmentality of Multi-

Stakeholder Networks

13. Anette Grønning

Personen bag

Tilstedevær i e-mail som inter-

aktionsform mellem kunde og med-

arbejder i dansk forsikringskontekst

14. Jørn Helder

One Company - One Language?

The NN-case

15. Lars Bjerregaard Mikkelsen

Differing perceptions of customer

value

Development and application of a tool for mapping perceptions of customer value at both ends of customer-supplier dyads in industrial markets

16. Lise Granerud

Exploring Learning

Technological learning within small manufacturers in South Africa

17. Esben Rahbek Pedersen

Between Hopes and Realities:

Reflections on the Promises and

Practices of Corporate Social

Responsibility (CSR)

18. Ramona Samson

The Cultural Integration Model and

European Transformation.

The Case of Romania

\section{7}

1. Jakob Vestergaard

Discipline in The Global Economy

Panopticism and the Post-Washington

Consensus
2. Heidi Lund Hansen

Spaces for learning and working

A qualitative study of change of work, management, vehicles of power and social practices in open offices

3. Sudhanshu Rai

Exploring the internal dynamics of software development teams during user analysis

A tension enabled Institutionalization Model; "Where process becomes the objective"

4. Norsk ph.d.

Ej til salg gennem Samfundslitteratur

5. Serden Ozcan

EXPLORING HETEROGENEITY IN

ORGANIZATIONAL ACTIONS AND

OUTCOMES

A Behavioural Perspective

6. Kim Sundtoft Hald

Inter-organizational Performance

Measurement and Management in

Action

- An Ethnography on the Construction of Management, Identity and

Relationships

7. Tobias Lindeberg

Evaluative Technologies

Quality and the Multiplicity of

Performance

8. Merete Wedell-Wedellsborg

Den globale soldat

Identitetsdannelse og identitetsledelse i multinationale militære organisationer

9. Lars Frederiksen

Open Innovation Business Models Innovation in firm-hosted online user communities and inter-firm project ventures in the music industry - A collection of essays

10. Jonas Gabrielsen

Retorisk topos/ære - fra statisk 'sted'

til persuasiv aktivitet 
11. Christian Moldt-Jørgensen

Fra meningsløs til meningsfuld

evaluering.

Anvendelsen af studentertilfredshedsmålinger på de korte og mellemlange videregående uddannelser set fra et psykodynamisk systemperspektiv

12. Ping Gao

Extending the application of actor-network theory

Cases of innovation in the telecommunications industry

13. Peter Mejlby

Frihed og fængsel, en del af den samme drøm?

Et phronetisk baseret casestudie af frigørelsens og kontrollens sameksistens i værdibaseret ledelse!

14. Kristina Birch

Statistical Modelling in Marketing

15. Signe Poulsen

Sense and sensibility:

The language of emotional appeals in insurance marketing

16. Anders Bjerre Trolle

Essays on derivatives pricing and dynamic asset allocation

17. Peter Feldhütter

Empirical Studies of Bond and Credit Markets

18. Jens Henrik Eggert Christensen Default and Recovery Risk Modeling and Estimation

19. Maria Theresa Larsen

Academic Enterprise: A New Mission for Universities or a Contradiction in Terms?

Four papers on the long-term implications of increasing industry involvement and commercialization in academia
20. Morten Wellendorf

Postimplementering af teknologi i den

offentlige forvaltning

Analyser af en organisations kontinuerlige arbejde med informationsteknologi

21. Ekaterina Mhaanna

Concept Relations for Terminological

Process Analysis

22. Stefan Ring Thorbjørnsen

Forsvaret $i$ forandring

Et studie i officerers kapabiliteter under påvirkning af omverdenens forandringspres mod øget styring og læring

23. Christa Breum Amhøj

Det selvskabte medlemskab om managementstaten, dens styringsteknologier og indbyggere

24. Karoline Bromose

Between Technological Turbulence and Operational Stability

- An empirical case study of corporate venturing in TDC

25. Susanne Justesen Navigating the Paradoxes of Diversity in Innovation Practice

- A Longitudinal study of six very

different innovation processes - in practice

26. Luise Noring Henler

Conceptualising successful supply chain partnerships

- Viewing supply chain partnerships from an organisational culture perspective

27. Mark Mau

Kampen om telefonen

Det danske telefonvæsen under den tyske besættelse 1940-45

28. Jakob Halskov

The semiautomatic expansion of existing terminological ontologies using knowledge patterns discovered 
on the WWW - an implementation and evaluation

29. Gergana Koleva European Policy Instruments Beyond Networks and Structure: The Innovative Medicines Initiative

30. Christian Geisler Asmussen Global Strategy and International Diversity: A Double-Edged Sword?

31. Christina Holm-Petersen Stolthed og fordom Kultur- og identitetsarbejde ved skabelsen af en ny sengeafdeling gennem fusion

32. Hans Peter Olsen

Hybrid Governance of Standardized

States

Causes and Contours of the Global

Regulation of Government Auditing

33. Lars Bøge Sørensen

Risk Management in the Supply Chain

34. Peter Aagaard

Det unikkes dynamikker

De institutionelle mulighedsbetingelser bag den individuelle udforskning $i$ professionelt og frivilligt arbejde

35. Yun Mi Antorini

Brand Community Innovation

An Intrinsic Case Study of the Adult Fans of LEGO Community

36. Joachim Lynggaard Boll

Labor Related Corporate Social Performance in Denmark Organizational and Institutional Perspectives

\section{8}

1. Frederik Christian Vinten

Essays on Private Equity

2. Jesper Clement Visual Influence of Packaging Design on In-Store Buying Decisions
3. Marius Brostrøm Kousgaard Tid til kvalitetsmåling?

- Studier af indrulleringsprocesser i forbindelse med introduktionen af kliniske kvalitetsdatabaser i speciallægepraksissektoren

4. Irene Skovgaard Smith Management Consulting in Action Value creation and ambiguity in client-consultant relations

5. Anders Rom

Management accounting and integrated information systems How to exploit the potential for management accounting of information technology

6. Marina Candi

Aesthetic Design as an Element of Service Innovation in New Technologybased Firms

7. Morten Schnack

Teknologi og tværfaglighed

- en analyse af diskussionen omkring indførelse af EPJ på en hospitalsafdeling

8. Helene Balslev Clausen

Juntos pero no revueltos - un estudio sobre emigrantes norteamericanos en un pueblo mexicano

9. Lise Justesen

Kunsten at skrive revisionsrapporter. En beretning om forvaltningsrevisionens beretninger

10. Michael E. Hansen

The politics of corporate responsibility: CSR and the governance of child labor and core labor rights in the 1990s

11. Anne Roepstorff

Holdning for handling - en etnologisk undersøgelse af Virksomheders Sociale Ansvar/CSR 
12. Claus Bajlum

Essays on Credit Risk and

Credit Derivatives

13. Anders Bojesen

The Performative Power of Competence - an Inquiry into Subjectivity and

Social Technologies at Work

14. Satu Reijonen

Green and Fragile

A Study on Markets and the Natural

Environment

15. Ilduara Busta

Corporate Governance in Banking

A European Study

16. Kristian Anders Hvass

A Boolean Analysis Predicting Industry Change: Innovation, Imitation \& Business Models

The Winning Hybrid: A case study of isomorphism in the airline industry

17. Trine Paludan

De uvidende og de udviklingsparate Identitet som mulighed og restriktion blandt fabriksarbejdere på det aftayloriserede fabriksgulv

18. Kristian Jakobsen

Foreign market entry in transition economies: Entry timing and mode choice

19. Jakob Elming

Syntactic reordering in statistical machine translation

20. Lars Brømsøe Termansen

Regional Computable General Equilibrium Models for Denmark

Three papers laying the foundation for regional CGE models with agglomeration characteristics

21. Mia Reinholt

The Motivational Foundations of Knowledge Sharing
22. Frederikke Krogh-Meibom

The Co-Evolution of Institutions and Technology

- A Neo-Institutional Understanding of Change Processes within the Business Press - the Case Study of Financial Times

23. Peter D. Ørberg Jensen

OFFSHORING OF ADVANCED AND HIGH-VALUE TECHNICAL SERVICES: ANTECEDENTS, PROCESS DYNAMICS AND FIRMLEVEL IMPACTS

24. Pham Thi Song Hanh

Functional Upgrading, Relational

Capability and Export Performance of

Vietnamese Wood Furniture Producers

25. Mads Vangkilde

Why wait?

An Exploration of first-mover advantages among Danish e-grocers through a resource perspective

26. Hubert Buch-Hansen

Rethinking the History of European

Level Merger Control

A Critical Political Economy Perspective

2009

1. Vivian Lindhardsen

From Independent Ratings to Communal Ratings: A Study of CWA Raters'

Decision-Making Behaviours

2. Guðrið Weihe

Public-Private Partnerships: Meaning and Practice

3. Chris Nøkkentved

Enabling Supply Networks with Collaborative Information Infrastructures An Empirical Investigation of Business Model Innovation in Supplier Relationship Management

4. Sara Louise Muhr Wound, Interrupted - On the Vulnerability of Diversity Management 
5. Christine Sestoft

Forbrugeradfærd i et Stats- og Livsformsteoretisk perspektiv

6. Michael Pedersen

Tune in, Breakdown, and Reboot: On the production of the stress-fit selfmanaging employee

7. Salla Lutz

Position and Reposition in Networks

- Exemplified by the Transformation of the Danish Pine Furniture Manufacturers

8. Jens Forssbæck

Essays on market discipline in commercial and central banking

9. Tine Murphy

Sense from Silence - A Basis for Organised Action

How do Sensemaking Processes with Minimal Sharing Relate to the Reproduction of Organised Action?

10. Sara Malou Strandvad Inspirations for a new sociology of art: A sociomaterial study of development processes in the Danish film industry

11. Nicolaas Mouton

On the evolution of social scientific metaphors:

A cognitive-historical enquiry into the divergent trajectories of the idea that collective entities - states and societies, cities and corporations - are biological organisms.

12. Lars Andreas Knutsen

Mobile Data Services:

Shaping of user engagements

13. Nikolaos Theodoros Korfiatis Information Exchange and Behavior A Multi-method Inquiry on Online Communities
14. Jens Albæk

Forestillinger om kvalitet og tværfaglighed på sygehuse

- skabelse af forestillinger i læge- og plejegrupperne angående relevans af nye idéer om kvalitetsudvikling gennem tolkningsprocesser

15. Maja Lotz

The Business of Co-Creation - and the Co-Creation of Business

16. Gitte P. Jakobsen

Narrative Construction of Leader Identity in a Leader Development Program Context

17. Dorte Hermansen

"Living the brand" som en brandorienteret dialogisk praxis:

Om udvikling af medarbejdernes brandorienterede dømmekraft

18. Aseem Kinra

Supply Chain (logistics) Environmental Complexity

19. Michael Nørager

How to manage SMEs through the transformation from non innovative to innovative?

20. Kristin Wallevik

Corporate Governance in Family Firms The Norwegian Maritime Sector

21. Bo Hansen Hansen

Beyond the Process

Enriching Software Process Improvement with Knowledge Management

22. Annemette Skot-Hansen

Franske adjektivisk afledte adverbier, der tager præpositionssyntagmer indledt med præpositionen à som argumenter

En valensgrammatisk undersøgelse

23. Line Gry Knudsen

Collaborative R\&D Capabilities

In Search of Micro-Foundations 
24. Christian Scheuer

Employers meet employees

Essays on sorting and globalization

25. Rasmus Johnsen

The Great Health of Melancholy

A Study of the Pathologies of Performativity

26. Ha Thi Van Pham

Internationalization, Competitiveness

Enhancement and Export Performance

of Emerging Market Firms:

Evidence from Vietnam

27. Henriette Balieu

Kontrolbegrebets betydning for kausa-

tivalternationen i spansk

En kognitiv-typologisk analyse

\section{0}

1.

Yen Tran

Organizing Innovationin Turbulent

Fashion Market

Four papers on how fashion firms create and appropriate innovation value

2. Anders Raastrup Kristensen

Metaphysical Labour

Flexibility, Performance and Commitment in Work-Life Management

3. Margrét Sigrún Sigurdardottir

Dependently independent

Co-existence of institutional logics in

the recorded music industry

4. Ásta Dis Óladóttir

Internationalization from a small do-

mestic base:

An empirical analysis of Economics and Management

5. Christine Secher

E-deltagelse i praksis - politikernes og forvaltningens medkonstruktion og konsekvenserne heraf

6. Marianne Stang Våland

What we talk about when we talk about space:
End User Participation between Processes of Organizational and Architectural Design

7. Rex Degnegaard

Strategic Change Management

Change Management Challenges in

the Danish Police Reform

8. Ulrik Schultz Brix

Værdi i rekruttering - den sikre beslut-

ning

En pragmatisk analyse af perception

og synliggørelse af værdi i rekrutte-

rings- og udvæ/ge/sesarbejdet

9. Jan Ole Similä

Kontraktsledelse

Relasjonen mellom virksomhetsledelse og kontraktshåndtering, belyst via fire norske virksomheter

10. Susanne Boch Waldorff

Emerging Organizations: In between

local translation, institutional logics

and discourse

11. Brian Kane

Performance Talk

Next Generation Management of

Organizational Performance

12. Lars Ohnemus

Brand Thrust: Strategic Branding and

Shareholder Value

An Empirical Reconciliation of two

Critical Concepts

13. Jesper Schlamovitz

Håndtering af usikkerhed i film- og

byggeprojekter

14. Tommy Moesby-Jensen

Det faktiske livs forbindtlighed

Førsokratisk informeret, ny-aristotelisk

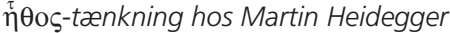

15. Christian Fich

Two Nations Divided by Common

values

French National Habitus and the

Rejection of American Power 
16. Peter Beyer

Processer, sammenhængskraft

og fleksibilitet

Et empirisk casestudie af omstillings-

forløb i fire virksomheder

17. Adam Buchhorn

Markets of Good Intentions

Constructing and Organizing

Biogas Markets Amid Fragility

and Controversy

18. Cecilie K. Moesby-Jensen

Social læring og fælles praksis

Et mixed method studie, der belyser

læringskonsekvenser af et lederkursus

for et praksisfællesskab af offentlige

mellemledere

19. Heidi Boye

Fødevarer og sundhed $i$ sen-

modernismen

- En indsigt i hyggefænomenet og

de relaterede fødevarepraksisser

20. Kristine Munkgård Pedersen

Flygtige forbindelser og midlertidige

mobiliseringer

Om kulturel produktion på Roskilde

Festival

21. Oliver Jacob Weber

Causes of Intercompany Harmony in

Business Markets - An Empirical Inve-

stigation from a Dyad Perspective

22. Susanne Ekman

Authority and Autonomy

Paradoxes of Modern Knowledge

Work

23. Anette Frey Larsen

Kvalitetsledelse på danske hospitaler

- Ledelsernes indflydelse på introduktion og vedligeholdelse af kvalitetsstrategier i det danske sundhedsvæsen

24. Toyoko Sato

Performativity and Discourse: Japanese Advertisements on the Aesthetic Education of Desire
25. Kenneth Brinch Jensen

Identifying the Last Planner System

Lean management in the construction industry

26. Javier Busquets

Orchestrating Network Behavior

for Innovation

27. Luke Patey

The Power of Resistance: India's National Oil Company and International Activism in Sudan

28. Mette Vedel

Value Creation in Triadic Business Relationships. Interaction, Interconnection and Position

29. Kristian Tørning

Knowledge Management Systems in

Practice - A Work Place Study

30. Qingxin Shi

An Empirical Study of Thinking Aloud Usability Testing from a Cultural

Perspective

31. Tanja Juul Christiansen

Corporate blogging: Medarbejderes

kommunikative handlekraft

32. Malgorzata Ciesielska

Hybrid Organisations.

A study of the Open Source - business setting

33. Jens Dick-Nielsen

Three Essays on Corporate Bond

Market Liquidity

34. Sabrina Speiermann

Modstandens Politik

Kampagnestyring i Velfærdsstaten.

En diskussion af trafikkampagners styringspotentiale

35. Julie Uldam

Fickle Commitment. Fostering political engagement in 'the flighty world of online activism' 
36. Annegrete Juul Nielsen

Traveling technologies and

transformations in health care

37. Athur Mühlen-Schulte

Organising Development

Power and Organisational Reform in

the United Nations Development

Programme

38. Louise Rygaard Jonas

Branding på butiksgulvet

Et case-studie af kultur- og identitetsarbejdet i Kvickly

\section{1}

1. Stefan Fraenkel

Key Success Factors for Sales Force Readiness during New Product Launch A Study of Product Launches in the Swedish Pharmaceutical Industry

2. Christian Plesner Rossing

International Transfer Pricing in Theory and Practice

3. Tobias Dam Hede

Samtalekunst og ledelsesdisciplin

- en analyse af coachingsdiskursens genealogi og governmentality

4. Kim Pettersson

Essays on Audit Quality, Auditor Choice, and Equity Valuation

5. Henrik Merkelsen

The expert-lay controversy in risk research and management. Effects of institutional distances. Studies of risk definitions, perceptions, management and communication

6. Simon S. Torp

Employee Stock Ownership:

Effect on Strategic Management and Performance

7. Mie Harder Internal Antecedents of Management Innovation
8. Ole Helby Petersen

Public-Private Partnerships: Policy and Regulation - With Comparative and Multi-level Case Studies from Denmark and Ireland

9. Morten Krogh Petersen

'Good' Outcomes. Handling Multiplicity in Government Communication

10. Kristian Tangsgaard Hvelplund Allocation of cognitive resources in translation - an eye-tracking and keylogging study

11. Moshe Yonatany

The Internationalization Process of

Digital Service Providers

12. Anne Vestergaard

Distance and Suffering

Humanitarian Discourse in the age of Mediatization

13. Thorsten Mikkelsen

Personligsheds indflydelse på forret-

ningsrelationer

14. Jane Thostrup Jagd

Hvorfor fortsætter fusionsbølgen ud-

over "the tipping point"?

- en empirisk analyse af information

og kognitioner om fusioner

15. Gregory Gimpel

Value-driven Adoption and Consumption of Technology: Understanding Technology Decision Making

16. Thomas Stengade Sønderskov Den nye mulighed Social innovation i en forretningsmæssig kontekst

17. Jeppe Christoffersen Donor supported strategic alliances in developing countries

18. Vibeke Vad Baunsgaard Dominant Ideological Modes of Rationality: Cross functional 
integration in the process of product innovation

19. Throstur Olaf Sigurjonsson Governance Failure and Icelands's Financial Collapse

20. Allan Sall Tang Andersen Essays on the modeling of risks in interest-rate and inflation markets

21. Heidi Tscherning

Mobile Devices in Social Contexts

22. Birgitte Gorm Hansen

Adapting in the Knowledge Economy Lateral Strategies for Scientists and Those Who Study Them

23. Kristina Vaarst Andersen Optimal Levels of Embeddedness The Contingent Value of Networked Collaboration

24. Justine Grønbæk Pors

Noisy Management

A History of Danish School Governing from 1970-2010

25. Stefan Linder

Micro-foundations of Strategic

Entrepreneurship

Essays on Autonomous Strategic Action

26. Xin Li

Toward an Integrative Framework of National Competitiveness

An application to China

27. Rune Thorbjørn Clausen

værdifuld arkitektur

Et eksplorativt studie af bygningers

rolle $i$ virksomheders værdiskabelse

28. Monica Viken

Markedsundersøkelser som bevis $i$

varemerke- og markedsføringsrett

29. Christian Wymann

Tattooing

The Economic and Artistic Constitution of a Social Phenomenon
30. Sanne Frandsen

Productive Incoherence

A Case Study of Branding and

Identity Struggles in a Low-Prestige

Organization

31. Mads Stenbo Nielsen

Essays on Correlation Modelling

32. Ivan Häuser

Folelse og sprog

Etablering af en ekspressiv kategori, eksemplificeret på russisk

33. Sebastian Schwenen

Security of Supply in Electricity Markets 


\section{TITLER I ATV PH.D.-SERIEN}

1992

1. Niels Kornum

Servicesamkørsel - organisation, økonomi og planlægningsmetode

1995

2. Verner Worm

Nordiske virksomheder i Kina

Kulturspecifikke interaktionsrelationer ved nordiske virksomhedsetableringer i Kina

1999

3. Mogens Bjerre

Key Account Management of Complex Strategic Relationships

An Empirical Study of the Fast Moving Consumer Goods Industry

2000

4.

Lotte Dars $\varnothing$

Innovation in the Making

Interaction Research with heterogeneous Groups of Knowledge Workers creating new Knowledge and new Leads

2001

5. Peter Hobolt Jensen

Managing Strategic Design Identities The case of the Lego Developer Network

2002

6. Peter Lohmann

The Deleuzian Other of Organizational Change - Moving Perspectives of the Human

7. Anne Marie Jess Hansen

To lead from a distance: The dynamic interplay between strategy and strategizing - A case study of the strategic management process
2003

8. Lotte Henriksen

Videndeling

- om organisatoriske og ledelsesmæssige udfordringer ved videndeling $i$ praksis

9. Niels Christian Nickelsen

Arrangements of Knowing: Coordinating Procedures Tools and Bodies in Industrial Production - a case study of the collective making of new products

2005

10. Carsten Ørts Hansen

Konstruktion af ledelsesteknologier og effektivitet

\section{TITLER I DBA PH.D.-SERIEN}

\section{7}

1. Peter Kastrup-Misir Endeavoring to Understand Market Orientation - and the concomitant co-mutation of the researched, the re searcher, the research itself and the truth

2009

1. Torkild Leo Thellefsen

Fundamental Signs and Significance effects

A Semeiotic outline of Fundamental Signs, Significance-effects, Knowledge Profiling and their use in Knowledge Organization and Branding

2. Daniel Ronzani When Bits Learn to Walk Don't Make Them Trip. Technological Innovation and the Role of Regulation by Law in Information Systems Research: the Case of Radio Frequency Identification (RFID)

\section{0}

1. Alexander Carnera

Magten over livet og livet som magt Studier i den biopolitiske ambivalens 